INSTITUTO DE PESQUISAS ENERGÉTICAS E NUCLEARES

Autarquia Associada à Universidade de São Paulo

\title{
ESTUDO DE CONJUGAÇÃO DO ANTICORPO ANTI-CD20 PARA MARCAÇÃO COM RADIONUCLÍDEOS METÁLICOS OU LANTANÍDEOS.
}

\section{Akinkunmi Ganiyu Akanji}

\begin{abstract}
Tese apresentado como parte dos requisitos para obtenção do Grau de Doutor em Ciências na Área de Tecnologia Nuclear - Aplicações.
\end{abstract}

Orientadora:

Dra. Elaine Bortoleti de Araújo 
Dedico este trabalho "in memorium" àqueles que me deu a vida, criaram e ensinaram os valores básicos, primordiais e essenciais para uma vida digna, meus queridos e amados pais; e que acima de TUDO estar DEUS, o respeito pelo próximo, pela vida e a natureza.

Meus avos maternos, paternos, antepassados em geral pela cultura e princípios fundamentais na minha vida e meu viver.

A Umbanda meu renascimento, meus Pais de cabeça, meus Guias e Protetores, o povo do oriente, o povo do caminho, em fim as "ALMAS" minha vida e meu viver Salve as almas..... CACARU... CAIÍA AS ALMAS...!!! 


\section{AGRADECIMENTOS}

À Dra. Elaine, pela generosidade e oportunidade, pelo conhecimento transmitido, pelo incentivo, por acreditar em $\mathrm{mim}$ e pela amizade. Muitíssimo Obrigado. ASHÉ!!!

À Dra. Maria Tereza que acompanhou todas as etapas deste trabalho e contribuiu ativamente para o aperfeiçoamento de todas elas. ASHÉ!!!

À MSc. Neuza e Dra. Margareth pelas facilidades oferecidas.

Ao MSc. Jair Mengatti, por sempre ter contribuído no que foi necessário para a realização deste trabalho.

Ao Natan, Marcelo, José Luis, Carlos, Vivian e todos os integrantes de equipe do Controle de Qualidade.

Ao Dr. Patrick Jack Spencer e seus alunos do Centro de Biotecnologia (CB), pela ajuda inestimável, atenção, contribuição e colaboração, sempre disposto a ouvir, resposta para minhas duvidas e ajuda sem medir esforços - meus sinceros e profundos agradecimentos. ASHÉ..!!!

Ao Dr. Carlos Soares do Centro de Biotecnologia (CB) que sempre contribuir e colaborou desde o nosso primeiro trabalho, sempre prestativo - meus profundos agradecimentos. ASHÉ..!!!

À Dra. Miriam Suzuki pela ajuda e colaboração, sempre disposta e prestativa, quero que saiba que sua ajuda foi fundamental na realização dos ensaios de ligação específica. Meus profundos e sinceros agradecimentos.

Aos meus queridos e queridas operário (a)s de pesquisa: Adriana, Camila, Josefina, Priscilla, Renata, Luis Alberto, Ricardo, Bruna e Laís. Sem esquecer a Kátia e Laura. ASHÉ...!!! 
Em especial a minha querida e parceira Adriana, sempre disposta para pensar e analisar os dados juntos comigo, e nunca medir esforços para me ajudar. Apreendi muito com vc. Meus profundos agradecimentos!!!

Em especialíssimo ao Luis Alberto, Ricardo, Renata, Adriana e Laís que emprestaram seus braços e pernas nos ensaios de biodistribuição, quero que saibam que a contribuição de vocês transformou minha incerteza em possibilidades... que Deus abençoe a cada um de vocês ASHÉ!!!

Ao Instituto de Pesquisas Energéticas e Nucleares, em especial a Radiofarmácia, pelo provimento dos recursos necessários para o desenvolvimento e divulgação deste trabalho.

À Dna Neide seus colegas do Biotério do IPEN, sempre prestativos e ajuda inestimável quando solicitada.

À Dna Nely e Dna Fátima da secretaria da Radiofarmácia sempre prestativas, e ajuda quando solicitado.

Ao Sr. Jorge do setor de importação, sempre prestativo e ajuda inestimável na realização deste trabalho.

Ao Sr. Santana do setor de compras sempre prestativo.

À banca examinadora.

Aos funcionários da divisão de pós-graduação do IPEN.

Aos demais amigos recentes e os velhos que deixei pelo caminho da vida.

À CNEN pela bolsa concedida. 
Caminhando devagar preto-velho vai adiante, não detenha os passos, filho, pois Paivelho diz: Avante!

O caminho esta difícil?

Provação ou tempestade?

Permanece no caminho, até que suja claridade...!!!

(Pai João de Arruanda) 


\title{
ESTUDO DE CONJUGAÇÃO DO ANTICORPO ANTI-CD20 PARA MARCAÇÃO COM RADIONUCLÍDEOS METÁLICOS OU LANTANÍDEOS
}

\author{
Akinkunmi Ganiyu Akanji
}

\section{RESUMO}

Linfomas são cânceres que se iniciam a partir da transformação maligna de um linfócito no sistema linfático. Os linfomas são divididos em duas categorias principais: os linfomas de Hodgkin e todos os outros linfomas, denominados linfomas não-Hodgkin (LNH). Os pacientes com LNH são comumente tratados com radioterapia apenas ou combinada com quimioterapia utilizando-se de anticorpo monoclonal anti-CD20, principalmente o rituximab (MabThera ${ }^{\circledR}$ ). O uso de anticorpos monoclonais (Acm) conjugados à quelantes bifuncionais radiomarcados com radionuclídeos metálicos ou lantanídeos é uma realidade de tratamento para portadores de LNH pelo princípio de radioimunoterapia (RIT). Este estudo concentrou-se nas condições de conjugação do anticorpo monoclonal rituximab (MabThera ${ }^{\circledR}$ ) com grupamentos quelantes bifuncionais DOTA e DTPA. Na marcação dos Acm conjugados com lutécio-177, foram estudadas as condições de prépurificação do Acm, condições de conjugação, determinação de número de quelantes acoplados à molécula do anticorpo, purificação do anticorpo conjugado, radiomarcação do anticorpo conjugado, com lutécio-177, purificação do anticorpo marcado, a ligação específica in vitro dos compostos marcados às células Raji, e distribuição biológica em camundongos $B A L B / C$ sadios. As três metodologias empregadas na pré-purificação do anticorpo (diálise, cromatografia de exclusão molecular com coluna Sephadex G-50 e ultrafiltração) demonstram-se eficientes e proporcionaram recuperação da amostra superior a 90\%. A metodologia de ultrafiltração foi considerada a mais simples e prática, podendo ser aplicada a procedimentos rotineiros de produção de radiofármacos. Além disso, proporcion ou a recuperação final de amostra de $97 \%$ em microlitros. Nas conjugações do 
anticorpo com os quelantes DOTA e DTPA em razões molares diferentes do Acm:quelante, observou-se número de grupamentos quelantes acoplados à molécula do Acm proporcional à razão molar estudada. Quando foi avaliada a influência de condições diferentes de conjugação no número de quelantes acoplados à molécula do Acm, não foram observadas diferenças significativas, com resultados de pureza radioquímica $(P R)$ inferior a $80 \%$ em todas as condições estudadas. Na comparação de métodos de purificação do Acm conjugado, a abordagem inédita apresentada neste estudo, na qual a cromatografia de exclusão molecular foi combinada com a ultrafiltração resultou em maior eficiência na purificação e preservação da estrutura do anticorpo. Nos estudos de radiomarcação do anticorpo conjugado com DOTA e DTPA, os imunoconjugados de DTPA apresentaram, de forma geral, maior eficiência de marcação com resultados reprodutíveis quando comparados com os imunoconjugados de DOTA, considerando-se as diferentes razões molares utilizadas. As metodologias cromatográficas empregadas no controle de pureza radioquímica do composto radiomarcado proporcionaram a discriminação das diferentes espécies radioquímicas no meio de marcação. A metodologia de purificação do composto conjugado e radiomarcado utilizada proporcionou a obtenção de compostos com alta pureza radioquímica, $97,4 \pm 1,3 \%$ (DOTA $1: 50$ ) e $98,7 \pm 0,2 \%$ (DTPA 1:50). Nos estudos de ligação específica às células tumorais Raji, o anticorpo conjugado com quelante DTPA nas razões molares de 1:50 e 1:20 apresentaram perfil semelhante de ligação, com aumento da porcentagem de ligação específica proporcional à concentração celular, enquanto que o imunoconjugado na razão molar de 1:10 apresentou alta porcentagem de ligação não específica. Os resultados obtidos nos estudos de biodistribuição in vivo do anticorpo conjugado e radiomarcado nem sempre se mostraram compatíveis com a biodistribuição de anticorpos radiomarcados íntegros. No caso do quelante DOTA, o imunoconjugado obtido a partir da razão molar 1:20, apresentou melhores características de biodistribuição. No caso do quelante DTPA, a razão molar utilizada pareceu refletir diretamente no clareamento sanguíneo do anticorpo e todas as razões molares utilizadas apresentaram instabilidade in vivo. 


\title{
THE STUDY OF CONJUGATION OF ANTI-CD20 MONOCLONAL ANTIBODY FOR LABELING WITH METALIC OR LANTHANIDES RADIONUCLIDES
}

\author{
Akinkunmi Ganiyu Akanji
}

\begin{abstract}
Lymphomas are malignancies or cancers that start from the malign transformation of a lymphocyte in the lymphatic system. Lymphomas are divided in two major categories: Hodgkin lymphoma and non-Hodgkin lymphoma (NHL). Patient with $\mathrm{NHL}$ are generally treated with radiotherapy alone or combined with immunotherapy using monoclonal antibody rituximab (MabThera ${ }^{\circledR}$ ). Currently, monoclonal antibodies (Mab) conjugated with bifunctional chelate agents and radiolabeled with metallic or lanthanides radionuclides are a treatment reality for patients with NHL by the principle of radioimmunotherapy (RIT). This study focused on the conditions of conjugation of Acm rituximab (MabThera ${ }^{\circledR}$ ) with bifunctional chelating agents DOTA and DTPA and labeling with 177-luthetium. Various parameters were studied: method of Acm purification, conditions of Acm conjugation and the determination of the number of chelate coupled to the Acm, the purification of the conjugated Mab, labeling conditions with lutetium-177, purification of the radiolabeled immunoconjugate, radiochemical purity (RP), in vitro specific binding determination to Raji cells (Human Burkitt) and biological distribution performed in normal $B A L B / C$ mouse. The three methodologies employed in pre-purification of Acm (dialysis, size exclusion chromatograph and ultrafiltration) demonstrated to be efficient; they provided sample recovery exceeding $90 \%$. However, the methodology of ultrafiltration resulted in greater sample recovery and in microliters. The number of chelate attached to the Mab molecule was proportional to the molar ratio studied. When the influence of different conditions of conjugation in the number of chelate bounded to the Mab was studied, no notable differences were observed. The RP <
\end{abstract}


$80 \%$ was observed in all the methods applied. Purification of the conjugated antibody by different methods showed that the innovative combination of Sephadex and ultrafiltration methods resulted in higher efficiency of purification. The optimized conditions for purification of the conjugated antibody preserved the protein integrity. Radiolabelling studies of DOTA and DTPA immunoconjugated showed that DTPA derivatives presented, in general, radiochemical yield superior than DOTA conjugated Mab, considering the different molar ratios studied. The chromatographic methods employed in the RP determination were efficient to separate the different radiochemical species presented in the reaction medium. The methodology used in the purification of the labeled Mab resulted in labeled compounds with high radiochemical purity, $97.4 \pm 1.3 \%$ (DOTA 1:50) and $98.7 \pm 0.2 \%$ (DTPA 1:50). Considering specific cell binding assays (Raji cells), the Mab conjugated to DTPA at 1:50 and 1:20 molar ratios presented similar results, and the percent of cell binding were proportional to the cell concentration, whereas the cell binding for 1:10 molar ratio showed high percent of nonspecific cell binding. The results of in vivo biodistribution studies of labeled Mab not always were compatible with the biodistribution of intact radiolabelled antibody. The DOTA immunoconjugated produced at 1:20 molar ratio, showed better performance in biodistribution studies. In the case of DTPA immunoconjugated, the blood clearance seems to be influenced by the molar ratio applied and the immunoconjugated produced with DTPA chelate at different molar ratio resulted in high in vivo instability compounds. 
1.0 INTRODUÇÃO

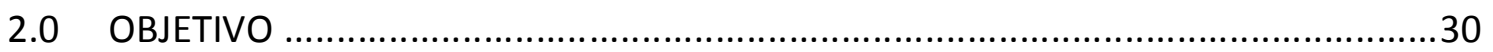

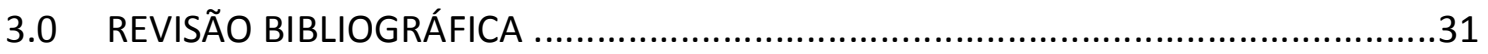

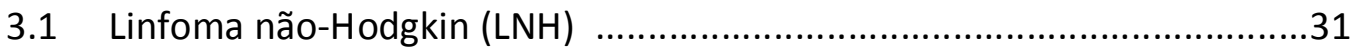

3.2 Radioimunoterapia............................................................................

3.3 Radiofármacos utilizados em radioimunoterapia....................................35

3.4 Relatos de estudos clínicos utilizando rituximab marcado com lutécio-

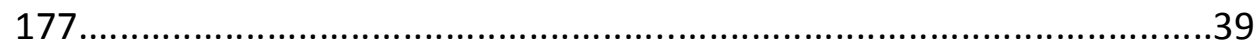

3.5 Propriedades radioquímicas do lutécio-17 ...........................................40

3.6 Principais métodos de marcação de anticorpos com lutécio-177 . .44

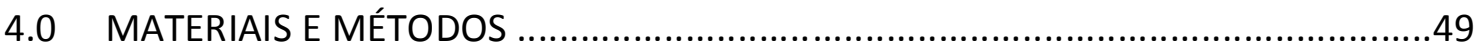

4.1 Materiais .....................................................................................

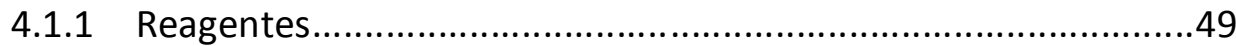

4.1.2 Equipamentos e materiais em geral .........................................50

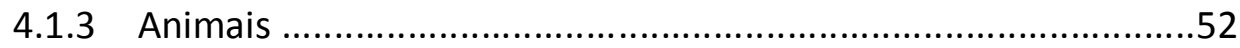

4.1.4 Células Raji de linfomas de Burkitt humano ...............................52

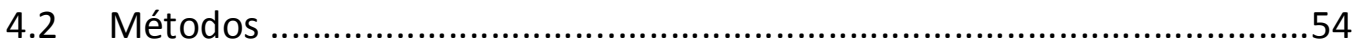

4.2.0 Cronograma experimental .....................................................53

4.2.1 Preparação do anticorpo monoclonal anti-CD20 (rituximab, MabThera $\left.{ }^{\circledR}\right)$...................................................................

4.2.2 Estudo de conjugação de quelante a o anticorpo.........................55

4.2.2.1 Condição geral de conjugação.......................................55

4.2.2.2 Avaliação de condições de conjugação............................55

4.2.2.3 Determinação de números de quelantes incorporados à molécula do anticorpo...................................................56

4.2.2.4 Estudo de purificação do anticorpo conjugado................57

4.2.3 Estudo de método de marcação do anticorpo conjugado com

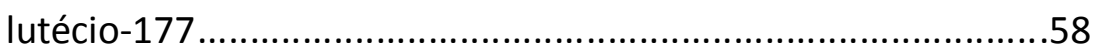

4.2.3.1 Condições de marcação padrão.......................................58

4.2.3.2 Variação das condições de marcação.................................58

4.2.4 Estudo de método de controle de pureza radioquímica do anticorpo conjugado e marcado com lutécio-177 .......................59 
4.2.5 Estudo do método de purificação do anticorpo conjugado e marcado com lutécio-177...

4.2.6 Ensaio de ligação específica in vitro dos compostos conjugados e marcados com lutécio-177 às células Raji ("Binding")

4.2.7 Estudo de distribuição biológica em camundongos Balb-c sadios .63

5.0 RESULTADOS E DISCUSSÕES .65

5.1 Preparação do anticorpo monoclonal anti-CD20 (rituximab, MabThera ${ }^{\circledR}$ ) .65

5.2 Estudo de conjugação de quelante ao anticorpo .................................67

5.2.1 Avaliação de condições de conjugação 67

5.2.2 Determinação de números de quelantes incorporados à molécula do anticorpo 69

5.2.3 Estudo de purificação do anticorpo conjugado .72

5.3 Estudo de método de marcação do anticorpo conjugado com lutécio-177

5.3.1 Estudo de método de controle de pureza radioquímica do anticorpo conjugado e marcado com lutécio-177 ....

5.3.2 Estudo de método de purificação do anticorpo conjugado e marcado com lutécio-177

5.4 Estudo de estabilidade in vitro do anticorpo conjugado e marcado com Lutécio-177.

5.5 Ensaio de ligação específica in vitro dos compostos conjugados e marcado com Lutécio-177 às células Raji ("Binding") .93

6.0 Estudo de distribuição biológica em camundongos Balb-c sadios. .96

7.0 Conclusões. .109 


\section{LISTA DE TABELAS}

Tabela 1. Estimativas de números de casos novos por câncer, e taxas de incidência por 100 mil habitantes, segundo sexo e localização primaria para o Brasil em 2012

Tabela 2. Estimativas de números de casos novos por câncer para o mundo, nos países de primeiro mundo, e nos países em desenvolvimento para o ano 2008 23

Tabela 3. Antígenos comuns das células-B de LNH e seus anticorpos correspondentes .24

Tabela 4. Alguns exemplos de combinações de medicações utilizadas para tratamento de células-B de $\mathrm{LNH}$ 27

Tabela 5. Distribuição proporcional de dez tipos de cânceres mais incidentes estimados para 2012 por sexo no Brasil

Tabela 6. Alguns radiofármacos disponíveis e utilizados para fins diagnósticos e terapêuticos .35

Tabela 7. Propriedades radioquímicas de alguns radionuclídeos utilizados em diagnostico de imagem e terapêuticos

Tabela 8. Rf das espécies radioquímicas observadas nos sistemas cromatográficos utilizados .60

Tabela 9. Purificação prévia do anticorpo anti-CD20: recuperação da amostra (grama) nas três metodologias avaliadas na purificação do anticorpo .67

Tabela 10. Pureza radioquímica (\%) do anticorpo conjugado com DOTA purificado e concentrado (1mg) marcado com $37 \mathrm{MBq}(1 \mathrm{mCi})$ lutécio-177 (n=3) .68

Tabela 11. Pureza radioquímica (\%) do anticorpo conjugado com DOTA e DTPA em diferentes razões molares: estudo de variação de massa para atividade de marcação $(n=5)$ .69

Tabela 12. Números de quelantes acoplados à molécula do anticorpo nos tempos de 1 hr e 24 hs de conjugação com quelante DOTA $(n=5)$ 
Tabela 13. Números de quelantes acoplados à molécula do anticorpo em duas condições diferentes de conjugação: (temperatura ambiente (T.A) e $43^{\circ} \mathrm{C}$ ) na 1 a hora DOTA $(n=5)$

Tabela 14. Pureza radioquímica (\%) do anticorpo conjugado com DOTA (24 hs), razão molar: 1:5, 1:10 e 1:20 marcado com $37 \mathrm{MBq}(1 \mathrm{mCi}){ }^{177} \mathrm{Lu}(\mathrm{N}=5)$

Tabela 15. Pureza radioquímica (\%) do anticorpo conjugado com DOTA e DTPA purificado e concentrado marcado com $37 \mathrm{MBq}(1 \mathrm{mCi}){ }^{177} \mathrm{Lu}(\mathrm{n}=5)$

Tabela 16. Pureza radioquímica (\%) do anticorpo conjugado com DOTA e DTPA marcado com $37 \mathrm{MBq}(1 \mathrm{mCi}){ }^{177}$ Lu da Perkin Elmer e IDB (Holanda) ( $\mathrm{n}=2$ )

Tabela 17. Pureza radioquímica (\%) do imunoconjugado com DOTA nas razões molares de 1:50 e 1:20: variação da atividade específica da marcação . .90

Tabela 18. Pureza radioquímica (\%) do anticorpo conjugado com DOTA e DTPA marcado com $37 \mathrm{MBq}(1 \mathrm{mCi}){ }^{177} \mathrm{Lu}$, purificado em cromatografia de exclusão molecular (PD 10) $(n=2)$ 92

Tabela 19. Biodistribuição do rituximab-DOTA- ${ }^{177}$ Lu conjugado na razão molar $1: 50$, em diferentes tempos após a administração de 0,185 MBq do radioimunoconjugado em camundongos $B A L B / C$ sadios $(n=4)$

Tabela 20. Biodistribuição do rituximab-DOTA- ${ }^{177}$ Lu conjugado na razão molar 1:20, em diferentes tempos após a administração de 0,185 MBq do radioimunoconjugado em camundongos $B A L B / C$ sadios $(n=4)$ 99

Tabela 21. Biodistribuição do rituximab-DTPA- ${ }^{177}$ Lu conjugado na razão molar 1:50, em diferentes tempos após a administração de 0,185 MBq do radioimunoconjugado em camundongos $B A L B / C$ sadios $(n=4)$ 103

Tabela 22. Biodistribuição do rituximab-DTPA- ${ }^{177}$ Lu conjugado na razão molar 1:20, em diferentes tempos após a administração de 0,185 MBq do radioimunoconjugado em camundongos $B A L B / C$ sadios $(n=4)$ 105

Tabela 23. Biodistribuição do rituximab-DTPA- ${ }^{177}$ Lu conjugado na razão molar 1:10, em diferentes tempos após a administração de 0,185 MBq do radioimunoconjugado em camundongos $B A L B / C$ sadios $(n=4)$ 



\section{LISTA DE FIGURAS}

Figura 1. Localização dos linfonodos no corpo humano .19

Figura 2. Mecanismo de ação de rituximab (MabThera $\left.{ }^{\circledR}\right)$ .26

Figura 3. Estrutura química dos grupos quelantes bifuncionais, p-SCN-Bn-NOTA, DOTA, DTPA e PCTA

Figura 4. Representação química do anticorpo monoclonal anti-CD20 rituximab conjugado com DOTA radiomarcado com lutécio-177 .48

Figura 5. Perfil de SDS-PAGE do anticorpo conjugado com DOTA e DTPA em diferentes razões molares: (a) DOTA 1:50; (b) DOTA 1:20; (c) DOTA 1:10; (d) DTPA 1:50; (e) DTPA 1:20; (f) DTPA 1:10 .74

Figura 6. Perfil CLAE do anticorpo conjugado com DOTA na razão molar de 1:50 purificado por cromatografia de exclusão molecular Sephadex G-25 (PD 10) e concentrado por ultrafiltração (tubo Amicon Ultra-15), junção das frações 3-5 contendo anticorpo conjugado .75

Figura 7. Perfil CLAE do anticorpo conjugado com DOTA na razão molar de 1:50 purificado por cromatografia de exclusão molecular Sephadex G-25 (PD 10) e concentrado por ultrafiltração (tubo Amicon Ultra-15 30.0000 MWCO) .75

Figura 8. Perfil CLAE do anticorpo conjugado com DOTA na razão molar de 1:50 purificado por cromatografia de exclusão molecular Sephadex G-25 (PD 10) e concentrado por ultrafiltração (tubo Amicon Ultra-15 30.0000 MWCO) .76

Figura 9. Perfil CLAE do anticorpo conjugado com DOTA na razão molar de 1:50 purificado por cromatografia de exclusão molecular Sephadex G-25 (PD 10) e concentrado por ultrafiltração (tubo Amicon Ultra-15 30.0000 MWCO), primeiro ultrafiltrado da concentração da junção das frações 3-5 do anticorpo conjugado .......77

Figura 10. Perfil CLAE (UV-280) do grupamento quelante DOTA ..............................77

Figura 11. Perfil CLAE (UV-280) do anticorpo monoclonal anti-CD20 rituximab ...........78

Figura 12. Perfil de CLAE (UV - $280 \mathrm{~nm}$ ) do anticorpo conjugado com DTPA na razão molar de 1:20 antes da purificação 
Figura 13. Perfil de CLAE (UV - $280 \mathrm{~nm}$ ) do anticorpo conjugado com DTPA na razão molar de 1:20 purificado na coluna PD 10 e concentrado com tubo Amicon Ultra-15 (30.000 MWCO), junção das frações 3-5 da purificação, contendo o anticorpo conjugado .79

Figura 14. Perfil CLAE (UV $280 \mathrm{~nm}$ ) do ultrafiltrado do anticorpo conjugado com DTPA na razão molar de 1:20 purificado na coluna PD 10 e concentrado com tubo Amicon Ultra-15 (30.000 MWCO $15 \mathrm{~mL}$ ), primeiro ultrafiltrado da concentração da junção das frações 3-5 do anticorpo conjugado 80

Figura 15. Perfil CLAE (UV $280 \mathrm{~nm}$ ) do ultrafiltrado do anticorpo conjugado com DTPA na razão molar de 1:20 purificado na coluna PD 10 e concentrado com tubo Amicon Ultra-15 (30.000 MWCO $15 \mathrm{~mL}), 13^{\circ}$ ultrafiltrado da concentração da junção das frações 3-5 do anticorpo conjugado

Figura 16. Perfil de CLAE (UV-280) do quelante p-SCN-Bn-DTPA (UV $280 \mathrm{~nm}$ ) .81

Figura 17. Perfil CLAE radioativo do anticorpo conjugado com DOTA 1:100 purificado e marcado com lutécio-177

Figura 18. Perfil CLAE radioativo do anticorpo conjugado com DOTA 1:50 purificado e marcado com lutécio-177

Figura 19. Ligação específica in vitro às células Raji (Binding) do anticorpo conjugado com DTPA na razão molar 1:50

Figura 20. Ligação específica in vitro às células Raji (Binding) do anticorpo conjugado com DTPA na razão molar 1:20

Figura 21. Ligação específica in vitro às células Raji (Binding) do anticorpo conjugado com DTPA na razão molar 1:10

Figura 22. Biodistribuição (em \% de atividade captada pelo tecido ou órgão) do rituximab-DOTA- ${ }^{177} \mathrm{Lu}(1: 50)$ em camundongos $B A L B / C$ sadios $(n=4)$ .98

Figura 23. Biodistribuição (em \% de atividade captada por grama do tecido ou órgão) do rituximab-DOTA $-{ }^{177} \mathrm{Lu}(1: 50)$ em camundongos $B A L B / C$ sadios $(n=4)$ .98

Figura 24. Biodistribuição (em \% de atividade captada pelo tecido ou órgão) do rituximab-DOTA- ${ }^{177} \mathrm{Lu}(1: 20)$ em camundongos $B A L B / C$ sadios $(n=4)$ 
Figura 25. Biodistribuição (em \% de atividade captada por grama do tecido ou órgão) do rituximab-DOTA- ${ }^{177} \mathrm{Lu}(1: 20)$ em camundongos $B A L B / c$ sadios $(\mathrm{n}=4)$

Figura 26. Biodistribuição (em \% de atividade captada pelo tecido ou órgão) do rituximab-DTPA- ${ }^{177} \mathrm{Lu}(1: 50)$ em camundongos $B A L B / C$ sadios $(n=4)$ .104

Figura 27. Biodistribuição (em \% de atividade captada por grama do tecido ou órgão) do rituximab-DTPA- ${ }^{177} \mathrm{Lu}(1: 50)$ em camundongos $B A L B / c$ sadios $(\mathrm{n}=4)$ .104

Figura 28. Biodistribuição (em \% de atividade captada pelo tecido ou órgão) do rituximab-DTPA- ${ }^{177} \mathrm{Lu}(1: 20)$ em camundongos $B A L B / C$ sadios $(n=4)$ .106

Figura 29. Biodistribuição (em \% de atividade captada por grama do tecido ou órgão) do rituximab-DTPA- ${ }^{177} \mathrm{Lu}(1: 20)$ em camundongos $B A L B / C$ sadios $(n=4)$ 106

Figura 30. Biodistribuição (em \% de atividade captada pelo tecido ou órgão) do rituximab-DTPA- ${ }^{177}$ Lu $(1: 10)$ em camundongos $B A L B / C$ sadios $(n=4)$ .108

Figura 31. Biodistribuição (em \% de atividade captada por grama do tecido ou órgão) do rituximab-DTPA- ${ }^{177}$ Lu (1:10) em camundongos $B A L B / C$ sadios $(n=4)$ 108 


\subsection{INTRODUÇÃO}

Linfomas são cânceres que se iniciam a partir da transformação maligna de um linfócito no sistema linfático. O prefixo "linfo" indica sua origem a partir da transformação maligna de um linfócito e o sufixo "oma" é derivado da palavra grega que significa "tumor". Os linfomas resultam de um dano ao DNA de um linfócito, ocorrido após o nascimento, representando, portanto, uma doença adquirida e não hereditária [1].

Essa alteração ou mutação do DNA do linfócito, que leva a uma transformação maligna, resulta no crescimento descontrolado do linfócito, e o acúmulo dessas células em divisão resulta em massas tumorais nos linfonodos e em outros locais (Figura 1) $[1,2]$.

Os linfomas geralmente têm início nos linfonodos ou em aglomerados de tecidos linfáticos, em órgãos como o estômago e os intestinos. Em alguns casos, os linfomas podem envolver a medula óssea e o sangue, ou então, se disseminam para outros órgãos. Os linfomas são divididos em duas categorias principais: os linfomas de Hodgkin e todos os outros linfomas, denominados linfomas não-Hodgkin [1,2,4,5].

O sangue é composto por plasma e células suspensas, na qual se desenvolvem vários elementos químicos, tais como: proteínas, hormônios, minerais e anticorpos. As células sanguíneas incluem os glóbulos vermelhos também conhecidos como hemácias ou eritrócitos, os glóbulos brancos e as plaquetas. Os glóbulos vermelhos desempenham função importante no corpo humano, eles carregam hemoglobina que se liga ao oxigênio transportando o mesmo aos tecidos. Os glóbulos vermelhos constituem aproximadamente de $45 \%$ do volume do sangue em indivíduos saudáveis. Os glóbulos brancos ou leucócitos são fundamentais no combate as infecções. Os eosinófilos e basófilos, subtipos de glóbulos brancos são importantes na resposta a processos alérgicos [1].

Os linfócitos, outro tipo de leucócitos, encontram-se nos gânglios linfáticos, no baço, nos canais linfáticos, amígdalas, adenóides, revestimento intestinal e tórax e no sangue. Os linfócitos circulam pelos vasos linfáticos conectados aos gânglios linfáticos espelhados por todo o corpo. Existem três tipos de linfócitos: os linfócitos B que produzem anticorpos em respostas a antígenos externos localizados na medula óssea; 
os linfócitos $T$, que possuem várias funções, a mais importante auxiliar os linfócitos B na produção de anticorpos; e as células exterminadoras naturais ou células NK ("natural killer") são chamadas assim por ter capacidade natural de atacar as células infectadas por vírus sem precisarem de anticorpos ou de outro intermediário $[1,4]$.

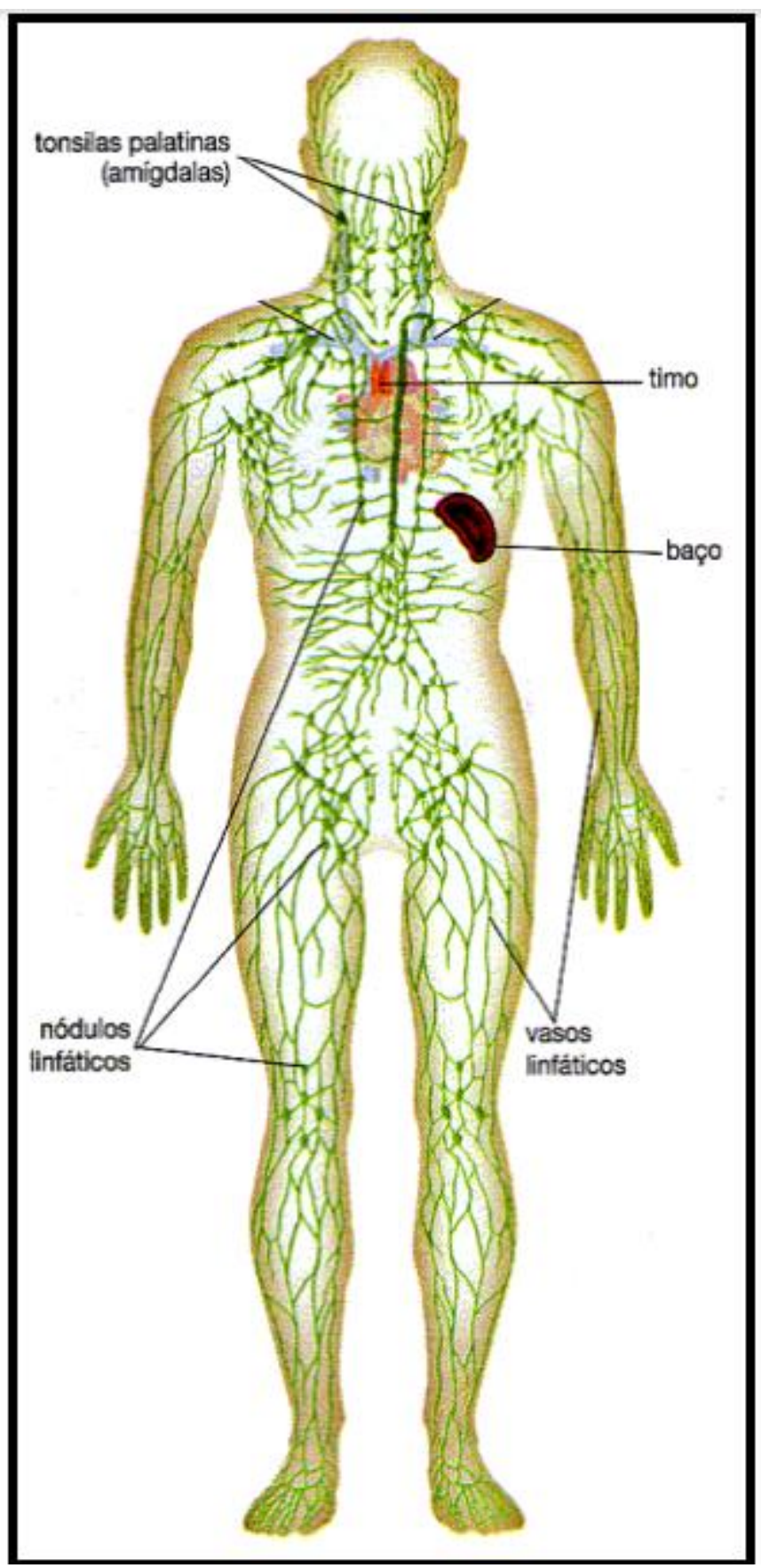

Figura 1. Localização dos linfonodos no corpo humano [5].

Além disso, as células T e NK são elementos importantes no estudo e desenvolvimento de imunoterápicos para as doenças onco-hematológicas [1]. 
Ademais, as plaquetas constituem um décimo do volume das hemácias, porém, são importantes no combate a lesão de vasos sanguíneos; agregam-se umas às outras, vedando assim o vaso e interrompendo o sangramento [1].

A Organização Mundial da Saúde (OMS) estimou que, no ano 2030, haverá 27 milhões de casos incidentes de câncer, 17 milhões de mortes por câncer e 75 milhões de pessoas vivas, anualmente, com câncer no mundo; e que o maior efeito desse aumento vai incidir em países de baixas e médias rendas [2].

Segundo Instituto Nacional de Câncer Jose Alencar Gomes da Silva (INCA), órgão do Ministério da Saúde, as estimativas de incidências de câncer no Brasil para o ano de 2012, que serão válidas também para o próximo ano 2013, apontam a ocorrência de aproximadamente 518.510 casos novos de câncer, incluindo os casos dos linfomas de Hodgkin e não-Hodgkin. São esperados um total de 257.870 casos novos de câncer em geral para o sexo masculino e 260.640 para o sexo feminino, reforçando a magnitude do problema do câncer no país [2].

A distribuição dos casos novos de câncer segundo o tipo de tumor em relação às cinco regiões do país, para o sexo masculino, mostra-se heterogênea entre estados e capitais do país, o que fica em evidência ao se observar a representação especial da diferentes taxas brutas de incidência. Deste modo, as regiões Sul e Sudeste, de maneira geral, apresentam as maiores taxas, enquanto as regiões Norte e Nordeste, as menores. As taxas da região Centro-Oeste apresentam um padrão intermediário (Tabela 1) [2].

A incidência do linfoma não-Hodgkin aumenta com a idade: cerca de quatro casos a cada 100 mil indivíduos ocorrem aos 20 anos de idade. A taxa de incidência aumenta dez vezes, passando para 40 casos a cada 100 mil indivíduos na faixa etária dos 60 anos, e mais de 20 vezes, chegando a 80 casos por 100 mil indivíduos após os 75 anos de idade [1].

Segundo Instituto Nacional de Câncer Jose Alencar Gomes da Silva (INCA), esperam-se 5.190 casos novos de linfoma não Hodgkin em homens e 4.450 em mulheres, para o Brasil, no ano de 2012. Isso representa uma taxa bruta de 5,40\% para 
os homens e 4,44\% para as mulheres (Tabela 1). Esses valores correspondem a um risco estimado de 5 casos novos a cada 100 mil homens e 4 a cada 100 mil mulheres (Tabela 1) [2].

Tabela 1. Estimativas de números de casos novos por câncer, e taxas de incidência por 100 mil habitantes, segundo sexo e localização primaria para o Brasil em 2012.

\section{Estimativa dos Casos Novos}

\begin{tabular}{ccccc}
\hline \multicolumn{1}{c}{ Homens } & \multicolumn{5}{c}{ Mulheres } \\
Localização Primaria & \multicolumn{4}{c}{ Todos os Estados } \\
Neoplasia Maligna & Casos & Taxa & Casos & Taxa \\
Próstata & 60.180 & 62,54 & - & - \\
Mama Feminina & - & - & 52.680 & 52,50 \\
Colo do Útero & - & - & 17.210 & 17,49 \\
Traquéia,Brônquio,Pulmão & 17.210 & 17,90 & 10.110 & 10,08 \\
Colon e Reto & 14.180 & 14,75 & 15.960 & 15,94 \\
Estômago & 12.670 & 15,20 & 7.960 & 15,94 \\
Cavidade oral & 9.990 & 10,41 & 4.180 & 4,18 \\
Laringe & 6.110 & 6,31 & - & - \\
Bexiga & 6.210 & 6,49 & 2.690 & 2,71 \\
Esôfago & 7.770 & 8,10 & 2.690 & 2,71 \\
Ovário & - & - & 6.190 & 6,17 \\
Linfoma Não-Hodgkin & 5.190 & 5,40 & 4.450 & 4,44 \\
Glândula Tireóide & - & - & 10.590 & 10,59 \\
Sistema Nervoso Central & 4.820 & 5,02 & 4,450 & 4,46 \\
Leucemias & 4.570 & 4,76 & 3,940 & 3,94 \\
Corpo do Útero & - & - & 4.520 & 4,53 \\
Pele Melanoma & 3.170 & 3,29 & 3.060 & 3,09 \\
Outras Localizações & 43.120 & 44,80 & 38.720 & 38,61 \\
Subtotal & 195.190 & 202,85 & 189.150 & 188,58 \\
Pele Não Melanoma & 62.680 & 65,17 & 71.490 & 71,30 \\
\hline Todas as Neoplasias & 287.870 & 267,99 & 260.640 & 259,86 \\
\hline
\end{tabular}

Fonte [2].

O linfoma não Hodgkin (LNH) compreende uma variedade de doenças para as quais os padrões de incidência são heterogêneos nas populações. Foram computados cerca de 360 mil casos novos e 191 mil óbitos no mundo para o ano de 2008. América 
do Norte, Austrália, Nova Zelândia e algumas partes da Europa possuem as mais altas taxas de incidência desse tipo de câncer $[2,3]$.

Foram computados cerca de 200 mil casos novos e 34 mil óbitos nos países do primeiro mundo para o ano de 2008; e cerca de 100 mil casos novos e 72 mil óbitos nos países em desenvolvimento (Tabela 2) [3].

Em geral, essas taxas são baixas na África, com exceção do linfoma de Burkitt (um subtipo de LNH). Esse tipo de linfoma é provocado pela infecção do vírus EpsteinBarr (EBV) muito comum no território africano. Como a maioria dos cânceres, o risco para o desenvolvimento do LNH aumenta com a idade. Os homens apresentam um risco maior do que as mulheres para desenvolver a doença. Na maior parte dos casos, a etiologia para LNH é desconhecida, embora exista uma associação com a função imune alterada [2].

O linfoma de Hodgkin apresenta um padrão de risco diferente. A incidência é de cinco a seis casos a cada 100 mil indivíduos com idades em torno dos 20 anos. Este índice cai para menos da metade na meia idade e aumenta em indivíduos mais idosos [2].

O padrão de incidência da doença também difere entre grupos étnicos, ao ocorrer mais freqüentemente em indivíduos mais jovens (de 10 a 40 anos), de ascendência europeia, do que naqueles de ascendência africana, asiática ou hispânica [1].

A especificidade do anticorpo utilizado em imunoterapia ou radioimunoterapia é determinada principalmente pelo antígeno a ser reconhecido. Esse antígeno deve ser específico para o tumor com mínimo ou nenhuma expressão em células sadias. Entretanto, na prática, incluindo os de células-B de LNH, são muito mais tumorassociados do que tumor-específicos. Em tese, entende-se que o antígeno afim de células-B de LNH são expressos também na superfície de células normais, órgãos e tecidos (dependendo do antígeno), em porcentagem menor ou número reduzido. Deste modo, os anticorpos a eles dirigidos são relativamente e não absolutamente 
específicos. A Tabela 2 demonstra os antígenos comuns das células-B e os respectivos anticorpos não-conjugados dirigidos contra os mesmos [5].

Tabela 2. Estimativas de números de casos novos por câncer para o mundo, nos países de primeiro mundo, e nos países em desenvolvimento para o ano de 2008.

\begin{tabular}{|c|c|c|c|c|}
\hline \multicolumn{5}{|c|}{ Números mundiais } \\
\hline & \multicolumn{2}{|c|}{ Estimativa de casos novos } & \multicolumn{2}{|c|}{ Estimativa de óbitos } \\
\hline Neoplasias & Homens & Mulheres & Homens & Mulheres \\
\hline Pulmão, Brônquio & 1.095 .200 & 513.600 & 951.000 & 427.400 \\
\hline Próstata & 903.500 & - & 258.400 & - \\
\hline Colón e Reto & 663.600 & 570.100 & 320.600 & 288.100 \\
\hline Mama Feminina & - & 1.383 .500 & - & 458,400 \\
\hline Linfoma Não-Hodgkin & 199.600 & 156.300 & 109.500 & - \\
\hline Leucemias & 195.900 & - & 143.700 & 113.800 \\
\hline \multicolumn{5}{|c|}{ Números dos países de primeiro mundo } \\
\hline & \multicolumn{2}{|c|}{ Estimativa de casos novos } & \multicolumn{2}{|c|}{ Estimativa de óbitos } \\
\hline Neoplasias & Homens & Mulheres & Homens & Mulheres \\
\hline Pulmão, Brônquio & 482.600 & 241.700 & 412.000 & 188.400 \\
\hline Próstata & 648.400 & - & 136.500 & - \\
\hline Colón e Reto & 389.700 & 337.700 & 166.200 & 153.900 \\
\hline Mama Feminina & - & 692.200 & - & 189.500 \\
\hline Linfoma Não-Hodgkin & 95.700 & 84.800 & - & 33.500 \\
\hline \multicolumn{5}{|c|}{ Números dos países em desenvolvimento } \\
\hline & \multicolumn{2}{|c|}{ Estimativa de casos novos } & \multicolumn{2}{|c|}{ Estimativa de óbitos } \\
\hline Neoplasias & Homens & Mulheres & Homens & Mulheres \\
\hline Pulmão, Brônquio & 612.500 & 272.000 & 539.000 & 239.000 \\
\hline Próstata & 255.000 & - & 121.900 & - \\
\hline Colón e Reto & 274.000 & 232.400 & 154.400 & 134.100 \\
\hline Mama Feminina & - & 691.300 & - & 268.900 \\
\hline Linfoma Não-Hodgkin & 103.800 & - & 71.600 & - \\
\hline Leucemias & 116.500 & 93.400 & 95.100 & 75.100 \\
\hline
\end{tabular}

Fonte [3].

A maioria desses antígenos é chamada de "CD" ("cluster of differentiation"), como: CD19, CD20, CD21, CD22, CD37, CD52, e HLA-DR representando outro grupo de antígenos importante expresso pelas células-B dos LNH [5].

Uma conseqüência direta da expressão destes antígenos alvos nas células-B normais e seus precursores é o uso comum do anticorpo não marcado, em doses 
relativamente altas, antes da administração dos anticorpos marcados, com objetivo de bloquear os antígenos alvos nas células-B normais e seus precursores, proporcionando assim uma ligação mais favorável no tumor [5].

Tabela 3. Antígenos comuns das células-B de LNH e seus anticorpos correspondentes

\begin{tabular}{ccc} 
Antígeno alvo & Anticorpo não-conjugado & Nome genérico do anticorpo \\
\hline CD19 & Anti-B4 HD37 & - \\
CD21 & OKB7 & - \\
CD20 & B1 & Tositumomab \\
2B8 & Ibritumomab \\
C2B8 22 & HLL2 & Rituximab (Rituxan) \\
HLA-DR & Lym-1 & Epratuzumab (Lymphocide) \\
\hline
\end{tabular}

Fonte [5].

O uso de anticorpos monoclonais (Acm) para terapia de linfomas, dirigidos ao antígeno CD20 de células-B de linfomas do tipo não-Hodgkin (LNH) é uma realidade [1]. Anticorpos monoclonais possuem potencial de provocar a morte seletiva de células tumorais por meio de diversos mecanismos imunológicos inerentes e como vetores de distribuição de toxinas, radionuclídeos e pró-drogas [4-6].

O uso de Acm produzidos pelo clone selecionado de células provou-se vantajoso, considerando a sua especificidade. Assim, eles se ligam somente aos sítios específicos de ligação nos antígenos, resultando em obtenção de efeito terapêutico desejado com efeitos colaterais insignificantes [6-8].

Os Acms anti-CD20 dirigidos contra os antígenos CD20 de células-B dos linfomas Não-Hodgkin (LNH) já são disponíveis comercialmente com aprovação do FDA ("Food and Drug Administration") dos Estados Unidos (EUA). Os três principais Acm(s) aprovados para imunoterapia de células-B de LNH são: (1) Rituximab (MabThera ${ }^{\circledR}$ 
anticorpo quimérico (humano/murínico), (2) Ibritumomab tiuxetan (murínico), e (3) Tositumomab (murínico), além de vários outros aguardando aprovação.

Esses anticorpos anti-CD20 provaram-se capazes de induzir apoptose de células-B tumorais humanas assegurando assim sua capacidade fármaco-terapêutica $[5,7-13]$.

As células-B dos LNH são ideais para essa modalidade de tratamento por sua acessibilidade para os anticorpos terapêuticos, sensibilidade ao mecanismo de morte celular citotoxicidade-complemento-dependente (CCD) e citotoxicidade-anticorpodependente célula-mediada (CADC) e apoptose. Vale ressaltar que para essa modalidade de tratamento é imprescindível à característica específica do antígeno dirigido e seu nível de expressão na superfície das células-B. A Figura 2 demonstra o mecanismo de ação do rituximab.

Além disso, a citotoxicidade anticorpo-mediada somente é alcançada se o antígeno dirigido não for internalizado, e nem se desprender após ligação ao anticorpo. O anticorpo e o antígeno devem ser capazes de formar um composto estável de anticorpo-antígeno na superfície da membrana celular capaz de mediar o CCD, CADC e apoptose [5-7,9-13]. O antígeno que mais se adéqua ao critério de linhagem de células-B com especificidade, alta densidade com modulação limitada e sem desprender-se da superfície celular após ligar-se, possuindo potencialidade para indução de apoptose, é o CD20, o antígeno alvo do Rituximab [9,11-15].

Rituximab, anticorpo anti-CD20 quimérico, específico para o antígeno CD20, reage com $95 \%$ das células-B, e 90\% das células-B de $\mathrm{LNH}$. Apresentou o melhor resultado clínico com taxa de indução de remissão superior a $60 \%$ em pacientes com LNH indolente, e 35\% em pacientes com LNH reincidente e agressivo, quando agente único de tratamento. Apresentou taxa de resposta alta (aproximadamente 70\%) quando foi usado em pacientes com diagnóstico inicial e submetido à monoterapia com Rituximab [9,11-13]. 


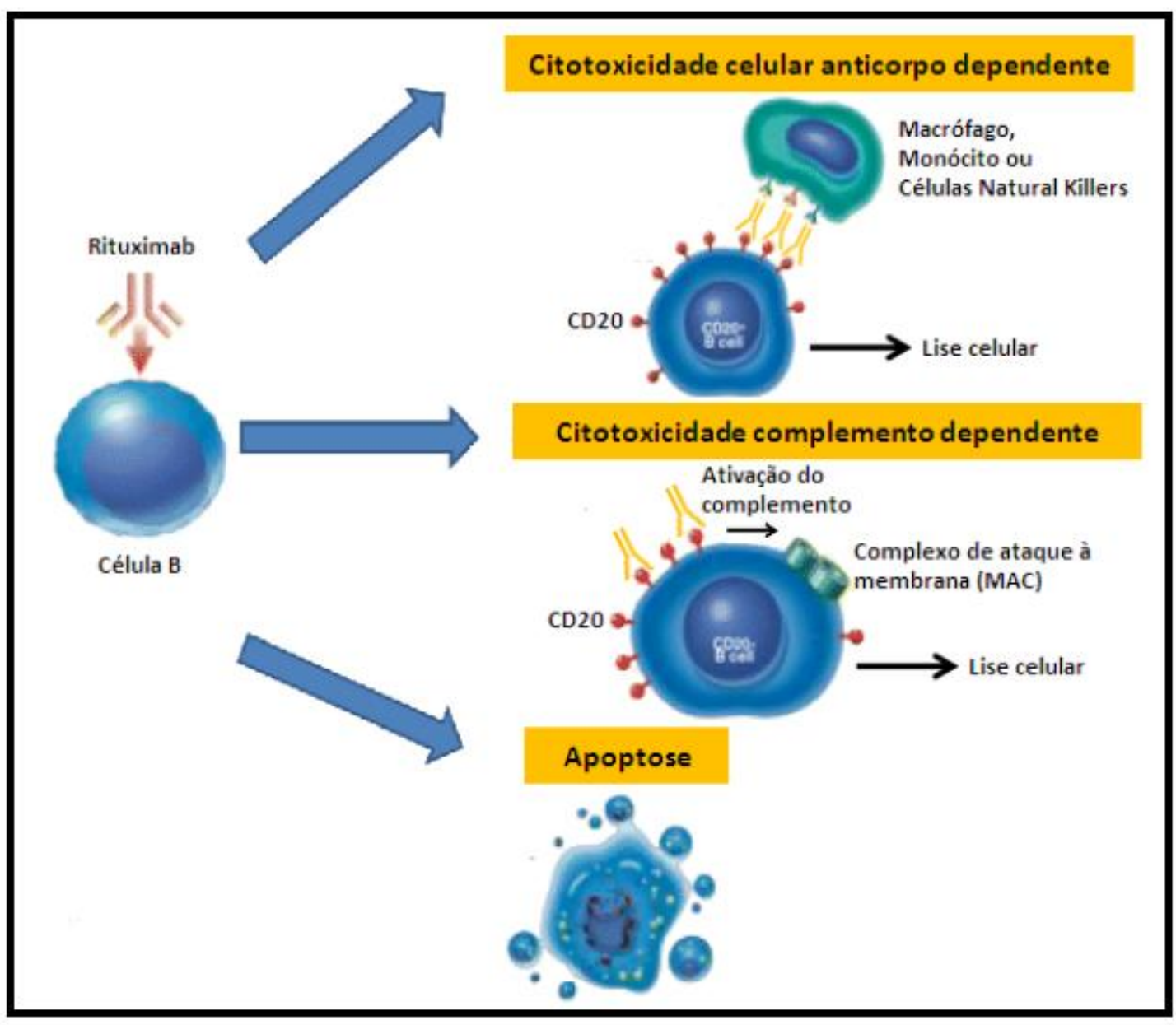

Figura 2. Mecanismo de ação do rituximab [5].

Além disso, as células-B voltam a níveis normais dentro de seis meses após o final de tratamento com rituximab [11,13]. Porém, a radioterapia, sozinha ou combinada com quimioterapia, é a modalidade de tratamento rotineira para os portadores de linfomas de células-B. Apesar de taxas de respostas altas obtidas inicialmente com este regime de tratamento, ele demonstrou-se ineficiente em muitos pacientes que acabaram apresentando recaída [4,6,10,13-18].

Ademais, o anticorpo monoclonal rituximab foi aprovado como agente específico para pacientes portadores de $\mathrm{LNH}$, combinado com quimioterapia (Ciclofosfamida + Daunomicina + Oncovin + Prednisona). Neste caso, demonstrou resposta superior em pacientes com LNH agressivo. O rituximab combinado com CHOP apresentou um aumento significante de sobrevida global (SG) comparado com quimioterapia (CHOP) sozinha. A Tabela 4 demonstra alguns exemplos de 
combinações de quimioterápicos utilizados no tratamento de linfomas de células-B de LNH $[1,4,6-9]$.

Contudo, este fato salientou a importância e necessidade de uma nova abordagem de tratamento com garantias reais de alívio aos portadores desse tipo de neoplasia, a Radioimunoterapia (RIT) $[9,11,12,18,19]$.

Tabela 4. Alguns exemplos de combinações de medicações utilizadas para tratamento de células-B de LNH.

\begin{tabular}{cc}
\hline Sigla & Combinação \\
CP & Clorambucil + Prednisona \\
CVP & Ciclofosfamida + Vincristina + Prednisona \\
CHOP & Ciclofosfamida + Daunomicina + Oncovin + Prednisona \\
m BACOD & Metotrexano + Bleomicina + Adriamicina + Ciclofosfamida \\
ABVD & Adriamicina + Bleomicina + Vinblastina + Dacarbazina \\
ICE & Ifosfamida + Carboplastina + Etopside
\end{tabular}

Fonte [1].

Radioimunoterapia é uma nova promessa de tratamento para portadores de LNH de células-B refratários ou quimioterapia recorrentes. Essa abordagem consiste na combinação de princípio de tratamento sistêmico e distribuição "in loco" de radiação aos tecidos tumorais poupando os tecidos normais. Isso é realizado com uso de radioimunoconjugados - anticorpos para antígenos tumor-associados quimicamente conjugados à radionuclídeos apropriados [11,12,14,17,19-21].

A finalidade da RIT consiste em administrar dose máxima de tratamento a fim de distribuir a dose máxima de radiação ao tecido tumoral com toxicidade mínima ou tolerável aos órgãos críticos como a medula, fígado, baço e rins $[13,16,18,19,21,25$ 28]. 
Além disso, o sucesso ou o melhor proveito dos radioimunoconjugados utilizados para RIT depende de fatores tais como: expressão preferencial de antígenos tumor-associado por células tumorais comparado às células normais, distribuição e penetração efetiva dos radioimunoconjugados para dentro do tumor, a retenção prolongada do radionuclídeo no sítio do tumor, a energia alta depositada pelo radionuclídeo para danificar as células tumorais com mínimo dano aos tecidos normais e, finalmente, a estabilidade dos radioimunoconjugados $[11,18,19]$.

Além disso, a RIT é considerada vantajosa em comparação ao uso de outra modalidade de tratamento de neoplasias, incluindo o uso de anticorpos não marcados, principalmente considerando o efeito aditivo da citotoxicidade radio-induzida e a capacidade da radioatividade associada de localizar e eliminar células tumorais distantes do sítio de ligação do anticorpo radiomarcado. Isso significa dizer que com RIT não é necessário o anticorpo marcado ligar-se a todas as células dentro do tumor para distribuir seu efeito citotóxico a todas elas [19,29,30].

Dois radiofármacos obtiveram aprovação do FDA dos E.U.A e já são comercialmente disponíveis: são o Ibritumomab tiuxetan $-{ }^{90} \mathrm{Y}$ (Zevalin, IDEC/Schering), e Tositumomab- ${ }^{131}$ I (Bexxar; Coriza/GlaxoSmithKline). Esses radiofármacos são aprovados especificamente para RIT de pacientes com LNH de baixo-grau e folicular $[5,11,17-19,25,26,31,32]$.

Os anticorpos anti-CD20 usados em Zevalin e Bexxar (Ibritumomab e Tositumomab, respectivamente) são ambos de origem murínica, isso devido à desejável meia-vida circulante desses anticorpos, quando comparada aos quiméricos, que por sua vez possuem meia-vida circulante significativamente mais longa. Essa característica peculiar dos anticorpos murínicos proporciona absorção, ou seja, penetração máxima no tumor 48 a 72 horas após administração, com irradiação relativamente mínima dos órgãos normais [14,19,30-32].

Vale lembrar que esses medicamentos não são disponíveis no Brasil para a classe médica nuclear brasileira e a importação dos mesmos depende do registro dos radiofármacos no País e o custo do produto seria, certamente, elevado. Será de suma importância sócio-econômica o desenvolvimento no IPEN de um radiofármaco para RIT 
de pacientes brasileiros portadores de $\mathrm{LNH}$, com capacidade terapêutica eficiente e disponível para a classe médica nuclear brasileira.

O anticorpo a ser empregado no desenvolvimento deste radiofármaco será o próprio rituximab, disponível comercialmente na forma de imunoterápico, tendo em vista que sua eficácia e segurança já foram comprovados em seres humanos. A utilização do rituximab conjugado com quelante DOTA e radiomarcado com o lantanídeo lutécio-177 tem sido proposta como alternativa para RIT de LNH [25]. 


\section{OBJETIVO}

Estudar a conjugação de agentes quelantes bifuncionais ao anticorpo anti-CD20 e otimizar as condições de marcação do anticorpo conjugado com lutécio-177, visando contribuir para a elaboração de um radiofármaco com potencial para o tratamento de linfoma não - Hodgkin (LNH).

De forma inédita, o trabalho pretende avaliar a estabilidade e eficiência de marcação do anticorpo ao utilizarem-se diferentes quelantes bifuncionais no processo de conjugação bem como realizar avaliação cinética e de especificidade comparativa dos anticorpos marcados. Também pretende estudar a influência do método de

purificação prévia do anticorpo monoclonal na eficiência de conjugação e da marcação. 


\subsection{REVISÕES BIBLIOGRÁFICAS}

\subsection{Linfomas não-Hodgkin (LNH)}

Assim como o linfoma de Hodgkin (LH), o LNH geralmente se origina em tecidos linfóides e pode se espalhar para outros órgãos. O LNH, entretanto, é muito menos previsível do que o $\mathrm{LH}$ e frequentemente se dissemina a sítios extranodais. $\mathrm{O}$ prognóstico depende do tipo histológico, estadiamento e tratamento (Instituto Nacional de Câncer 2010) [5].

Os LNH podem ser divididos em indolentes (baixo grau) e agressivos (alto grau). Os indolentes, que correspondem a $40 \%$ dos diagnósticos, possuem baixo índice de proliferação celular, células de tamanho pequeno, formação de grandes massas linfonodais, envolvimento freqüente de medula óssea e de sítios extranodais $[5,6]$.

Paradoxalmente, são tumores de baixa agressividade, com sobrevida de anos mesmo sem tratamento específico, mas geralmente são incuráveis. Por outro lado, linfomas de alto grau, que representam $60 \%$ dos diagnósticos, apresentam alto índice de proliferação celular, células grandes, linfonodomegalias localizadas e como possuem alta agressividade, levam a óbito rapidamente se não tratados, no entanto, são mais curáveis [5,6].

Segundo levantamento feito pelo Instituto Nacional de Câncer Jose Alencar Gomes da Silva (INCA), o linfoma não Hodgkin em homens é o oitavo mais frequente na região Norte (2/100 mil), a nona mais frequente na região Sudeste (7/100 mil). Enquanto que nas regiões Sul (6/100 mil) e Nordeste (3/100 mil), é a décima incidência de câncer mais frequente; e na região Centro-Oeste (5/100 mil), é a décima primeira incidência de câncer mais frequente. Para as mulheres, é o oitavo mais frequente na região Sudeste (6/100 mil) e o 11 으 na região Centro-Oeste (4/100 mil), enquanto, nas regiões Sul (5/100 mil), Nordeste (2/100 mil) e Norte (1/100 mil), é o 12 ㅇincidência de câncer mais frequente [2].

A estimativa para 2012 de numero de casos novos para os 10 tipos de câncer mais frequentes entre homens e mulher pode ser observada na Tabela 5 . O LNH é o 8o 
câncer mais frequente entre os homens, com 170 novos casos representando 2,3\% dos casos [2].

Tabela 5. Distribuição proporcional de dez tipos de câncer mais incidentes estimad os para 2012 por sexo no Brasil

\begin{tabular}{|c|c|c|c|c|c|c|c|}
\hline Localização primária & casos novos & percentual & & & Localização primária & casos novos & percentual \\
\hline Próstata & 60.180 & $30,8 \%$ & Homens & Mulheres & Mama Feminina & 52.680 & $27,9 \%$ \\
\hline Traqueia, Brônquio e Pulmäo & 17.210 & $8,8 \%$ & & & Colo do Útero & 17.540 & $9,3 \%$ \\
\hline Cólon e Reto & 14.180 & $7,3 \%$ & & & Cólon e Reto & 15.960 & $8,4 \%$ \\
\hline Estômago & 12.670 & $6,5 \%$ & & & Glândula Tireoide & 10.590 & $5,6 \%$ \\
\hline Cavidade Oral & 9.990 & $5,1 \%$ & & & Traqueia, Brônquio e Pulmão & 10.110 & $5,3 \%$ \\
\hline Esôfago & 7.770 & $4,0 \%$ & & & Estômago & 7.420 & $3,9 \%$ \\
\hline Bexiga & 6.210 & $3,2 \%$ & & & Ovário & 6.190 & $3,3 \%$ \\
\hline Laringe & 6.110 & $3,1 \%$ & & & Corpo do Útero & 4.520 & $2,4 \%$ \\
\hline Linfoma não Hodgkin & 5.190 & $2,7 \%$ & & & Linfoma nẩo Hodgkin & 4.450 & $2,4 \%$ \\
\hline Sistema Nervoso Central & 4.820 & $2,5 \%$ & & & Sistema Nervoso Central & 4.450 & $2,4 \%$ \\
\hline
\end{tabular}

Fonte [2].

\subsection{Radioimunoterapia (RIT)}

Radioimunoterapia é uma das modalidades terapêutica mais importante e eficiente utilizada no tratamento de pacientes portadores de linfomas não-Hodgkin (LNH) [58]. Atualmente, anticorpos monoclonais anti-CD20 radiomarcados com radionuclídeos beta emissores são comumente e utilizados nesta modalidade de tratamento, pois a energia proveniente da radiação beta potencializa a eficiência terapêutica do anticorpo anti-CD20 rituximab utilizado no tratamento de células-B de LNH $[29,30,37,58,59]$.

Os linfócitos e as células dos linfomas são altamente sensíveis à radiação e devido ao alcance milimétrico das partículas beta, a RIT possibilita um efeito de fogo cruzado ("cross-fire"), irradiando mesmo as células tumorais que não se ligaram diretamente ao anticorpo radiomarcado, mas encontram-se próximos de células que se ligaram ao anticorpo radiomarcado. Desta forma, o anticorpo radiomarcado possui 
a capacidade de localizar e com seu efeito de citotoxidade radio-induzida, eliminar células ligadas e distantes do sítio de ligação do anticorpo radiomarcado [5,37].

Os radiofármacos terapêuticos utilizados em radioimunoterapia, em geral, são radioimunoconjugados desenvolvidos essencialmente para distribuir doses terapêuticas de radiação ionizante às células tumorais poupando ou com mínimo dano às células ou tecidos normais $[12,18,19,60]$.

Dosagens terapêuticas de radiação podem ser distribuídas em três formas diferentes: feixes externos de radiação, braquiterapia ou sementes implantadas, e administração sistêmica. A terapia de Bach envolve uso de sementes (fontes radioativos) fisicamente implantadas no local do tumor e permanece até sejam removidas com intervenção cirúrgica [60].

Essa modalidade de tratamento é muito importante e mais usada em terapia de pacientes com câncer de próstata [60]. Esse procedimento é útil para tratamento de tumores de fácil acesso. No caso de administração sistêmica de radiofármacos terapêuticos, desenvolvidos para distribuir doses de radioatividade às células tumorais específicas "in situ", oferecem amplas oportunidades, inclusive de tratamento de disseminação de células tumorais e metástases [60,61].

De forma ideal, os radiofármacos terapêuticos devem chegar ao sítio do tumor em concentrações suficientes capazes de distribuir doses citotóxicas de radiação às células tumorais e, ao mesmo tempo, apresentar clareamento sanguíneo rápido e em órgãos ou tecidos sadios minimizando danos de radiação aos tecidos normais [60].

Além disso, o sucesso ou o melhor proveito dos radioimunoconjugados utilizados para RIT depende de critérios importantes tais como: expressão preferencial de antígenos tumor-associados por células tumorais comparado às células normais ou sadias, distribuição e penetração efetiva dos radioimunoconjugados para dentro do tumor; a retenção prolongada do radionuclídeo no sítio do tumor; a energia alta depositada pelo radionuclídeo, suficiente para danificar as células tumorais com mínimo dano aos tecidos normais e, por fim, a estabilidade "in vivo" dos radioimunoconjugados $[12,18,19]$. 
Contudo, alguns parâmetros devem ser considerados no desenvolvimento ou elaboração de um radiofármaco específico para RIT de células-B de LNH, tais como: (a) escolha do anticorpo monoclonal, (b) escolha do radionuclídeo, (c) escolha do grupamento quelante para acoplar o radionuclídeo ao anticorpo, e finalmente o tamanho do tumor e a heterogeneidade do antígeno alvo $[16,18,19]$.

O radiofármaco tumor especifico dirigido é desenvolvido baseado na sua ligação ao receptor do composto radiomarcado no tecido tumoral; em geral, esses radiofármacos são compostos por: uma biomolécula ou imunoconjugado, um agente quelante bifuncional (BFC), e o radionuclídeo.

A biomolécula serve como carregador específico de radioatividade para o tecido tumoral com concentração substancial de receptor conhecida, e se ligam com alta afinidade e especificidade resultando em ótima distribuição e penetração efetiva de radiação proveniente do radionuclídeo empregado. Várias biomoléculas incluindo anticorpos, peptídeos e não-peptídeos já foram utilizados com sucesso como carregador de radionuclídeos terapêuticos [60].

A Tabela 6 demonstra alguns radiofármacos baseados em anticorpos e peptídeos aprovados pela FDA ("Food and Drug Administration") para fins diagnósticos e terapêuticos de doenças como trombose e câncer [60]. 
Tabela 6. Alguns radiofármacos disponíveis e utilizados para fins diagnósticos e terapêuticos

\begin{tabular}{lcc}
\hline \multicolumn{1}{c}{ Radiofármaco } & Marca Registrada & \multicolumn{1}{c}{ Finalidade Principal } \\
\hline Índio-111 Capromab & ProstaScint & Imagem de câncer de próstata \\
Pendetide & & \\
Índio-111 Pentatireotide & Octreotide & Imagem de tumores neuro-endócrinos \\
Índio-111 Satumomab & OncoScint & Imagem de metástase associado com câncer \\
pendetide & AcuTect & de ovário e coloretal \\
Tc-99m Apcitide & CEA-Scan & Imagem de veias com trombose profunda \\
Tc-99m Arcitumomab & Imagem de câncer de coloretal \\
Tc-99m Depreotide & Imagem de tumores receptores de \\
Y-90 Ibritumomab & Zevalin & Imomastatina \\
Tiuxetan & & Tratamento de linfomas não-Hodgkin \\
I-131 Tositumomab & Bexxar & Tratamento de linfomas não-Hodgkin \\
\hline
\end{tabular}

Fonte [60].

\subsection{Radiofármacos utilizados em radioimunoterapia}

Vários estudos e ensaios clínicos utilizando-se diversos radiofármacos destinados a RIT de vários tipos e tamanhos de tumores estão em curso em diversas instituições e centros de medicina nuclear em diversos países. Porém, somente dois obtiveram aprovação do FDA dos E.U.A e já são comercialmente disponíveis: são o Ibritumomab tiuxetan- ${ }^{90} Y$ (Zevalin, IDEC/Schering), e Tositumomab- ${ }^{131}$ I (Bexxar; Coriza/GlaxoSmithKline). Esses radiofármacos são aprovados especificamente para RIT de pacientes com LNH de baixo-grau e folicular [11,17-19,26,30,31]. Os anticorpos anti-CD20 usados em Zevalin e Bexxar (Ibritumomab e Tositumomab, respectivamente) são ambos de origem murínica, isso devido à desejável meia-vida circulante desses anticorpos, quando comparada aos quiméricos, que por sua vez possuem meia-vida circulante significativamente mais longa. Essa característica peculiar dos anticorpos murínicos proporciona absorção, ou seja, penetração máxima 
no tumor 48 a 72 horas após administração, com irradiação relativamente mínima dos órgãos normais [14,19,30,31].

Alguns radionuclídeos têm sido utilizados, cada um com suas características particulares em relação à sua energia de emissão, com vantagens e desvantagens, dependendo, em especial, do estágio clínico da doença (ex., doença volumosa contra doença microscópica residual). Ítrio-90 apresenta energia média de 0,93 MeV e energia máxima de 2,3 MeV, meia-vida de 2,7 dias e alcance médio em tecido de aproximadamente 2,5 $\mathrm{mm}$. Enquanto o iodo-131 apresenta energia média de 0,19 MeV e energia máxima de 0,81 MeV, meia-vida de 8,04 dias e alcance médio em tecido de aproximadamente $0,3 \mathrm{~mm}$.

Essas propriedades são ideais para o tratamento de doença microscópica devido ao efeito de "irradiação cruzada" ("crossfire") permitindo que a radiação alcance e afete (e potencialmente mate) células tumorais que não estejam diretamente ligadas ao anticorpo ou que estejam em local de difícil acesso para o anticorpo. Esse efeito é característico das partículas beta emissoras e devido à combinação relativamente benéfica entre a meia-vida física dos radionuclídeos com a meia-vida biológica dos anticorpos anti-CD20 murínicos [14,19,21,26,32,35].

A eficácia e a segurança do regime de tratamento usando-se o Ibritumomab tiuxetan radiomarcado com ítrio-90 foram avaliadas em três ensaios clínicos multicêntricos. No primeiro ensaio isolado com 54 pacientes com LNH Rituximab recorrente, a taxa de resposta global (TRG) foi de $74 \%$, com remissão completa (RC) de $15 \%$ dos 54 pacientes. A duração média de remissão foi de 6,4 meses (intervalo de 0,5 - 24,9 meses) e o tempo médio para progressão da doença foi de 6,8 meses (intervalo de 1,1-25,9 meses) [29,33].

O segundo ensaio metódico foi aplicado à pacientes com LNH de baixo-grau recidivo ou refratário a Ibritumomab tiuxetan $(n=73)$ ou Rituximab $(n=70)$ [14]. No estudo, o Ibritumomab tiuxetan obteve uma TRG superior ( $80 \%$ ) contra a obtida com Rituximab que apresentou RC em apenas 30 \% dos pacientes. A média de duração da remissão foi de 13,9 meses (intervalo de 1,0 - 30,1 meses) e o tempo para progressão da doença foi de 11,2 meses (intervalo de 0,8 - 31,5 meses) [29,33]. 
O terceiro estudo foi conduzido com 30 pacientes que apresentaram trombocitopenia moderada. Neste estudo, as respostas foram analisadas baseadas no preceito de intenção-para-tratamento, sendo a TRG obtida de 83 \%, com tempo médio de duração de aproximadamente 12 meses [33].

Em resumo, as TRGs obtidas com Ibritumomab tiuxetan nos três ensaios clínicos citados acima, variaram entre 74 e 83 \% obtidos com pacientes que já passaram por um regime de pré-tratamento e sem esperança de que responderiam a um novo regime quimioterápico $[29,33]$.

Foram obtidos resultados encorajadores numa série de ensaios clínicos realizados com Tositumomab e Tositumomab- ${ }^{131} \mathrm{l}$. Num estudo isolado de Fase I/II envolvendo 59 pacientes portadores de células-B de LNH, a TRG obtida foi de $71 \%$ $[18,29]$. Davies e colaboradores relataram o resultado de um estudo Fase II conduzido em dois centros a fim de estabelecer a eficácia e segurança do regime de tratamento com Tositumomab e Tositumomab- ${ }^{131} \mathrm{I}$ em pacientes que tiveram a primeira e segunda recaída de LNH indolente e/ou indolente recorrente. Dos 41 pacientes participantes do estudo, 31 (76 \%) pacientes responderam, 20 (49 \%) pacientes apresentaram remissão completa (RC), ou RC não confirmada e 11 pacientes (27 \%) apresentaram remissão parcial (RP) [30].

Outro estudo foi conduzido em três centros envolvendo 40 pacientes com LNH de baixo-grau e transformado, que não respondiam mais a tratamento com Rituximab ou que apresentavam progressão da doença após tratamento com Rituximab. A TRG, RC e o tempo para progressão da doença foram avaliados por uma comissão sem conhecimento prévio da situação clínica dos pacientes [34].

Foram incluídos neste estudo pacientes que já passaram por quatro regimes anteriores de tratamento. Neste grupo de pacientes especificamente, fazendo-se uso de Tositumomab e Tositumomab- ${ }^{131}$ I, a TRG obtida foi de $68 \%$, com tempo médio de duração de 16 meses, e RC foi observada em apenas 33 \% dos pacientes, e tempo médio de duração das RC maior que 25 meses [34]. 
Deste modo, pode-se dizer que o regime de Tositumomab e Tositumomab- ${ }^{131}$ I é eficaz em pacientes recorrentes de tratamento com Rituximab [33]. Todavia, foi realizado um estudo comparativo, entre o anticorpo marcado (Tositumomab e Tositumomab- ${ }^{131}$ I) e o anticorpo não marcado (Tositumomab). Neste estudo, 78 pacientes foram inscritos, portadores de LNH de baixo-grau ou baixo-grau transformado, e que já passaram por um a cinco regimes de tratamento quimioterápico. A maioria dos pacientes tinha aproximadamente $25 \%$ de comprometimento medular, doença mensurável e não receberam nenhuma dose mieloablativa anterior. Os pacientes foram randomizados para cada grupo de estudo, quando oportuno. No início do estudo, 42 pacientes receberam doses de Tositumomab e Tositumomab- ${ }^{131}$ I e os 36 pacientes restantes receberam apenas as doses de Tositumomab não marcado. Os pacientes do primeiro grupo apresentaram TRG confirmada de $55 \%$, enquanto que foi de $17 \%$ no segundo grupo. Além disso, a TRG confirmada foi muito superior (33\%) nos grupos de Tositumomab- ${ }^{131}$ I do que nos grupos de Tositumomab não marcado (8 \%) [34].

Isso vem a confirmar a importância da radioatividade conjugada ao anticorpo anti-CD20. Adicionalmente, o tempo de progressão livre da doença foi mais longo no grupo de Tositumomab e Tositumomab- ${ }^{131}$ I (6,3 meses) do que no grupo que recebeu o Tositumomab não marcado (5,5 meses). Pacientes que falharam com Tositumomab não marcado e que foram transferidos e tratados com Tositumomab e Tositumomab${ }^{131}$ I apresentaram RC de $42 \%$, e TRG de $68 \%$. Neste grupo de pacientes o tempo de progressão livre da doença foi de 12,4 meses. Deste modo, o componente radioativo [131 I] do Tositumomab foi de suma importância para a eficácia terapêutica do radiofármaco Tositumomab- ${ }^{131}$ I [34].

Outros estudos clínicos relatados com Tositumomab- ${ }^{131}$ I confirmou a potencialização do efeito terapêutico da imunoterapia quando combinado com RIT [31,32]. 


\subsection{Relatos de estudos clínicos utilizando rituximab marcado com Lutécio-177}

Um estudo de Forrer e colaboradores (2009) relata a marcação do anticorpo monoclonal rituximab (Mabthera) conjugado ao quelante p-SCN-Bz-DOTA com lutécio-177. Obtiveram um composto com rendimento de marcação superior a 99 \% e o composto demonstrou alta pureza radioquímica após sete dias de marcação, superior a $97 \%$, indicando estabilidade do produto. Além disso, esse imunoconjugado (rituximab-DOTA- ${ }^{177} \mathrm{Lu}$ ) radiomarcado apresentou ótima imunoreatividade [37].

O estudo de dosimetria foi realizado com o mesmo composto em dois pacientes com LNH recorrente. Neste estudo, os pacientes receberam a dosagem de $20 \mathrm{mCi}\left(740 \mathrm{MBq} / \mathrm{m}^{2}\right.$ ) do composto, e a dosagem total administrada foi de $40 \mathrm{mCi}$ (1.480 MBq) e $30 \mathrm{mCi}(1.110 \mathrm{MBq}$ ) respectivamente. Os pacientes apresentaram ótima tolerância ao composto e ótima resposta tumoral específica foi observada nos pacientes, algum tempo após a administração do composto [37].

Ademais, a dosagem medular nos pacientes participantes do estudo foi calculada em 536 mGy (0,36 mGy / MBq) e 425 mGy (0,38 mGy / MBq) respectivamente, e a DMT resultante foi calculada em $351 \mathrm{mGy}(0,24 \mathrm{mGy} / \mathrm{MBq})$ e $277 \mathrm{mGy}(0,25 \mathrm{mGy} / \mathrm{MBq})$ nos dois pacientes do estudo [37].

Outro estudo realizado por Audicio e colaboradores (2011) relata a marcação do anticorpo anti-CD20 rituximab conjugado ao quelante DOTA com lutécio-177. Obtiveram um composto com rendimento de marcação superior a 97\%. 0 imunoconjugado demonstrou ótima estabilidade quando foi armazenado sob refrigeração $\left(2-8^{\circ} \mathrm{C}\right)$, e congelado $\left(-20^{\circ} \mathrm{C}\right)$ no período de seis meses, indicando que o composto conjugado (rituximab-DOTA) pode ser armazenado de forma simples para uso rotineiro [58].

Além disso, o composto (rituximab-DOTA- ${ }^{177} \mathrm{Lu}$ ) radiomarcado apresentou rendimento de marcação que varia entre 75 a 79\%, com pureza radioquímica superior a 97\% após purificação. Obtiveram-se atividade específica máxima de $300 \mathrm{MBq} / \mathrm{mg}$ $(8,1 \mathrm{mCi} / \mathrm{mg})$, apropriada para uso clínico, segundo trabalho anterior de Forrer e colaboradores $(2009)[37,58]$. 
O sistema cromatográfico utilizado no controle de pureza radioquímica demonstrou ser eficiente, além de simples e prático na separação das diferentes espécies radioquímicas presentes na mistura. O composto radiomarcado apresentou estabilidade de 72 horas após a marcação em temperatura ambiente [59].

Ademais, o composto demonstrou ótima estabilidade in vitro. Estudo de citométria de fluxo realizado com células-B humanas demonstrou $10 \%$ de expressão de antígeno CD20. O estudo de ligação específica demonstrou que o aumento da ligação específica do composto foi proporcional ao crescimento da concentração celular; a capacidade máxima de ligação foi de $35 \pm 5 \%$; a inibição de ligação às células foi de $78,1 \pm 2,1 \%$ quando 2,2 pM de solução do anticorpo frio foi adicionada à mistura. Esses resultados demonstram que o anticorpo anti-CD20 (rituximab) conserva sua capacidade biológica e alta afinidade de ligação com o antígeno CD20, nas condições de conjugação e marcação utilizadas [59].

Estudo de biodistribuição em camundongos sadios demonstrou que o sistema urinário e sistema hepato-biliar são a principal via de eliminação do anticorpo radiomarcado. A captação no fígado foi de $17,8 \pm 0,2 \%, 24,7 \pm 0,6 \%$ e $41,0 \pm 6,2 \%$, nos tempos estudados de 4, 16 e 24 horas respectivamente, e a captação na bexiga foi $11,6 \pm 0,6 \%, 5,1 \pm 0,1 \%$ e 5,2 $\pm 2,5 \%$, respectivamente, nos mesmos tempos estudados. Neste estudo, nenhuma captação significante foi observada em outros órgãos [59].

Além disto, o radioimunoconjugado demonstrou alta estabilidade in vivo indicada pela baixa captação óssea observada considerando alta afinidade do lutécio177 livre pelo tecido ósseo [59].

\subsection{Propriedades radioquímicas do Lutécio-177}

Vários radionuclídeos metálicos e lantanídeos beta emissores já foram estudados e testados para formulações utilizadas para radioimunoterapia, como iodo131, ítrio-90, samário-153 e homio-166, sendo, iodo-131 e ítrio-90 os mais utilizados [40,60-62]. Porém, esses radionuclídeos apresentam vantagens e desvantagens. 
A radioiodinação de Acms é relativamente simples, e o radioiodo é largamente disponível com custo acessível. Porém, não é um nuclídeo ideal para uso em RIT, já que Acms radiomarcados com esse nuclídeo podem sofrer dehalogenação in vivo. 0 radioiodo apresenta uma energia gama associada (0,364 MeV) útil para avaliação de biodistribuição e estudo de dosimetria. Porém, este energia gama é preocupante com respeito à segurança do paciente, acompanhante e equipe médica $[10,13,17,26,42,44]$.

Acms radiomarcados com ítrio-90 requerem o uso de quelantes bifuncionais, porém proporcionam um composto radiomarcado com ótima estabilidade in vivo. Assim, o ítrio-90 permanece retido nas células por mais tempo aumentando o tempo de irradiação do tumor $[26,33,35,37,44,47]$.

Como o ítrio-90 não possui energia gama, o Acm marcado com índio-111 tem sido utilizado como substituto químico e biológico para estudos de biodistribuição e estimativa de dose de radiação distribuída por anticorpos radiomarcados com ítrio-90 $[14,17-19,26,44]$.

Contudo, para melhorar as estratégias e resultados em RIT, o lutécio-177, um lantanídeo metálico vem sendo utilizado para substituir o iodo-131 e ítrio-90 na elaboração de radiofármacos para terapia de LNH, por apresentar propriedades físicas mais apropriadas para essa modalidade de tratamento $[18,23,25,35,37,40,60,61]$.

Anticorpos monoclonais radiomarcados com lutécio-177, igualmente aos marcados com o ítrio-90 apresentam vantagens sobre Acm marcados com iodo-131. Isto é, o catabolismo de proteínas radioiodadas leva à produção de iodo-tirosina dentro dos lisossomos, e o seu desprendimento subseqüente das células resulta em diminuição do tempo de permanência do radionuclídeo no sítio do tumor.

Ao contrário, nas proteínas queladas e depois incorporadas aos radiometais, isso não acontece, pois os radiometais permanecem retidos dentro dos lisossomos após seu catabolismo, levando assim, à maior dose de irradiação e tempo de permanência dentro do tumor. Devido a essa característica singular, os radiometais são chamados de radionuclídeos residuais [23,30,33,34,39,60,66]. 
O lutécio-177 possui energia beta máxima de 0,497 MeV, meia-vida de aproximadamente 6,74 dias e energia gama associada (113 KeV (6,5\%), $208 \mathrm{KeV}$ (11\%)), alcance médio tecidual aproximadamente de 0,2 $\mathrm{mm}$ proporcionando excelente possibilidade para estudo de biodistribuição e dosimetria $[16,23,25,33,35,37,38,41,63,64]$. A TAB. 7 demonstra propriedades radioquímicas de alguns radionuclídeos mais pesquisados e utilizados para finalidades diagnósticas e terapêuticas.

A faixa de alcance em tecido apresentada pelo lutécio-177, embora esteja dentro da faixa de alcance do ítrio-90, é maior que a do iodo-131. Essa superioridade em faixa de alcance tecidual, combinada com a energia beta relativamente baixa faz do lutécio-177 um radionuclídeo apropriado para o tratamento e erradicação de tumores pequenos ou doenças residuais mínimas $[23,35,37,39,63,64]$.

Além disso, os radionuclídeos beta emissores como lutécio-177 apresentam melhor distribuição homogênea de dose dentro do tumor devido ao efeito fogo cruzado ("cross-fire") mesmo quando são distribuídas de forma heterogênea dentro do tumor [60].

Ademais, em termos químicos, o lutécio-177 favorece o estado de oxidação +3 , o mesmo apresentado pelo ítrio-90, que é similar ao índio-111. Curiosamente, esses radionuclídeos apresentam pequenas diferenças em sua solução e coordenação química $[25,60]$.

Ao contrário dos Acms marcados com iodo-131, onde o iodo livre na forma de iodeto e anticorpos ( $\mathrm{Ac}^{-131}{ }^{13}$ ) radioiodados deslocam-se fora do tecido e são eliminados pela urina, quando desligam-se do anticorpo [25], os radiometais lutécio-177 e ítrio-90 livres são absorvidos pela medula e isso pode resultar em irradiação excessiva levando à toxicidade medular [39,40,62]. 
Tabela 7. Propriedades radioquímicas de alguns radionuclídeos utilizados em diagn óstico de imagem e terapêuticos

\begin{tabular}{|c|c|c|c|}
\hline Radionuclídeo & $\begin{array}{l}\text { Decaimento } \\
\text { emissão max. (\%) }\end{array}$ & Emissão Y (\%) & Meia-vida \\
\hline \multirow[t]{3}{*}{ Cu-64 } & $0,653 \mathrm{MeV} \beta+(17.6 \%)$ & $511 \mathrm{keV}(194,9)$ & $12,7 \mathrm{~h}$ \\
\hline & CE (43.9\%) & & \\
\hline & $0,579 \mathrm{MeV} \beta-(38,5 \%)$ & & \\
\hline \multirow[t]{3}{*}{$\mathrm{Cu}-67$} & $0,562 \mathrm{MeV} \beta-$ & $184,6 \mathrm{keV}(48,7)$ & $2,58 d$ \\
\hline & & $93,3 \mathrm{keV}(16,1)$ & \\
\hline & & $91,3 \mathrm{keV}(7)$ & \\
\hline \multirow[t]{4}{*}{ Ga-67 } & CE & $393,5 \mathrm{keV}(4,6)$ & $3,26 \mathrm{~d}$ \\
\hline & & $300 \mathrm{keV}(16,6)$ & \\
\hline & & $184,6 \mathrm{keV}(21,4)$ & \\
\hline & & $93,3 \mathrm{keV}(38,8)$ & \\
\hline \multirow[t]{2}{*}{ Ga-68 } & $0,836 \mathrm{MeV} \beta+(90 \%)$ & 1077 keV (3\%) & $67,71 \mathrm{~m}$ \\
\hline & CE (10\%) & $511 \mathrm{keV}(178,3 \%)$ & \\
\hline Y-90 & $2,28 \mathrm{MeV} \beta-$ & & $64,053 \mathrm{~h}$ \\
\hline Tc-99m & $\mathrm{TI}$ & 140 keV (89) & $6,0067 \mathrm{~h}$ \\
\hline \multirow[t]{2}{*}{$\ln -111$} & $\mathrm{CE}$ & $245 \operatorname{keV}(94,1)$ & $2,8047 d$ \\
\hline & & $171 \operatorname{keV}(90,7)$ & \\
\hline Sm-153 & $0.8076 \mathrm{MeV} \beta-$ & $103 \mathrm{keV}(29,25)$ & $46,50 \mathrm{~h}$ \\
\hline Ho-166 & 1.8547 MeV $\beta-$ & $80,57 \mathrm{keV}(6,56)$ & $26,824 \mathrm{~h}$ \\
\hline \multirow[t]{2}{*}{ Lu-177 } & $0,498 \mathrm{MeV} \beta-$ & 208,4 keV (10.6) & $6,647 d$ \\
\hline & & $112,95 \mathrm{keV}(6.17)$ & \\
\hline Re-186 & 1,07 MeV $\beta-$ & 137,2 keV (9.47) & $3,7186 \mathrm{~d}$ \\
\hline $\operatorname{Re}-188$ & 2,12 MeV $\beta-$ & $155 \mathrm{keV}(15.6)$ & $17,003 \mathrm{~h}$ \\
\hline
\end{tabular}

Fonte [62].

A energia dos raios gama do lutécio-177 possibilita formas simples de proteção radiológica ao pacientes e funcionários, imagem de qualidade para finalidade de dosimetria, e facilidade de uso em protocolo com paciente externo. Finalmente, sua 
disponibilidade com excelente pureza radionuclídica, e com alta atividade específica, garante bom rendimentos nos processos de radiomarcação [35,36,60-63].

\subsection{Principais métodos de marcação de anticorpos com Lutécio-177}

Os imunoconjugados radiomarcados com elementos metálicos e lantanídeos radioativos utilizados para radioimunoterapia utilizam agentes quelantes bifuncionais (AQB), pois esses elementos formam ligações diretas com biomoléculas, e podem formar complexos estáveis com uma variedade de elementos radioativos $[44,60,62,66]$. Esses ligações devem ocorrer de tal maneira sem comprometer ou afetar as propriedades e a especificidade do anticorpo promovendo um composto com estabilidade termodinâmica e cinética inerte em condições fisiológicas [44,60,62,66]. Isso é importante para minimizar o desligamento ou a liberação do radiometal e seu translocamento ou captação pelo tecido ósseo [69].

Deste modo, a química de coordenação desses grupamentos quelantes e dos radionuclídeos metálicos ou lantanídeos tem importância significativa no processo de marcação de anticorpos e peptídeos. Pois cada radiometal ou lantanídeo, num dado estado de oxidação, demanda um requerimento e tratamento específico formando com o átomo doador de elétrons, complexo com propriedade cinética suficiente para aplicação "in vivo" [62].

Em geral, a radiomarcação do composto conjugado é realizada adicionando-se à mistura o radiometal ou lantanídeo em forma de cloreto diluído em ácido clorídrico. Para os anticorpos conjugados com quelante DOTA, adiciona-se o radiometal ou lantanídeo e a solução resultante geralmente é incubada por trinta a noventa minutos com aquecimento numa temperatura que varia de 37 a $43^{\circ} \mathrm{C}$, sob agitação leve. Ao contrário, as marcações dos anticorpos conjugados com DTPA acorrem por quinze a noventa minutos em temperatura ambiente, pois não apresentam cinética inicial lenta como os anticorpos conjugados com o quelante DOTA [36,37,42-44,58,63-66]. 
Vale ressaltar que a mistura de marcação de anticorpos conjugados com grupamentos quelantes DOTA e seus análogos e DTPA e seus derivados, e radiomarcado com radionuclídeos metálicos ou lantanídeos deve ocorrer no meio ácido, com pH na faixa de 4,5 a 6,0 , pois o meio ácido garante que o radiometal permanece ionizado em solução durante o procedimento de marcação, embora prótons sejam liberados durante a reação de complexação.

Essa faixa de $\mathrm{pH}$ é importante pois a maioria dos metais formam hidróxidos insolúveis com água desligando-se e prejudicando a formação de ligação forte e estável do metal com o grupamento quelante.

Ademais, a presença de íons de coordenação fracos como acetato e citrato no meio de marcação facilita a complexação ou formação de ligações covalentes fortes de metais com grupamentos quelantes proporcionando a obtenção de produto com alta pureza radioquímica e rendimento satisfatório $[44,60,62,66]$.

Segundo relato de Cooper e colaboradores (2006), os Ac-DOTA/DTPA conjugados marcados com baixa atividade específica produzem alto rendimento de marcação, próximo a 100 \%. Ao contrário, os compostos radiomarcados com alta atividade específica, apresentam baixo rendimento de marcação $(<95 \%)$, sendo necessária a purificação desses compostos para a retirada do radiometal livre da mistura de marcação [44].

Os grupamentos quelantes disponíveis e utilizados em radiomarcação com radionuclídeos metálicos incluindo os lantanídeos desempenham duas funções importantes: possui na sua estrutura uma base reativa que possibilita a ligação estável do radionuclídeo metálico ou lantanídeo, e uma segunda base reativa, que apresenta química ideal para ligação covalente com a biomolécula (proteína, anticorpo ou peptídeo). Deste modo, são denominados de grupamentos quelantes bifuncionais $[41,44,60,62,70]$. Em resumo, a técnica comum empregada na conjugação de grupamentos quelantes com biomoléculas envolve a ligação do grupo de amina primária livre (ou ácido carboxílico ativado) localizado na estrutura do quelante com o grupo de ácido carboxílico livre (ou grupo amina ativado) da biomolécula formando assim uma ligação amida estável [62]. 
No entanto, a escolha de um AQB é dependente do radionuclídeo metálico ou lantanídeo utilizado, uma vez que os requisitos de conjugação do metal em questão devem ser considerados (química de ligação, doação de elétrons, etc.,) para obter um composto cineticamente inerte com estabilidade termodinâmica "in vivo" satisfatória $[41,60,62]$.

A função principal dos $A Q B$ é a formação de ligações covalentes com radionuclídeos metálicos ou lantanídeos promovendo um composto de alta estabilidade "in vivo", com acúmulo mínimo em tecidos normais [40,41,60,62].

Vários AQB são comercialmente disponíveis, como ácido S-2-(4isotiocianatobenzil)-1,4,7-triazaciclononane-1,4,7-triacetico (p-SCN-Bn-NOTA), ácido 2(4-isotiocianatobenzil)-1,4,7,10-tetraazaciclododecano-1,4,7,10-tetraacético (p-SCNBn-DOTA), ácido 2-(4-isotiocianatobenzil)-dietilenetriaminepentaacético (p-SCN-BnDTPA), ácido 3,6,9,15-tetraazabiciclo[9.3.1]-pentadeca-1(15),11,13-trieno-4-S-(4isotiocianatobenzil)-3,6,9-triacético (p-SCN-Bn-PCTA) [62,73]. A Figura 3 demonstra a estrutura química desses grupamentos quelantes bifuncionais [73]. Os grupamentos quelantes bifuncionais macrocíclicos como o ácido 1,4,7,10tetraazaciclododecanotetraacético (DOTA) e seus análogos e anidrido acíclico do ácido dietilenotriaminopentaacético (DTPA) e seus derivados são os mais utilizados para conjugação de anticorpos monoclonais com elementos metálicos e lantanídeos [35,40$42,46,60,62,66]$.

Os imunoconjugados de DOTA e seus análogos são mais atrativos, pois formam ligações estáveis com grande variedade de íons metálicos com estabilidade cin ética e termodinâmica alta $[41,42,45-48]$.

Todavia, os imunoconjugados de DOTA e seus análogos apresentam uma cinética de marcação muito lenta e dependente das condições de marcação, tais como: razão quelante:anticorpo, $\mathrm{pH}$, temperatura de reação, tempo de aquecimento, tampão e concentração e presença de contaminantes $\mathrm{Zn}(\mathrm{II})$ e Fe(III) no meio de reação $[60,70-72]$. 


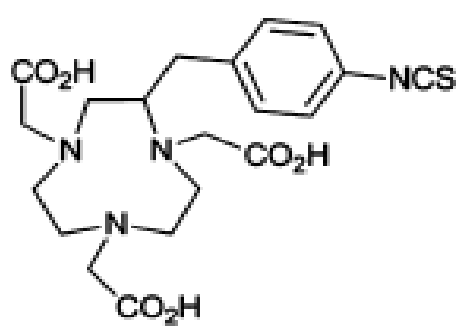

p-SCN-Bn-NOTA

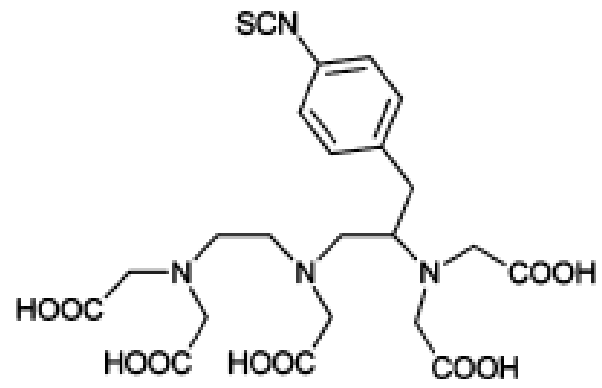

p-SCN-Bn-DTPA<smiles>O=C(O)CN1CCN(CC(=O)O)C(Cc2ccc(N(S)S(=O)(=O)O)cc2)CN(CC(=O)O)N(CC(=O)O)CC1</smiles>

p-SCN-Bn-DOTA<smiles>O=C(O)CN(CCN(CC(=O)O)Cc1cccc(CN(CC(=O)O)CC(=O)O)n1)Cc1ccc(NS(=O)(=O)[O-])cc1</smiles>

p-SCN-Bn-PCTA

Figura 3. Estrutura química dos grupamentos quelantes bifuncionais, $p-S C N-B n-N O T A$, p-SCN-Bn-DOTA, p-SCN-Bn-DTPA, e p-SCN-Bn-PCTA [72]

Ao contrário, os imunoconjugados de DTPA e seus análogos, quando marcados com lutécio-177 e ítrio-90, demonstraram baixa estabilidade "in vivo" provocando toxicidade medular por acúmulo do radionuclídeo na medula $[40,41,44,60,63,70]$. No entanto, a vantagem considerável dos imunoconjugados de DTPA é sua alta eficiência de marcação em condições amenas [60,62].

Já os imunoconjugados de DOTA demonstram-se mais estáveis em consequência do efeito macrocíclico de sua estrutura somado ao braço hepta- ou octapresente na sua forma estrutural $[41,60,62,70]$.

A Figura 4 ilustra a representação química da conjugação do anticorpo com o grupamento quelante até a obtenção do radiofármaco (rituximab-DOTA - ${ }^{177} \mathrm{Lu}$ ). 


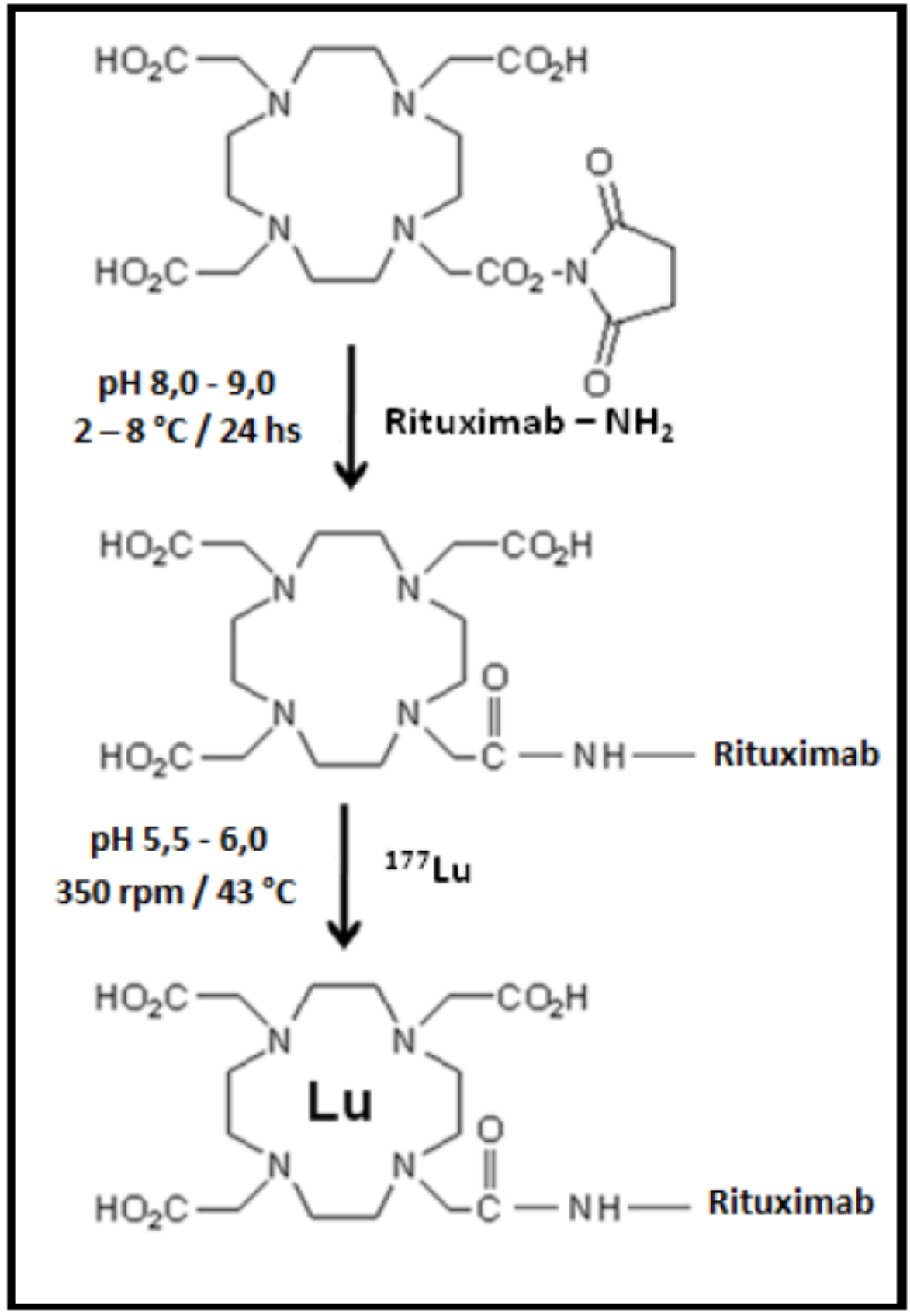

Figura 4. Representação química do anticorpo monoclonal anti-CD20 rituximab conjugado com DOTA radiomarcado com Lutécio-177 [5] 


\section{Materiais e Métodos}

\subsection{Materiais}

\subsubsection{Reagentes}

Os principais reagentes utilizados neste trabalho foram:

$\checkmark$ Rituximab - Anticorpo monoclonal anti-CD20 (Mabthera ${ }^{\circledR}$ ) (Roche, Brasil);

$\checkmark$ Lutécio-[ $\left.{ }^{177} \mathrm{Lu}\right] \mathrm{LuCl} 3 \mathrm{IDB}-$ Holanda, processado no IPEN-CNEN/SP;

$\checkmark$ Ácido p-SCN-Bn-DTPA - Ac. p-isotiocianato-benzildietilenotriaminopentaacético (Macrocyclics, EUA);

$\checkmark$ Ácido p-SCN - Bn-DOTA - Ac. p- benzil-isotiocianato-1,4,7,10tetraazaziclododecano tetraacético (Macrocyclics, EUA);

$\checkmark$ Acetato de amônio (Merck, Alemanha);

$\checkmark$ Acetato de sódio trihidratado 99,5\% (Sigma, EUA);

$\checkmark$ Ácido acético glacial 100\% (Merck, Alemanha);

$\checkmark$ Água purificada - Purificador Milli-RX 45 (Millipore, EUA);

$\checkmark$ Bicarbonato de sódio (Merck, Alemanha);

$\checkmark$ Cloreto de sódio (Merck, Alemanha);

$\checkmark \operatorname{EDTA}($ Merck, Alemanha);

$\checkmark$ Fosfato de sódio dibásico (Merck, Alemanha);

$\checkmark$ Fosfato de sódio monobásico hidratado (Merck, Alemanha);

$\checkmark$ Hepes sódico (Sigma, EUA);

$\checkmark$ Hidróxido de sódio lentilhas (Merck, Alemanha)

$\checkmark$ Matrigel alta concentração (BD-Biosciences, EUA). 
$\checkmark$ Meio de cultura RPMI 1640 (Cultilab, Brasil);

$\checkmark$ Metanol (Merck, Alemanha);

$\checkmark$ Penicilina:estreptomicina (Cultibab, Brasil);

$\checkmark$ Resina Chelex 100 (BioRad, EUA);

$\checkmark$ Sephadex G50 (Pharmacia Biotech, Alemanha / Reino Unido);

$\checkmark$ Soro fetal bovino (Cultilab, Brasil);

$\checkmark$ Tripsina bovina (Cultilab, Brasil).

\subsubsection{Equipamentos e materiais em geral}

Os principais equipamentos e materiais utilizados neste trabalho foram:

$\checkmark$ Agitador de tubos tipo vortex (Vertex, Brasil);

$\checkmark$ Agitador magnético com aquecimento 725A (Fisatom, Brasil);

$\checkmark$ Agitador/aquecedor Thermomixer comfort 1,5 mL (Eppendorf, EUA);

$\checkmark$ Balança analítica M220 (Denver Instrument, EUA);

$\checkmark$ Balança semi-analítica (Lutron, EUA);

$\checkmark$ Calibrador de atividade CRMTM-35R (Capintec, EUA);

$\checkmark$ Centrífuga refrigerada Mikro 220 (Hettich, Alemanha);

$\checkmark$ Contador automático tipo poço com cristal Nal (TI) - D5002 cobra II (PackardCamberra, EUA);

$\checkmark$ Cromatógrafo líquido de alta eficiência composto por sistema modulado constituído por bomba LC-10 ATvp, controlador automático de gradiente FCV- 
10 AL, degaseificador DGU-20A5, injetor automático de amostras SIL-10ADvp, detector UV SPD-10A e forno CTO-10 Avp (Shimadzu, Japão);

$\checkmark$ Detector radioativo (câmara de cintilação - Nal) do sistema CLAE - Shell Jr. 1000/2000 (Shell, EUA);

$\checkmark$ Espectrofotômetro Evolution 160 (Thermo Scientific, EUA);

$\checkmark$ Medidor de pH (Tecnopon, Brasil);

$\checkmark$ Cartucho de pré-coluna SEC-S 3000 - 4 x 3,0 mm (Phenomenex, EUA);

$\checkmark$ Coluna BioSep SEC-S 3000 para cromatografia líquida de alta eficiência - $300 \mathrm{x}$ 7,8 mm, $5 \mathrm{~m}$ (Phenomenex, EUA);

$\checkmark$ Coluna Sephadex G25 - PD-10 (Pharmacia Biotech, Alemanha / Reino Unido);

$\checkmark$ Dispositivo de ultrafiltração (Vivaspin ${ }^{\circledR}$ ) 30.000 MWCO (Pharmacia Biotech, Alemanha / Reino Unido);

$\checkmark$ Dispositivo de ultrafiltração Amicon Ultra - 1530.000 MWCO 15mL (Millipore, Inc, EUA);

$\checkmark$ GraphPad Prism 5.00 ${ }^{\circledR}$ (GraphPad Software, Inc., USA);

$\checkmark$ Material plástico descartável em geral, tais como ponteiras, seringas, tubos cônicos com tampa para reação tipo eppendorf, tubos cônicos tipo Falcon, criotubos e placas de cultura;

$\checkmark$ Papel cromatográfico Whatmann no 1 (Whatmann, Reino Unido);

$\checkmark$ Pipetas automáticas (Brand, Alemanha; Socorex, Suiça e Eppendorf, EUA);

$\checkmark$ Suporte cromatográfico de sílica gel 60 em placa de alumina (TLC-SG) (Merck, Alemanha);

$\checkmark$ Vidraria em geral, tais como béqueres, erlemeyers, balões volumétricos e provetas.

$\checkmark$ Membrana de dialise, 22/35, Pierce, EUA. 


\subsubsection{Animais}

Os estudos in vivo foram realizados em camundongos $B A L B / C$, de doze a vinte quatro semanas de idade e 20 a 40 gramas de peso (Biotério - IPEN). Todos os experimentos foram previamente aprovados pelo Comitê de Ética em Pesquisa do IPEN (Projeto $n^{\circ} 35 / 2009$ ) e realizados de acordo com as normas estabelecidas pela Sociedade Brasileira de Ciência em Animais de Laboratório (SBCAL).

\subsubsection{Células Raji de linfoma de Burkitt humano}

As células RAJl, derivadas de linfoma de Burkitt humano foram cultivadas a 37 ${ }^{\circ} \mathrm{C}$ e $5 \%$ de $\mathrm{CO}_{2}$ em meio de cultura RPMI 1640 enriquecido com 10\% de soro fetal bovino (SFB) e $1 \%$ de antibiótico. Semearam-se, em suspensão, $1 \times 10^{5}$ células. $\mathrm{mL}^{-1}$ e ao

atingirem $1 \times 10^{6}$ células. $\mathrm{mL}^{-1}$ foram diluídas em concentrações variadas, conforme 0 ensaio realizado. 
ETAPAS DE PREPARAÇÃO DO RITUXIMAB-DOTA- ${ }^{177} \mathrm{LU}$

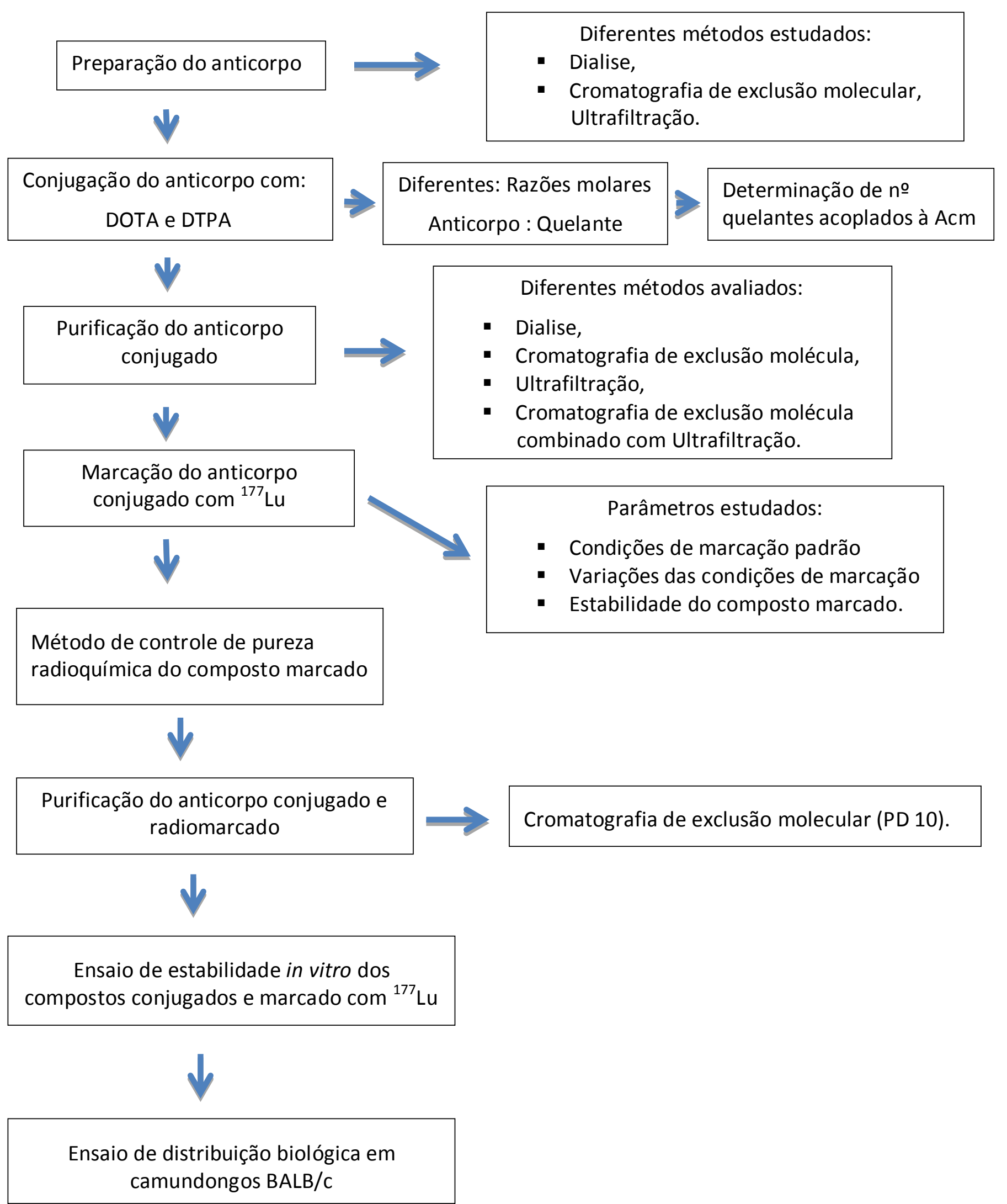




\subsection{Métodos}

\subsubsection{Preparação do anticorpo monoclonal anti-CD20 (Rituximab, MabThera ${ }^{\circledR}$ )}

Avaliaram-se três sistemas diferentes de purificação previa do anticorpo: diálise com membrana 22/35, Pierce, cromatografia de exclusão molecular com colunas preparadas de Sephadex-G50 $(1,5 \times 20 \mathrm{~cm})$ e ultrafiltração utilizando-se tubo concentrador de proteína (Vivaspin MWCO 30.000006 - 20 mL, ou Amicon Ultra - 15 MWCO 30.0000) para remoção de excipientes ou componentes presentes na solução original, que interferem na ligação da proteína com o agente quelante.

a) Diálise: $5 \mathrm{mg}(0,5 \mathrm{~mL})$ do anticorpo em sua solução original foram colocados em tubo de membrana de diálise pré-saturado com tampão de conjugação (tampão fosfato de sódio $0,2 \mathrm{M} \mathrm{pH} \mathrm{8,0);} \mathrm{a} \mathrm{membrana} \mathrm{contendo} \mathrm{o} \mathrm{anticorpo} \mathrm{foi} \mathrm{amarrada}$ à uma pipeta depois colocada num becker contendo $500 \mathrm{~mL}$ de tampão. $\mathrm{O}$ becker foi colocado sobre agitador magnético e o sistema foi colocado sob refrigeração $\left(2-8^{\circ} \mathrm{C}\right)$, o tampão do becker foi substituído 3 vezes em 24 horas. A absorbância da amostra foi determinada por meio de espectrofotometria (UV$280 \mathrm{~nm}$ ) e a concentração foi calculada em $\mathrm{mg} / \mathrm{mL}$.

b) Cromatografia de exclusão molecular com coluna Sephadex-G50 (1,5 x $20 \mathrm{~cm})$ : $5 \mathrm{mg}(0,5 \mathrm{~mL})$ do anticorpo em sua solução original foram transferidos para a coluna de Sephadex G-50 (1,5 x $20 \mathrm{~cm})$, pré-lavada e equilibrada com tampão de conjugação (tampão fosfato de sódio 0,2 M pH 8,0). Recolheram-se 50 frações, sendo que o anticorpo foi eluido na oitava até a vigésima primeira fração; a absorbância das frações reunidas foi determinada por meio de espectrofotometria (UV-280nm) e a concentração foi calculada em mg/mL.

c) Ultrafiltração: $5 \mathrm{mg}(0,5 \mathrm{~mL})$ do anticorpo em sua solução original foram transferidos para os tubos de ultracentrifugação e o volume da amostra elevado a 15 ou $20 \mathrm{~mL}$ com tampão de conjugação (tampão fosfato de sódio $0,2 \mathrm{M} \mathrm{pH}$ 8,0); o tubo foi centrifugado por 27 minutos a 3000 g (5560 rpm) e o procedimento foi repetido três vezes. Em seguida, o volume da solução resultante foi concentrado através de centrifugação por 3 ou 4 vezes sem adição 
de solução tampão, até o volume da amostra atingir a concentração original de $10 \mathrm{mg} / \mathrm{mL}$, a absorbância das frações reunidas foi determinada por meio de espectrofotometria (UV-280nm) e a concentração foi calculada em mg/mL.

\subsubsection{Estudo de conjugação de quelante ao Anticorpo monoclonal}

Para determinar a condição geral da conjugação, foram avaliadas as metodologias de conjugação do anticorpo ao quelante bifuncional DOTA e DTPA descritas por vários autores com algumas adaptações [37,40,41,58,62,65,74].

\subsubsection{Condição geral de conjugação}

Num frasco de reação foram colocados volume equivalente a $5 \mathrm{mg}$ do anticorpo previamente purificado e concentrado. Em seguida, adicionou-se solução de massa correspondente de agente quelante DOTA ou DTPA em diferentes razões molares. $\mathrm{O}$ pH da mistura foi ajustado para 8,0 e a reação ocorreu por uma hora sob agitação à temperatura ambiente, após esse período a solução resultante foi conservada sob refrigeração a $2-8^{\circ} \mathrm{C}$ por diferentes intervalos de tempo. Vale ressaltar que a conjugação do anticorpo deve ocorrer em meio isento de metais [8,2331]. Portanto, as soluções utilizadas nos procedimentos de purificação prévia do anticorpo, de conjugação e marcação foram preparadas a partir de água purificada e tratada em resina Chellex 100, e após estarem prontas foram tratadas novamente em resina para remoção completa de cátions.

\subsubsection{Avaliação de condições de conjugação}

\section{$\checkmark$ Agente quelante utilizado: DOTA e DTPA}

Segundo relatos de vários autores, quelantes bifuncionais acíclicos como DTPA e seus análogos e macrocíclicos como DOTA e seus análogos são atrativos para conjugação com anticorpos, pois formam íons estáveis com uma variedade de radiometais e lantanídeos. Além disso, o anticorpo conjugado com DOTA e radiomarcado com lantanídeo como lutécio-177 demonstra estabilidade in 
vitro e in vivo. Ao contrário de imunoconjugados de DTPA e seus análogos que podem apresentar instabilidade in vivo $[8,23,24,26-30]$.

Dois grupamentos quelantes foram estudados conjugação do anticorpo rituximab:

1) Ácido p-SCN - Bn - DOTA - Macrocyclics, EUA;

2) Ácido p-SCN - Bn - DTPA - Macrocyclics, EUA;

\section{$\checkmark$ Tempo e Temperatura de conjugação}

Foi avaliada a influência do tempo e da temperatura na conjugação do grupamento quelante DOTA e DTPA ao anticorpo. Foram realizadas conjugações por 1 hora, em temperatura ambiente ou $43^{\circ} \mathrm{C}$, seguido de incubação a $2-8^{\circ} \mathrm{C}$ por 24 e 48 horas.

\section{$\checkmark$ Razão molar Anticorpo: DOTA/DTPA}

De acordo com relatos de vários autores na literatura, o procedimento de conjugação de anticorpos com agentes quelantes bifuncionais ocorre sempre com excesso molar de quelante [9,23,24,26-30]. Entretanto, o excesso deve considerar a influência no rendimento de marcação e, principalmente, na imunoreatividade do anticorpo radiomarcado. Deste modo, foram estudadas conjugações com razões molares diferentes de rituximab:DOTA: 1:5, 1:10, 1:20, 1:50, 1:100 e rituximab:DTPA de: 1:20, 1:50.

\subsubsection{Determinação de número de quelantes incorporados à molécula do} anticorpo: 1:5, 1:10 e 1:20

O número de quelantes incorporados à molécula do anticorpo foi avaliado valendo-se de método específico descrito na literatura por Nikula [76] entre outros [35,40,44]. Após o término da reação de conjugação e antes da purificação do mesmo, retirou-se uma alíquota correspondente a $50 \mu \mathrm{g}$ do anticorpo. Adicionou-se $100 \mu \mathrm{L}$ de tampão acetato de sódio 0,4 M pH 5,5. Adicionou-se 11,1 MBq (300 $\mu \mathrm{Ci})$ de ${ }^{177} \mathrm{LuCl}_{3} ; \mathrm{o}$ 
$\mathrm{pH}$ da mistura foi ajustado para 5,5 a 6,0 e a reação ocorreu por 1 hora a $43^{\circ} \mathrm{C}$ sob agitação. Ao decorrer desse tempo, dois diferentes sistemas cromatográficos foram utilizados para quantificar o lutécio-177 livre, quelante não conjugado (DOTA- ${ }^{177} \mathrm{Lu}$ ou DTPA- ${ }^{177} \mathrm{Lu}$ ) e o produto rituximab-DOTA/DTPA- ${ }^{177} \mathrm{Lu}$, no meio de marcação.

Para separar o produto radiomarcado do lutécio-177 livre e do quelante não conjugado radiomarcado, utilizou-se cromatografia em camada delgada de sílica gel 60 (TLC-SG) como suporte e tampão EDTA 10 mM pH 4,5 como fase móvel. Para separar o quelante não conjugado utilizou-se o mesmo suporte e solução de $\mathrm{NaOH} 10 \mathrm{mM}$ em $\mathrm{NaCl}$ 0,9\% como fase móvel. O número de quelantes incorporados à molécula do anticorpo foi determinado utilizando-se a fórmula descrita na equação abaixo (Eq.1), proveniente de ref.

$\%$ da radioatividade na origem da fita de EDTA

(\% da radioatividade na fita EDTAX \% radioatividade na fita $\mathrm{NaOH}$ )

\subsubsection{Estudo de purificação do Anticorpo conjugado}

Foram avaliados quatro sistemas de purificação diferentes: diálise, cromatografia de exclusão molecular com coluna de Sephadex-G50, ultrafiltração utilizando-se de tubos Amicon Ultra-15 (MWCO $30.00015 \mathrm{~mL}$ ) e cromatografia de exclusão molecular com coluna de Sephadex-G25 (PD10 Pharmacia) combinado com ultrafiltração utilizando-se tubos Amicon Ultra-15 (MWCO $30.00015 \mathrm{~mL}$ ), para determinar o mais eficiente na separação do anticorpo conjugado do quelante livre.

No sistema combinando a coluna de Sephadex-G25 (PD10) com ultracentrifugação, o anticorpo conjugado foi aplicado na coluna PD10 e o seu volume foi elevado a 2,5 mL com tampão acetato de sódio $0,4 \mathrm{M} \mathrm{pH} \mathrm{5,5.} \mathrm{A} \mathrm{amostra} \mathrm{foi} \mathrm{eluida}$ com tampão acetato de sódio $0,4 \mathrm{M} \mathrm{pH} \mathrm{5,5}$. Foram coletadas 25 frações de $1 \mathrm{~mL}$ cada, sendo que o anticorpo conjugado foi eluido na terceira a quinta fração, e o conjunto das frações ( $3 \mathrm{~mL}$ ) com maior absorbância foi concentrado utilizando-se tubo Amicon; 
a absorbância da amostra foi determinada por meio de espectrofotometria (UV 280 $\mathrm{nm}$ ) e a concentração calculada em $\mathrm{mg} / \mathrm{mL}$.

As demais técnicas utilizadas neste estudo foram descritas anteriormente no item 4.2.1. Neste estudo foi utilizado o tampão acetato de sódio 0,4 M pH 5,5 para recolher o anticorpo conjugado no meio apropriado para a radiomarcação.

\subsubsection{Estudo de método de marcação do Anticorpo conjugado com lutécio-177}

Foram estudados dois parâmetros de marcação do composto conjugado.

\subsubsection{Condição de marcação padrão}

Para o anticorpo conjugado com DOTA, num tubo de marcação foram adicionados $1 \mathrm{mg}$ do anticorpo anti-CD20 conjugado, purificado e concentrado em 50 $\mu \mathrm{L}$ de tampão acetato de sódio $0,4 \mathrm{M}$ pH 5,5. Em seguida, adicionou-se $10 \mu \mathrm{L}$ de solução de cloreto de lutécio-177 contendo $37 \mathrm{MBq}(1 \mathrm{mCi}) . \mathrm{O} \mathrm{pH}$ da mistura foi ajustado para 5,5 com tampão acetato de amônio 0,4 M pH 5,5. A reação ocorreu por 30 minutos a 1 hora a $43^{\circ} \mathrm{C}$, sob agitação e, decorrido esse período, para algumas marcações, adicionou-se 3,3 $\mu \mathrm{L}$ de solução DTPA em tampão acetato de amônio $0,2 \mathrm{M}$ $\mathrm{pH} 4,5(0,05 \mathrm{~mol} / \mathrm{L})$ e a mistura foi incubada por 15 minutos à temperatura ambiente sem agitação, para quelar o lutécio-177 livre presente na reação [6,7,22,23,25-30].

Para a marcação do anticorpo conjugado com o quelante DTPA, $1 \mathrm{mg}$ do composto conjugado, purificado e concentrado foi colocado num tubo de marcação, adicionou-se $10 \mu \mathrm{L}$ de solução de cloreto de lutécio-177 contendo $37 \mathrm{MBq}(1 \mathrm{mCi})$, o $\mathrm{pH}$ da mistura foi ajustado para 5,5 com tampão acetato de sódio $0,4 \mathrm{M} \mathrm{pH} \mathrm{5,5.} \mathrm{A}$ reação ocorreu por uma hora à temperatura ambiente e sob agitação.

\subsubsection{Variação das condições de marcação}

Buscando otimizar as condições de marcação do composto conjugado, variouse a massa do composto conjugado (1 e $5 \mathrm{mg}$ ) e a atividade de lutécio-177 (37, 185 e $370 \mathrm{MBq})$. 


\subsubsection{Estudo de método de controle de pureza radioquímica do anticorpo conjugado e marcado com lutécio-177}

Foram estudadas diferentes metodologias para determinar a pureza radioquímica (\% do radionuclídeo incorporado à proteína conjugada) da mistura de marcação: cromatografia em papel Whatman 1, cromatografia em camada delgada de sílica gel (TLC-SG), e Cromatografia Líquida de Alta Eficiência (CLAE).

a) Cromatografia em papel e cromatografia em camada delgada

A pureza radioquímica, \% de rituximab-DOTA/DTPA-Lu-177 da mistura de marcação, foi avaliada utilizando-se três sistemas cromatográficos diferentes: (1) cromatografia em papel Whatman No. 1 como fase estacionária e solução de metanol : acetato de amônio 0,4 M (50:50 v/v) como fase móvel; (2) cromatografia em camada delgada de sílica gel (TLC-SG) como fase estacionária e tampão citrato de sódio 0,1 M pH 5,0 como fase móvel; (3) cromatografia em camada delgada de sílica gel (TLC-SG) como fase estacionária e solução de $\mathrm{NaOH} 10 \mathrm{mM}$ em NaCl 0,9\% como solvente. A proteína marcada foi aplicada a 1,50 $\mathrm{cm}$ da base da fita, que em seguida foi colocada na cuba cromatográfica (previamente saturada) contendo o solvente. Após a corrida, as fitas foram removidas do solvente, secadas e cortadas em segmentos de $1 \mathrm{~cm}$. A radioatividade das frações das fitas foi determinada em contador de radiação gama do tipo poço e a pureza radioquímica da marcação calculada (\%). Os Rf (relação da distância de migração da espécie em função da distância de migração do solvente) das diferentes espécies radioquímicas nos sistemas cromatográficos estudados estão descritos na Tabela 8. As fitas foram avaliadas em duplicata. 
Tabela 8. Rf das espécies radioquímicas observadas nos sistemas em fita de cromatográficos utilizados

\begin{tabular}{|c|c|c|}
\hline Sistema Cromatográfico & Componente & $\mathbf{R f}$ \\
\hline Camada delgada TLC-SG & Anti-CD20-DOTA/DTPA ${ }^{177} \mathrm{Lu}$ & 0,0 \\
\hline \multirow[t]{2}{*}{ Citrato de sódio 0,1 M pH 5} & ${ }^{177}$ Lu livre & $0,8-1,0$ \\
\hline & DOTA/DTPA- ${ }^{177} \mathrm{Lu}$ & $0,8-1,0$ \\
\hline Camada delgada TLC-SG & Anti-CD20-DOTA/DTPA- ${ }^{177} \mathrm{Lu}$ & 0,0 \\
\hline \multirow[t]{2}{*}{$\mathrm{NaOH} 10$ mM em NaCl 0,9\% } & ${ }^{177}$ Lu livre & 0,0 \\
\hline & DOTA/DTPA- ${ }^{177} \mathrm{Lu}$ & $0,8-1,0$ \\
\hline Papel Whatman no 1 & Anti-CD20-DOTA/DTPA- ${ }^{177} \mathrm{Lu}$ & 0,0 \\
\hline Metanol : acetato de & ${ }^{177}$ Lu livre & 0,0 \\
\hline amônio 0,4 M 50:50 (v/v) & DOTA/DTPA- ${ }^{177} \mathrm{Lu}$ & $0,8-1,0$ \\
\hline
\end{tabular}

b) Cromatografia Líquida de Alta Eficiência (CLAE)

Foi estudada a pureza radioquímica do produto marcado por meio de Cromatografia Líquida de Alta Eficiência (CLAE) com detetor de radiação e detetor UV $(280 \mathrm{~nm})$ e sistema de exclusão molecular utilizando-se uma coluna de gel (Biosep 3000, $37 \times 7,8 \mathrm{~mm}$, Phenomoex), tampão fosfato de sódio $0,2 \mathrm{M} \mathrm{pH} 7$ como solvente e fluxo de $1 \mathrm{~mL} /$ minuto; detector de UV com comprimento de onda de $280 \mathrm{~nm}$. 


\subsubsection{Estudo do método de purificação do Anticorpo conjugado e marcado com lutécio-177}

Ao se elaborar um radiofármaco para fins terapêuticos é consenso geral que o mesmo deve apresentar pureza radioquímica superior a 95\%. Deste modo, quando necessário for, o anticorpo conjugado e radiomarcado deverá ser purificado para atender a este requisito. Estudou-se a purificação do anticorpo radiomarcado utilizando-se coluna de exclusão molecular de Sephadex gel 25 (PD 10, Pharmacia) para a separação do anticorpo marcado do radionuclídeo livre.

Adicionou-se o composto radiomarcado na coluna e seu volume foi elevado a 2,5 mL com tampão acetato de sódio $0,4 \mathrm{M} \mathrm{pH} \mathrm{5,5,} \mathrm{e} \mathrm{a} \mathrm{amostra} \mathrm{foi} \mathrm{eluida} \mathrm{com} \mathrm{o}$ mesmo tampão. Foram coletados 15 frações de $1 \mathrm{~mL}$ cada, a radioatividade das frações foi determinada no calibrador de dose, e a pureza radioquímica das frações combinados correspondentes ao anticorpo radiomarcado foi determinada por cromatografia em camada delgada (TLC-SG) e o rendimento do mesmo calculado $[23,24,26-31]$.

\subsubsection{Ensaio de ligação específica in vitro dos compostos conjugados e marcados com lutécio-177 às células Raji ("Binding")}

O ensaio de ligação específica objetiva avaliar a ligação do anticorpo conjugado e radiomarcado a receptores de superfície presentes nas células tumorais de linfomas Raji Burkitt. Cinco quantidades diferentes de células $\left(0,125 \times 10^{6} ; 0,25 \times 10^{6} ; 0,5 \times 10^{6}\right.$; $1,0 \times 10^{6}$ e $1,5 \times 10^{6}$ ) foram diluídas em meio de cultura contendo $1 \%$ de soro fetal bovino (SFB) em suspensão num tubo cônico tipo eppendorf. Foram montadas para cada número de células duas triplicatas: uma para ligação total (3 tubos), e a segunda para ligação não especifica (3 tubos). Foi utilizado para esse ensaio o composto marcado e purificado com alta atividade específica e pureza radioquímica superior a $95 \%$. 
Foram preparados $4 \mathrm{~mL}$ de solução do composto marcado contendo aproximadamente 100000 contagens por minuto (cpm) em 0,25 mL de meio de cultura contendo $1 \%$ de soro fetal bovino (SFB).

Foram preparados $3 \mathrm{~mL}$ de anticorpo frio $4 \mu \mathrm{g} / \mathrm{mL}$ em meio de cultura contendo $1 \%$ de soro fetal bovino (SFB). Para cada número de células foram separados três tubos para ligação total (LT) e três para a ligação não específica (LNE), e o volume de $0,25 \mathrm{~mL}$ contendo as quantidades de células foram colocados nos tubos de concentrações correspondentes. Adicionou-se $0,25 \mathrm{~mL}$ de meio de cultura contendo 1 $\%$ de SFB aos tubos da LT. Adicionou-se $0,25 \mathrm{~mL}$ da solução contendo o anticorpo frio aos tubos da LNE (a concentração final ficou $1 \mu \mathrm{M}$ ). Os tubos foram homogeneizados no vortex rapidamente. Adicionou-se $0,25 \mathrm{~mL}$ da solução do composto marcado a todos os tubos.

Os tubos foram homogeneizados no vortex rapidamente. Incubou-se os tubos por uma hora e trinta minutos à temperatura ambiente sob agitação. Decorrido o tempo, os tubos foram centrifugados a $3000 \mathrm{rpm}$ por 5 minutos. Removou-se o sobrenadante. Adicionou-se $1 \mathrm{~mL}$ de meio de cultura contendo $1 \%$ de SFB a todos os tubos. Os tubos foram novamente centrifugados a $3000 \mathrm{rpm}$ por 5 minutos. 0 sobrenadante foi removido e atividade dos pellets foi contada no contador gama.

Para determinar a atividade total adicionada (AT), foram colocados $0,25 \mathrm{~mL}$ da solução contendo o composto marcado em triplicata e contado no contador gama. Foram determinadas para cada concentração de células, a \% de ligação total (\% LT), a \% de ligação não especifica (\% LNE), e a \% da ligação especifica (\% LE), utilizando-se às equações 02, 03 e 04 respectivamente.

EQ. 2

Média das contagens nos tubos LT

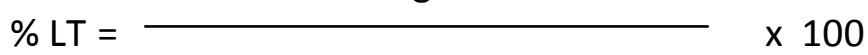

Média das contagens nos tubos A T 


$$
\% \text { LNE }=\frac{\text { Média das contagens nos tubos LNE }}{\text { Média das contagens nos tubos A T }} \times 100
$$

\title{
EQ. 4
}

\author{
$\% L E=\% L T-\% L N E$
}

\subsubsection{Estudo de distribuição biológica em camundongos $B A L B / c$ sadios}

Estudo de distribuição biológica dos Ac conjugados e marcados com lutécio-177 foram realizados em camundongos $B A L B / C$ normais adultos. Injetou-se por via endovenosa caudal 0,148 MBq $(40 \mu \mathrm{Ci})$ do anticorpo radiomarcado e purificado. Após 1, 4, e 24 horas os animais foram sacrificados e seus principais órgãos foram retirados, lavados e pesados. Por fim, a radioatividade dos órgãos foi determinada no contador gamma tipo poço. A captação nos órgãos foi calculada como a porcentagem da atividade injetada por órgão (\% $\mathrm{Al}, \mathrm{EQ} .5$ ) e por grama de órgão (\% $\mathrm{Al} / \mathrm{g}, \mathrm{EQ}$. 6), utilizando-se a média das contagens da triplicata de padrão de atividade administrada. Foram utilizados quatro animais em cada tempo estudado [73].

$$
\% \mathrm{Al}=\frac{\text { cpm órgão }}{\text { cpm padrão }} \times 100
$$




$$
\% \mathrm{Al} / \mathrm{g}=\frac{\mathrm{cpm} \text { órgão }}{\text { peso órgão }(\mathrm{g}) \times \mathrm{cpm} \text { padrão }} \times 100
$$

Para calcular a porcentagem de atividade injetada presente nos músculos, (\% $\mathrm{Al}$ músculo), e nos ossos (\% Al ossos) dos animais, foi retirado parte do músculo da coxa e do fêmur dos camundongos; calculou-se a porcentagem de atividade por grama e assumiu-se o peso dos músculos como $40 \%$ (EQ. 7) e dos ossos como 12\% (EQ.8) do peso total do camundongo [74].

$$
\% \mathrm{Al} \text { (músculo) }=\frac{\mathrm{cpm} \text { músculo } \times 40 \times \text { peso do animal }(\mathrm{g})}{\text { peso músculo }(\mathrm{g}) \times \mathrm{cpm} \text { padrão }}
$$

cpm fêmur X $12 X$ peso do animal (g)

peso osso $(g) \times$ cpm padrão 


\subsection{Resultados e discussões}

\subsection{Preparação do anticorpo monoclonal anti-CD20 (Rituximab-Mabthera ${ }^{\circledR}$ )}

$\mathrm{Na}$ fase inicial deste estudo foram testadas várias condições de conjugação do quelante DOTA ao anticorpo utilizando-se o anticorpo em sua solução original sem purificação prévia. Verificou-se que não ocorria a quelação do anticorpo com o agente quelante, pois o anticorpo não marcava. Verificou-se a necessidade de purificação prévia e a troca de tampão original do anticorpo (neutro 7,0) para o meio favorável para conjugação (alcalino). Segundo relatos de alguns autores como Jalilian e colaboradores (2012) [57] entre outros, o tratamento ou a purificação prévia do anticorpo, além de necessária é importante, pois esse procedimento proporciona a retirada de impurezas e contaminantes presentes na solução, que interferem no procedimento de conjugação, prejudicando assim a formação de ligação covalente forte e estável entre agente quelante e anticorpo $[37,44,49,57]$.

Além disso, a purificação prévia do anticorpo oferece facilidade para a transferência do anticorpo do meio original, apropriado para finalidade imunoterápica, para o meio apropriado aonde irá se conjugar ao agente quelante bifuncional DOTA ou DTPA e depois, radiomarcado com o lantanídeo lutécio-177, transformando-se assim em um produto com finalidade para radioimunoterapia. Foram testados vários tampões tais como: bicarbonato de sódio 0,2 M pH 8,5 - 9,0; Hepes 0,2 M pH 9,0; fosfato de sódio $0,2 \mathrm{M} \mathrm{pH} \mathrm{8,0.} \mathrm{Entretanto,} \mathrm{não} \mathrm{observamos} \mathrm{diferenças} \mathrm{significativas} \mathrm{no}$ rendimento final de marcação.

Quando amostra de $5 \mathrm{mg}$ do anticorpo anti-CD20 foi purificada por meio de diálise, recuperou-se 4,4 $\pm 0,3 \mathrm{mg}(87,4 \% \mathrm{n}=5)$ em volume aproximadamente de 3,0 mL, com perda de amostra proteica de 12,8\%. Embora a diálise seja uma metodologia eficiente na purificação de anticorpos ou moléculas proteicas em geral, entretanto, apresenta duas desvantagens considerando o tempo empregado de 24 horas ou mais, e grande volume de tampão utilizado nas várias trocas necessárias neste procedimento $[49,75,76]$. Além disso, o uso de grande volume de tampão pode aumentar o risco de introdução de contaminantes metálicos no meio, interferindo no 
procedimento de conjugação [75]. Finalmente, o volume final $(3 \mathrm{~mL})$ recuperado torna inviável o uso da amostra nos experimentos subseqüentes.

Quando o anticorpo foi purificado por cromatografia de exclusão molecular com coluna Sephadex-G50 (1,5 x $20 \mathrm{~cm})$, e a mesma massa de amostra de $5 \mathrm{mg}$ foi aplicada, foram recuperados $4,4 \pm 0,4 \mathrm{mg}(88,2 \% \mathrm{n}=5)$ em volume de $10 \mathrm{~mL}$; com perda de 11,8 \%. Essa metodologia apresenta uma vantagem em relação ao método anterior considerando o tempo empregado, tempo máximo de 40 minutos. Porém, apresenta desvantagem considerando o volume final recuperado de $10 \mathrm{~mL}$ que impossibilita o uso do mesmo nos experimentos subsequentes.

Na purificação do anticorpo por meio de ultrafiltração utilizando-se o tubo concentrador de proteína (Vivaspin $30.000 \mathrm{MWCO}$ ), que foi substituído pelo tubo Amicon Ultra-15 (MWCO $30.00015 \mathrm{~mL}$ ), foram recuperados 4,9 $\pm 0,1 \mathrm{mg}(97,2 \% \mathrm{n}=5)$. Comparados aos métodos anteriores utilizados na purificação do anticorpo, esse método apresentou várias vantagens: proporcionou a recuperação superior de massa da amostra, pode ser realizado em tempo inferior (2 - $3 \mathrm{hs}$ ) ao tempo empregado em diálise (24 hs) e finalmente, possibilitou a recuperação da amostra em volume de microlitros facilitando assim o seu uso nos experimentos seguintes. A Tabela 9 demonstra os valores de massa do anticorpo recuperados nas três metodologias de purificação empregadas. 
Tabela 9. Purificação prévia do anticorpo Anti-CD20: recuperação de amostra (grama) nas três metodologias avaliadas para purificação de 5,0 mg do anticorpo $(n=5)$

\begin{tabular}{ccc}
\hline Diálise & Sephadex G-50 & Ultrafiltração \\
4,2 & 4,4 & 4,9 \\
4,7 & 4,2 & 4,9 \\
4,6 & 3,8 & 4,9 \\
3,9 & 4,8 & 4,8 \\
4,3 & 4,7 & 4,7 \\
$4,4 \pm 0,3 \mathbf{g}$ & $4,4 \pm 0,4 \mathrm{~g}$ & $\mathbf{4 , 9 \pm 0 , 1} \mathbf{g}$ \\
\hline
\end{tabular}

\subsection{Estudo de conjugação de quelante ao Anticorpo monoclonal}

\subsubsection{Avaliação de condições de conjugação}

Foram testadas conjugações de anticorpo com o quelante DOTA com tempo de reação de 24 e 48 horas, sendo que durante a primeira hora utilizou-se temperatura ambiente sob agitação, e nas demais horas a mistura de reação foi conservada sob refrigeração $\left(2-8^{\circ} \mathrm{C}\right)$. Foi testada também a conjugação onde a mistura de reação foi aquecida a $43^{\circ} \mathrm{C}$ por uma hora e depois conservada sob refrigeração $\left(2-8^{\circ} \mathrm{C}\right)$. Essas avaliações foram realizadas com conjugações de razão molar anticorpo : quelante na proporção de 1:5; 1:10 e 1:20. Todas as condições de conjugação avaliadas apresentaram pureza radioquímica inferior ao esperado ( $\geq 95 \%$ ) conforme demonstrado na Tabela 10, para marcações utilizando $1 \mathrm{mg}$ do anticorpo conjugado. 
Tabela 10. Pureza radioquímica (\%) do anticorpo conjugado com DOTA purificado e concentrado (1 mg) marcado com $37 \mathrm{MBq}(1 \mathrm{mCi})$ lutécio-177 ( $\mathrm{n=3})$

\begin{tabular}{|c|c|c|c|c|}
\hline \multicolumn{5}{|c|}{ Pureza radioquímica (\%) } \\
\hline \multicolumn{5}{|c|}{ Condições de conjugação } \\
\hline \multirow{2}{*}{$\begin{array}{c}\text { Razão Molar } \\
\text { Ac:DOTA }\end{array}$} & \multicolumn{2}{|c|}{24 horas de reação } & \multicolumn{2}{|c|}{48 horas de reação } \\
\hline & 1a hora T.A. & $1^{\text {a h hora }} 43^{\circ} \mathrm{C}$ & 1a hora T.A. & 1 a hora $43^{\circ} \mathrm{C}$ \\
\hline $1: 5$ & $37,2 \pm 1,7$ & $12,7 \pm 0,2$ & $75,9 \pm 4,5$ & $8,7 \pm 0,7$ \\
\hline $1: 10$ & $22,7 \pm 5,6$ & $42,6 \pm 0,2$ & $13,7 \pm 0,8$ & $0,3 \pm 0,1$ \\
\hline $1: 20$ & $47,7 \pm 7,1$ & $18,3 \pm 0,1$ & $60,1 \pm 0,1$ & $19,9 \pm 0,1$ \\
\hline
\end{tabular}

T.A. $=$ temperatura ambiente

Vale ressaltar que os valores apresentados na Tabela acima (TAB. 10) são de controle de pureza radioquímica realizado imediatamente após o término do processo de radiomarcação do anticorpo conjugado com o quelante DOTA. Os resultados variaram bastante não apresentando um padrão de correlação com o tempo de incubação ou com a razão molar utilizada. De modo geral, o aquecimento a $43^{\circ} \mathrm{C}$ por uma hora parece não haver otimizado a conjugação, conforme demonstram os resultados de marcação. Desta forma, a condição padrão de conjugação foi mantida em reação à temperatura ambiente por 1 hora, seguida de reação por 24 horas à temperatura de $2-8{ }^{\circ} \mathrm{C}$, conforme descrito na maioria das referências bibliográficas consultadas $(36,37,42-44)$.

Quando a massa do anticorpo conjugado com o quelante DOTA e DTPA foi variada e o conjugado radiomarcado com a mesma atividade de $37 \mathrm{MBq}(1 \mathrm{mCi})$ de lutécio-177, observou-se compostos com PR superior a 90\% na maioria das marcações empregando $1 \mathrm{mg}$ e $500 \mu \mathrm{g}$ do anticorpo conjugado com DOTA e DTPA; massas inferiores resultaram em PR inferior a 90\% (TAB. 11).

Desta forma, ficou demonstrada a correlação entre a pureza radioquímica das marcações e a massa de anticorpo utilizada. Para 37 MBq de lutécio-177, a recomendação é de utilizar-se, no mínimo, $500 \mu \mathrm{g}$ do anticorpo, uma vez que massas menores ( $250 \mu \mathrm{g}$ e $125 \mu \mathrm{g}$ ) resultaram em diminuição da pureza radioquímica das marcações. Desta forma, os melhores resultados foram obtidos para atividades específicas entre $37 \mathrm{MBq} / \mathrm{mg}$ e $74 \mathrm{MBq} / \mathrm{mg}$. 
Tabela 11. Pureza radioquímica (\%) do anticorpo conjugado com DOTA e DTPA em diferentes razões molares, purificado e concentrado: estudo de variação da massa para atividade de marcação de $37 \mathrm{MBq}(1 \mathrm{mCi})$ de ${ }^{177} \mathrm{Lu}(\mathrm{n}=5)$

\begin{tabular}{|c|c|c|c|c|}
\hline \multicolumn{5}{|c|}{ Pureza radioquímica (\%) } \\
\hline & \multicolumn{2}{|c|}{ DOTA } & \multicolumn{2}{|r|}{ DTPA } \\
\hline \multicolumn{3}{|c|}{ Massa Ac conjugado } & o Molar & \\
\hline & 1:50 & $1: 20$ & 1:50 & $1: 20$ \\
\hline $1 \mathrm{mg}$ & $97,6 \pm 3,3$ & $93,3 \pm 1,7$ & $84,6 \pm 1,2$ & $93,6 \pm 0,6$ \\
\hline $500 \mu g$ & $97,4 \pm 3,6$ & $90,7 \pm 0,7$ & $94,7 \pm 4,6$ & $92,3 \pm 3,5$ \\
\hline $250 \mu \mathrm{g}$ & $84,4 \pm 3,2$ & $84,7 \pm 0,3$ & $90,5 \pm 0,1$ & $66,7 \pm 2,0$ \\
\hline $125 \mu \mathrm{g}$ & $73,0 \pm 3,4$ & $79,0 \pm 0,6$ & $85,0 \pm 0,1$ & $10,8 \pm 0,1$ \\
\hline
\end{tabular}

5.2.2 Determinação de número de quelantes incorporados à molécula do anticorpo

Neste estudo, avaliou-se o número de quelantes acoplados à molécula do anticorpo nas razões molares 1:5; $1: 10$ e 1:20. Nesse mesmo estudo também se avaliou a influência do tempo da conjugação no número de quelantes acoplados ao anticorpo. O número de quelantes acoplados à molécula do anticorpo foi proporcional à razão molar anticorpo:quelante empregada (TAB 12).

Quando a influência do tempo de conjugação no número de quelantes acoplados ao anticorpo foi avaliada, não se observou diferença significativa no número de quelantes acoplados à molécula do anticorpo nos tempos estudados. Esperava-se encontrar um aumento no número de quelantes incorporado para o tempo de 24 horas de reação. Entretanto, é importante considerar que o método cromatográfico utilizado para a determinação do número de quelantes não é preciso, quando comparado à metodologia de espectrometria de massa, mas mostrou-se útil para uma 
análise comparativa, na medida em que demonstrou a proporcionalidade entre o número de quelantes incorporados e a razão molar empregada. (TAB 12).

Tabela 12. Número de quelantes acoplados à molécula do anticorpo nos tempos de $1 \mathrm{hr}$ e 24 hs de conjugação com quelante DOTA ( $n=5)$

Número de quelantes incorporados à molécula do Ac

Razão Molar

Tempo (hs) 1:5

1

$2,3-4,1$

$3,7-7,4$

$3,0-15,8$

24

$2,2-3,2$

$3,1-9,7$

$6,3-18,6$

Considerando o fato da cinética de reação inicial lenta do DOTA $[60,70,71]$, foram avaliados o número de quelantes acoplados à molécula do anticorpo em duas condições de conjugação diferentes. Uma condição padrão onde a primeira hora de reação ocorreu em temperatura ambiente, e a segunda onde a primeira hora de reação ocorreu sob aquecimento $\left(43^{\circ} \mathrm{C}\right)$, ambas seguidas de incubação por 24 horas sob-refrigeração $\left(2-8^{\circ} \mathrm{C}\right)$. A Tabela 13 demonstra o número de quelantes acoplados à molécula do anticorpo quando as duas condições diferentes de conjugação foram avaliadas. 
Tabela 13. Número de quelantes acoplados à molécula do anticorpo em duas condições diferentes de conjugação: temperatura ambiente (T.A.) e $43^{\circ} \mathrm{C}$ na $1^{\text {a }}$ hora DOTA $(n=5)$

\section{Número de quelantes por anticorpo}

\section{Condições de conjugação}

$1 \mathrm{~h}$ a T.A +24 hs a $2-8^{\circ} \mathrm{C}$

$1 \mathrm{~h}$ a $43^{\circ} \mathrm{C}+24 \mathrm{hs}$ a $2-8^{\circ} \mathrm{C}$

Razão Molar

1 hora

24 horas

1 hora

24 horas

1:5

$2,33-4,10$

$2,25-3,19$

$1,15-2,84$

$2,85-4,95$

1:10

$3,68-7,38$

$3,14-9,71$

$4,85-5,66$

$7,35-9,97$

$1: 20$

$3,00-15,78$

$6,35-18,59$

$8,75-10,00$

$9,87-15,14$

Os valores apresentados neste estudo são estimativos, pois a metodologia empregada pode subestimar o número real de quelantes acoplados à molécula do anticorpo, conforme descrito na literatura [77]. Entretanto, possibilitou concluir que a incubação a $43{ }^{\circ} \mathrm{C}$ por uma hora parece não contribuir para o aumento do número de quelantes acoplados à molécula do anticorpo, considerando-se o intervalo das faixas observadas.

Várias metodologias consideradas eficientes para determinar o número de grupamentos quelantes acoplados à molécula do anticorpo foram propostas e relatadas na literatura, sendo as mais utilizadas e espectrometria de massa (MALDIMS) $[36,37,78]$. Entretanto, o uso de algumas destas metodologias representa a aquisição de equipamentos com custo elevado e incompatíveis com a rotina clínica. A metodologia para determinar o número de grupamentos quelantes acoplados à molécula do anticorpo utilizando-se espectrometria de massa (MALDI-MS) pode 
estimar em demasia o número real de quelantes disponíveis para marcação ou ligação com o radiometal [79].

\subsubsection{Estudo de purificação do anticorpo conjugado}

Neste estudo, a metodologia de diálise demonstrou ser eficiente na separação do anticorpo conjugado do quelante livre, porém, o volume da amostra coletada no final do procedimento foi muito alto $(3,0 \mathrm{~mL})$, dificultando o uso da amostra nos experimentos subsequentes, tendo em vista que o equipamento utilizado para aquecimento no procedimento de marcação (Termomixer) limitava o volume final de marcação em 1,5 mL. Além disso, o tempo longo do procedimento (24 horas) e o volume grande de tampão empregado também representam desvantagens dessa metodologia $[49,75,76]$. Finalmente, o uso de grande volume de tampão pode aumentar o risco de introdução de contaminantes metálicos no meio, e consequentemente interferir no procedimento ou eficiência de marcação [75].

A purificação do anticorpo conjugado por cromatografia de exclusão molecular com coluna Sephadex-G50 (1,5 x $20 \mathrm{~cm})$, demonstrou ser eficiente na separação do anticorpo conjugado do quelante livre, porém, deficitária em termos de volume da amostra recuperada $(10 \mathrm{~mL})$, isto é, o conjunto de tubos correspondentes contendo a amostra de anticorpo; esse volume final alto impossibilita o uso do mesmo nos experimentos subsequentes.

Pensando em praticidade e otimização de procedimentos para uma rotina de produção do radiofármaco correspondente, a purificação do anticorpo conjugado por meio de cromatografia de exclusão molecular com coluna Sephadex-G50 (1,5 x $20 \mathrm{~cm})$ pode não ser adequada, pois, gasta-se muito tempo entre o preparo do gel e a montagem final da coluna para uso. Além disto, a coluna precisa ser montada um dia antes de seu uso e conservada sob refrigeração $\left(2-8^{\circ} \mathrm{C}\right)$, sendo ainda sujeita a apresentar falhas ou rachaduras, podendo facilmente contaminar-se com microorganismos que poderiam representar fonte de contaminação microbiológica ou pirogênica do radiofármaco, não sendo, portanto, recomendada a reutilização em produções subsequentes. 
A purificação do anticorpo conjugado por meio de ultrafiltração utilizando-se o tubo concentrador de proteína demonstrou-se eficiente e proporcionou coletar a amostra em volume final de microlitros, ideal para a radiomarcação da amostra.

A metodologia de purificação do anticorpo conjugado por ultrafiltração utilizando-se o tubo concentrador de proteína mostrou-se simples, prática e eficiente, com ressalva de possível dano estrutural à molécula proteica. Vale comentar que, segundo Bartlett e colaboradores (2008), a metodologia onde ciclos repetitivos de ultrafiltração é utilizada para remoção de fluido contendo impurezas indesejadas, e a substituição do mesmo por fluido livre de impurezas é denominada de dialfiltração. Segundo o mesmo autor, mudanças rápidas de concentração proteica, resultado de ciclos sucessivos de centrifugação e trocas de tampão, pode apresentar impacto negativo à estabilidade do anticorpo [75]. Porém, neste trabalho não observamos nenhum dano à estrutura proteica, apesar do anticorpo ter passado por vários ciclos de centrifugação e trocas de tampão (resultados não apresentados).

No último procedimento de purificação, o anticorpo conjugado foi purificado primeiramente por cromatografia de exclusão molecular utilizando-se de coluna Sephadex-G25 (PD 10), e depois a mistura das frações contendo o anticorpo conjugado foi purificada por ultrafiltração utilizando-se o tubo concentrador de proteína. Deste modo, retirando qualquer resquício de quelante não conjugado presente na amostra, e ao mesmo tempo concentrando a amostra. Essa combinação demonstrou-se mais eficiente e rápida, pois, embora o anticorpo conjugado fosse recuperado de coluna PD10 em um volume de três mililitros, esse volume foi reduzido à microlitros pelo tubo concentrador de proteína em apenas cinco ciclos de centrifugações (entre lavagem e concentração), facilitando assim o uso da amostra em experimentos subseqüentes.

Além disso, possibilitou evitar a exposição do anticorpo ao processo estressante de onze a quatorze ciclos de centrifugações, como ocorre no caso de purificação e concentração da amostra utilizando-se somente de tubo concentrador de proteína. Ademais, a exposição do anticorpo ao longo processo de centrifugações sucessivas pode ser prejudicial à integridade da proteína. 
A Figura 5 demonstra a integridade estrutural do anticorpo conjugado com DOTA e DTPA por meio de ensaio de SDS-PAGE, purificados por método combinado. Nesta figura, as duas cadeias do anticorpo são distintas, demonstrando a ausência de quebra de estrutura proteica.

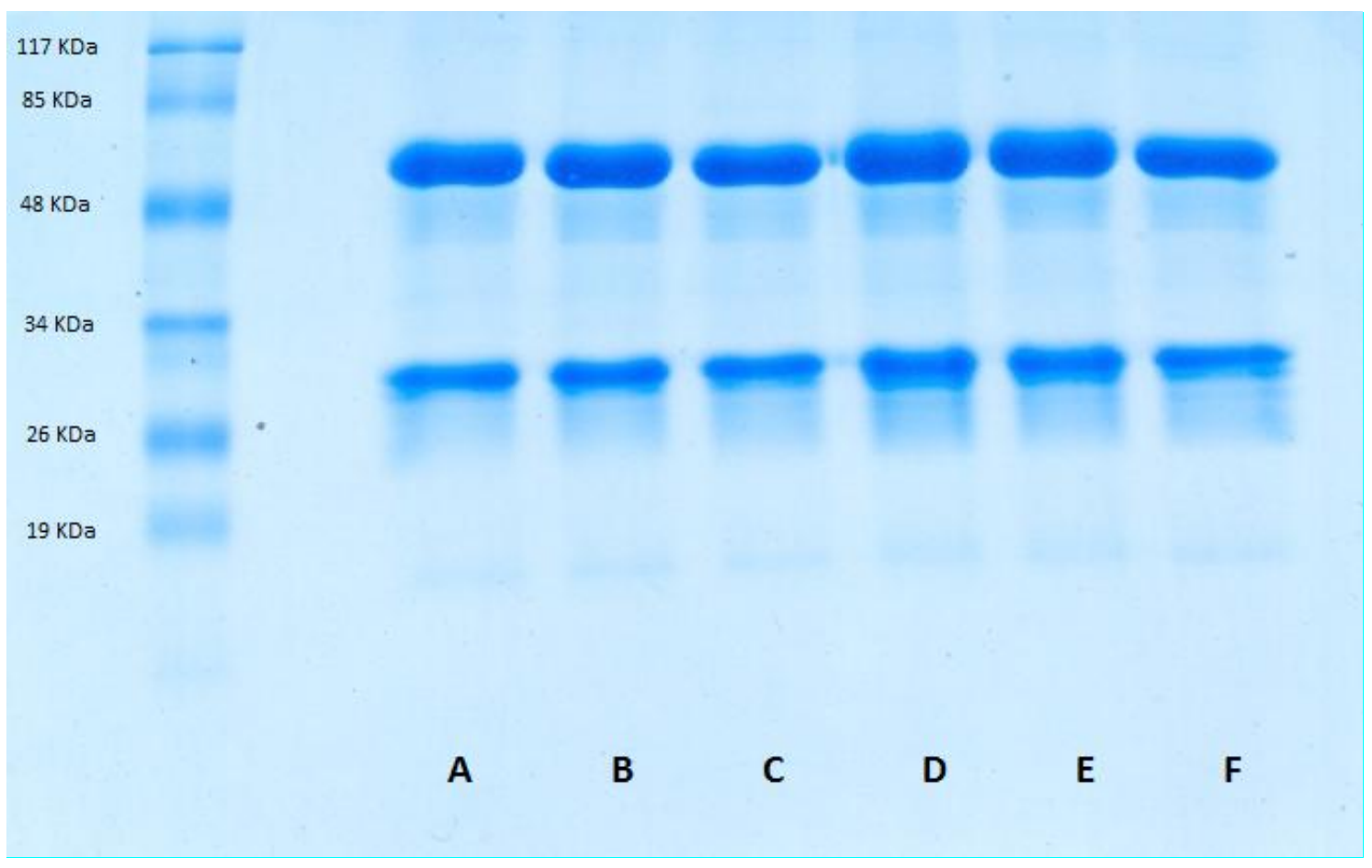

Figura 5. Perfil de SDS-PAGE do anticorpo conjugado com DOTA e DTPA em diferentes razões molares: (A) DOTA 1:50; (B) DOTA 1:20; (C) DOTA 1:10; (D) DTPA 1:50; (E) DTPA 1:20; (F) DTPA 1:10

A Figura 6 demonstra perfil de CLAE do anticorpo conjugado com DOTA na razão molar de 1:50, purificado na coluna PD 10 e concentrado por ultracentrifugação (04 ciclos de centrifugação). O conjunto das frações 3, 4 e 5 da purificação em PD10, que contém o anticorpo conjugado demonstra um único pico do anticorpo. A Figura 7, que demonstra o perfil da fração 6 do PD10 mostra o aparecimento de dois picos, um maior do anticorpo e o menor, provavelmente correspondente ao agente quelante. 


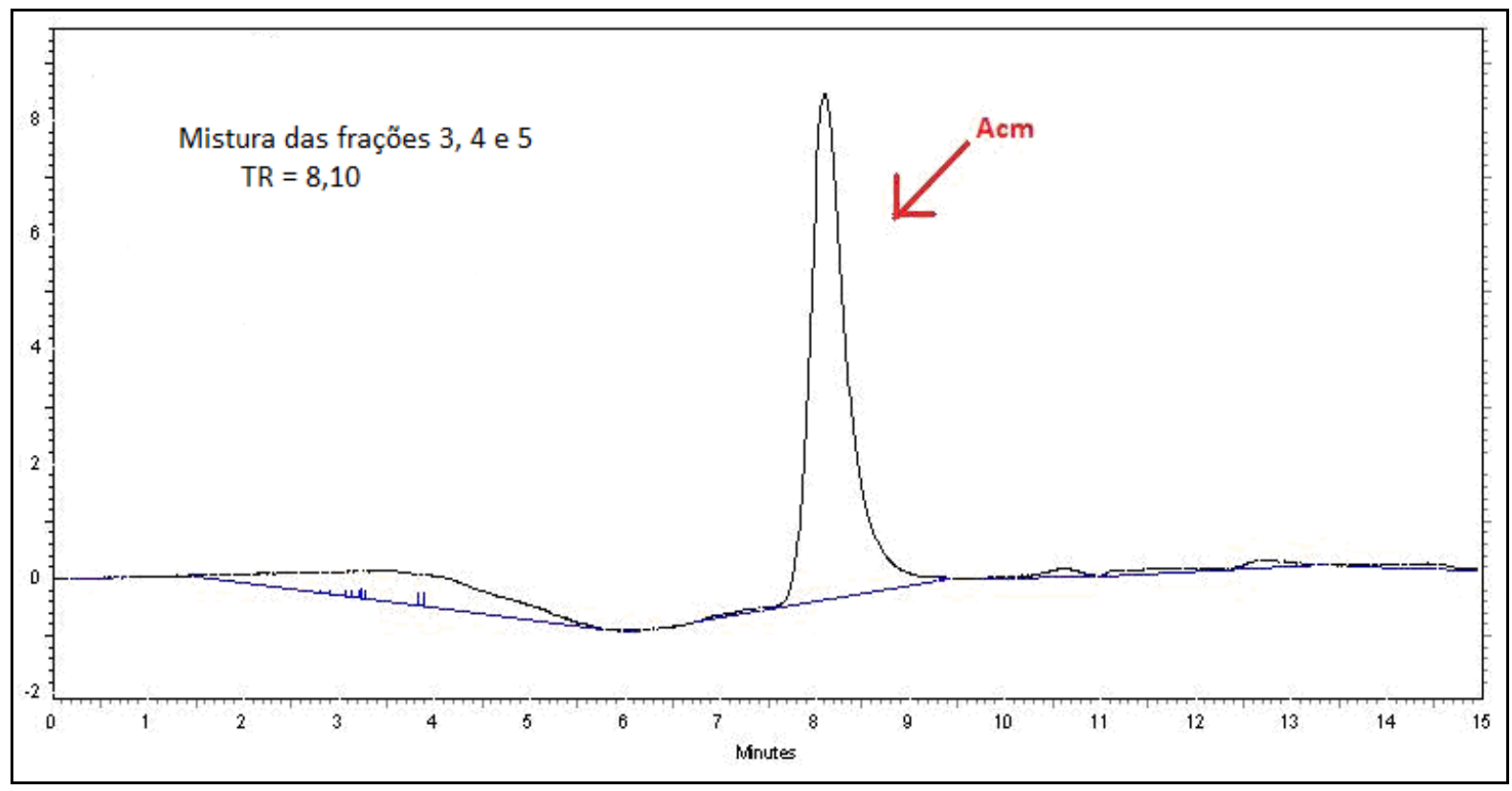

Figura 6. Perfil de CLAE (UV - $280 \mathrm{~nm}$ ) do anticorpo conjugado com DOTA na razão molar de 1:50 purificado na coluna PD 10 e concentrado com tubo Amicon Ultra-15 (30.000 MWCO), junção das frações 3-5 da purificação, contendo o anticorpo conjugado

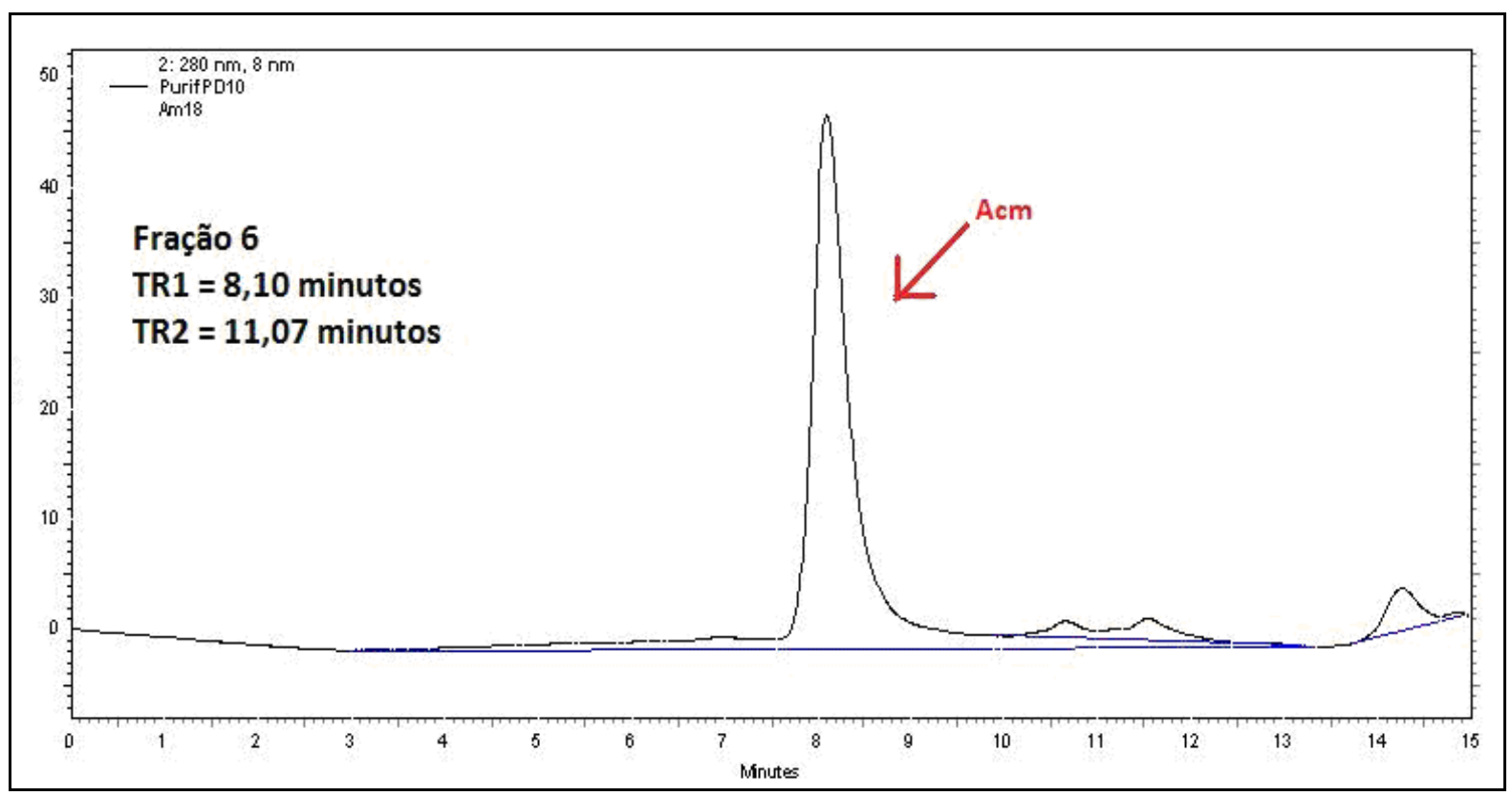

Figura 7. Perfil de CLAE (UV - $280 \mathrm{~nm}$ ) do anticorpo conjugado com DOTA na razão molar de 1:50 purificado na coluna PD 10 e concentrado com tubo Amicon Ultra-15 (30.000 MWCO), fração 6 da purificação

A Figura 8 demonstra o perfil da fração 7 do PD10 e apresenta o pico correspondente ao anticorpo ( $\mathrm{RT}=8,10$ minutos) e picos com $\mathrm{RT}$ maiores, um dos 
quais deve corresponder ao quelante. Como este tubo já apresenta contaminação do quelante em concentração significativa, não deverá ser considerado para a mistura de marcação.

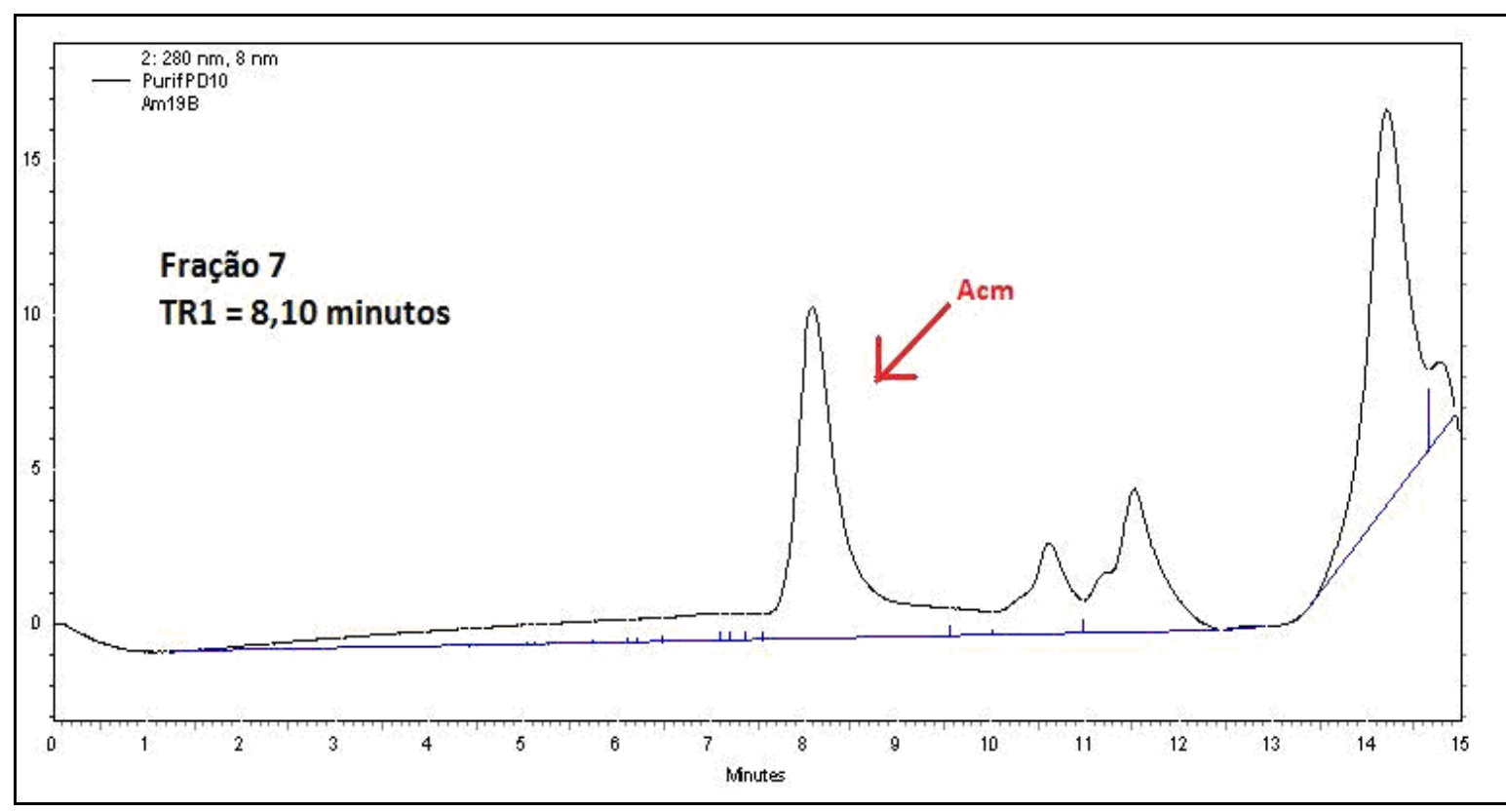

Figura 8. Perfil CLAE (UV - $280 \mathrm{~nm}$ ) do anticorpo conjugado com DOTA na razão molar de 1:50 purificado na coluna PD 10 e concentrado com tubo Amicon Ultra-15 (30.000 MWCO), fração 7 da purificação

A Figura 9 representa o perfil de CLAE do ultrafiltrado da concentração das frações 3-5 do anticorpo conjugado, mostrando um único pico, conforme demonstrado na cromatograma.

Desta forma, vale ressaltar que o método combinado, entretanto, implica em uma perda maior de massa do Acm uma vez que no processo de purificação na coluna PD10 apenas as frações de 3 a $5 \mathrm{~mL}$ são aproveitados para a etapa seguinte de purificação por ultracentrifugação, de modo a não manter grande concentração de quelante. 


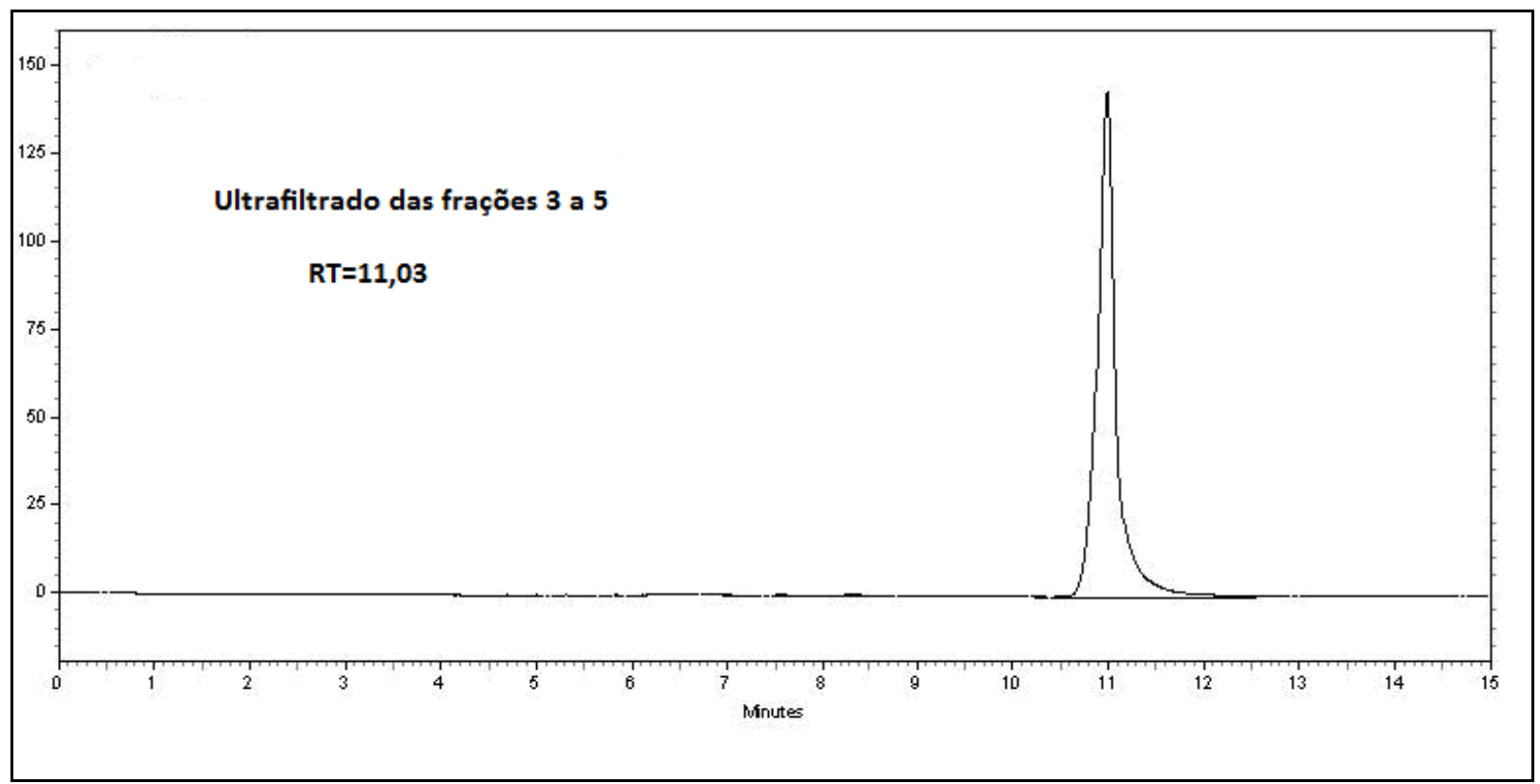

Figura 9. Perfil CLAE (UV - $280 \mathrm{~nm}$ ) do ultrafiltrado do anticorpo conjugado com DOTA na razão molar de 1:50 purificado na coluna PD 10 e concentrado com tubo Amicon Ultra-15 (30.000 MWCO $15 \mathrm{~mL}$ ), primeiro ultrafiltrado da concentração da junção das frações 3-5 do anticorpo conjugado

As Figuras 10 e 11 demonstram o perfil de CLAE do quelante DOTA e do anticorpo monoclonal anti-CD20 rituximab, respectivamente. Fica claro, ao analisar-se a Figura 10, que o pico com RT de 11,02 minutos que aparece nos cromatogramas das frações de purificação do anticorpo, corresponde ao quelante DOTA.

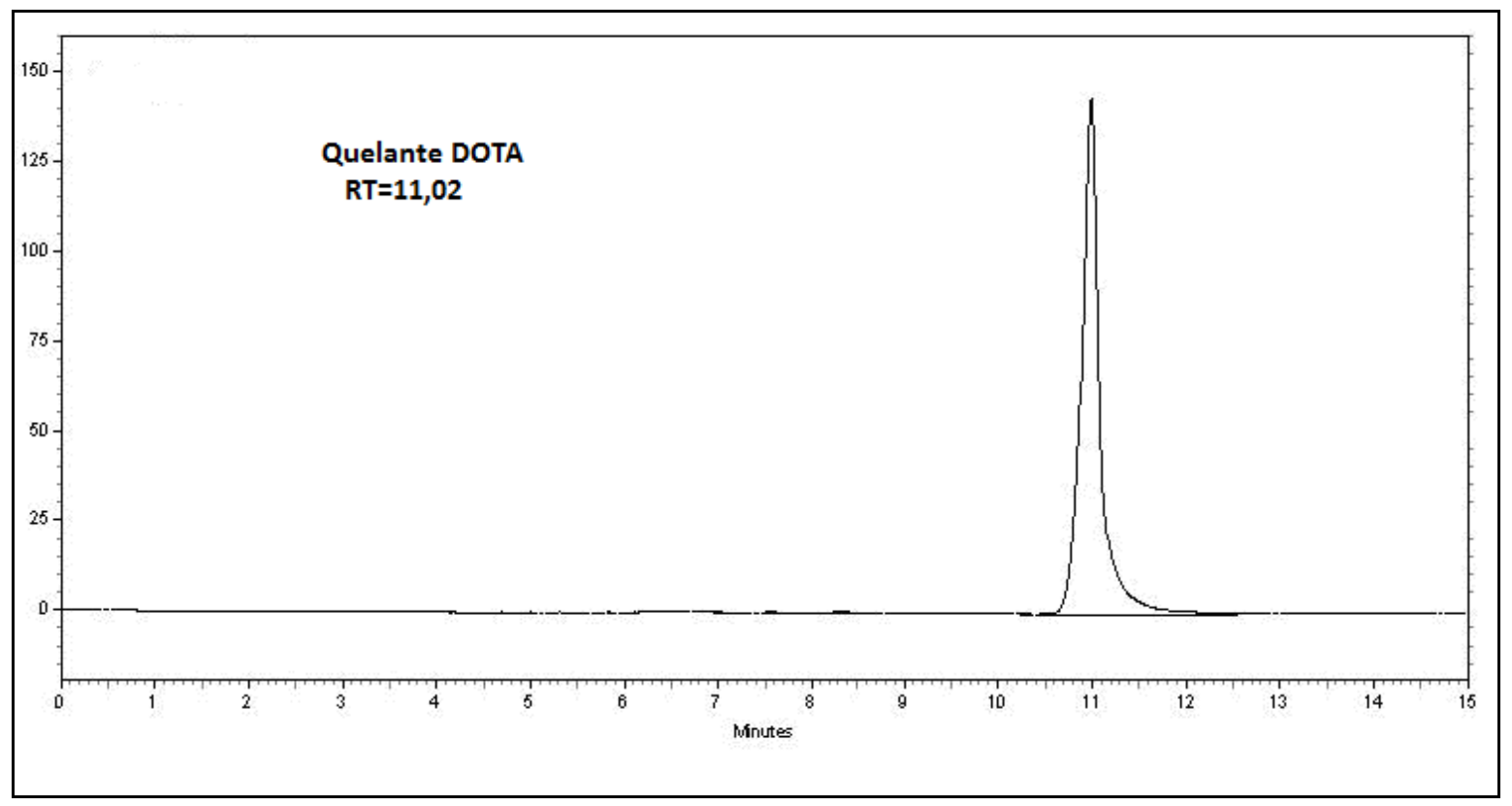

Figura 10. Perfil CLAE (UV - $280 \mathrm{~nm}$ ) do grupamento quelante p-SCN-Bn-DOTA 


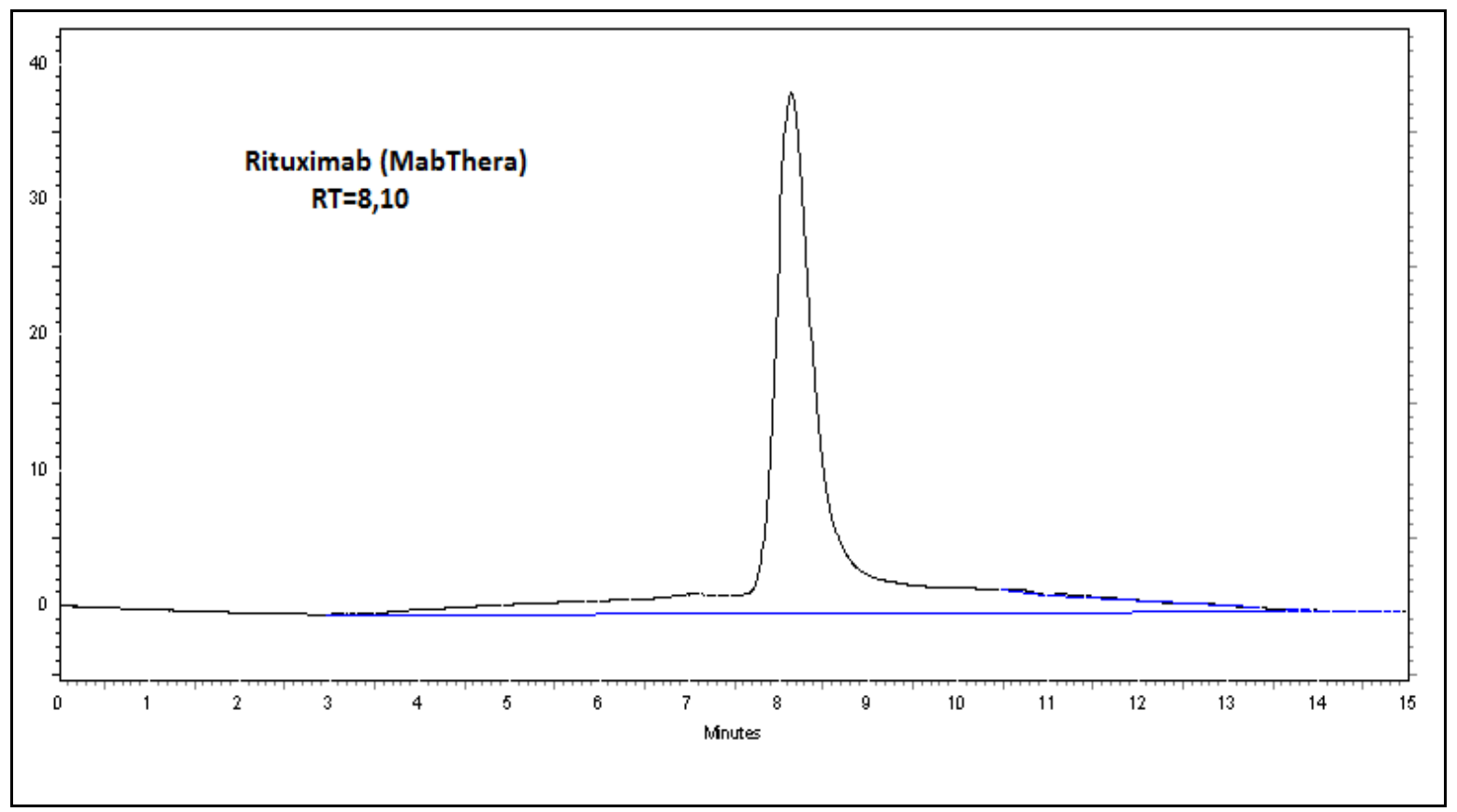

Figura 11. Perfil CLAE (UV - $280 \mathrm{~nm}$ ) do anticorpo monoclonal anti-CD20 rituximab, MabThera

A Figura 11 mostra que o RT do anticorpo monoclonal Rituximab obtido no perfil de CLAE foi o mesmo obtido para o anticorpo conjugado, indicando que a coluna de exclusão molecular empregada não apresenta resolução para separar, com RTs diferentes, as espécies com peso molecular distintos. Entretanto, o método cromatográfico de CLAE foi importante para constatar a integridade do anticorpo, tendo em vista que não foram observadas frações com peso molecular superior, sugestivas de agregação da estrutura do anticorpo.

As figuras 12 a 14 correspondem ao perfil de CLAE do processo de purificação do anticorpo quelado com DTPA na razão molar 1:20, nas diversas fases de purificação, conforme descritas a seguir, utilizando-se método combinado de coluna PD10 e ultracentrifugação (4 ciclos de purificação).

Na figura 12 apresenta-se o perfil de CLAE do anticorpo quelado com DTPA na razão 1:20, antes do processo de purificação, mostrando dois picos: o de RT menor correspondente ao anticorpo conjugado e o de RT maior, provavelmente correspondente ao quelante de DTPA. 


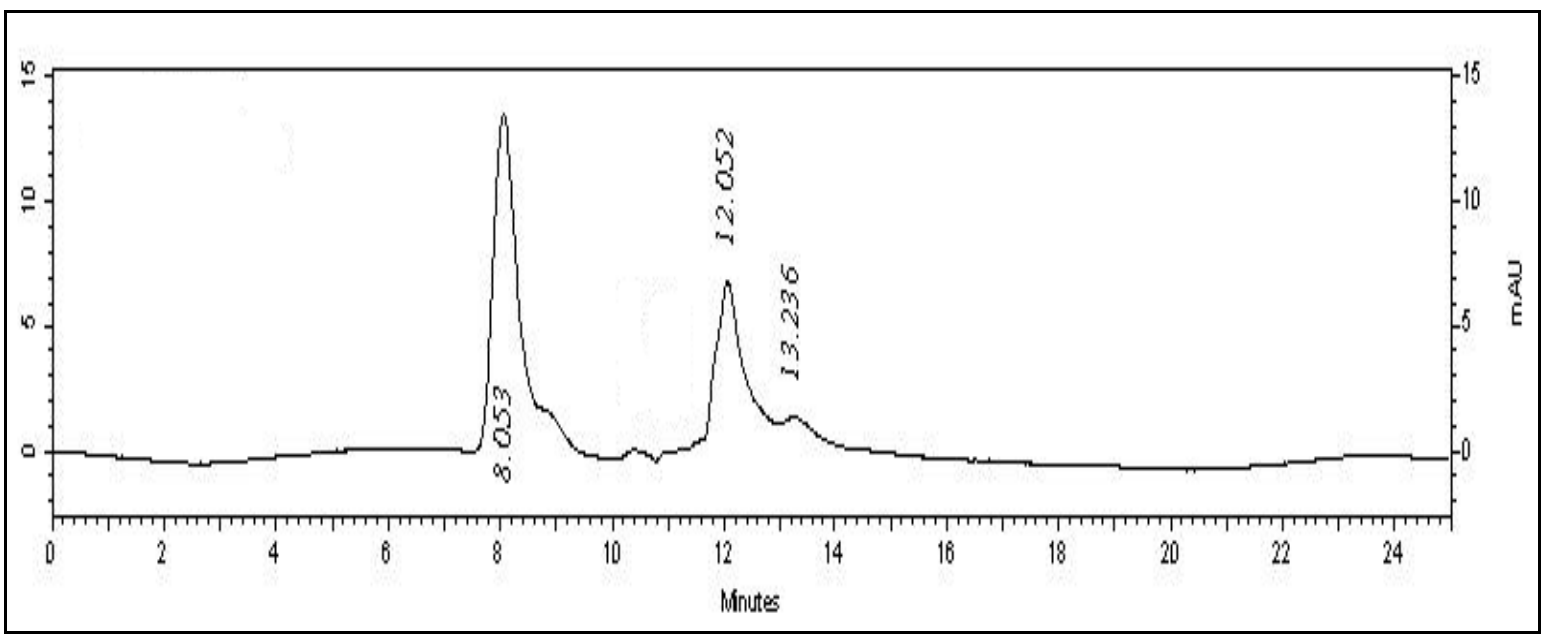

Figura 12. Perfil de CLAE (UV - $280 \mathrm{~nm}$ ) do anticorpo conjugado com DTPA na razão molar de 1:20 antes da purificação

A Figura 13 mostra que o processo de purificação do anticorpo foi eficiente. A mistura das frações 3 a 5 da purificação mostra o predomínio do pico do anticorpo, porém com uma pequena quantidade do quelante presente.

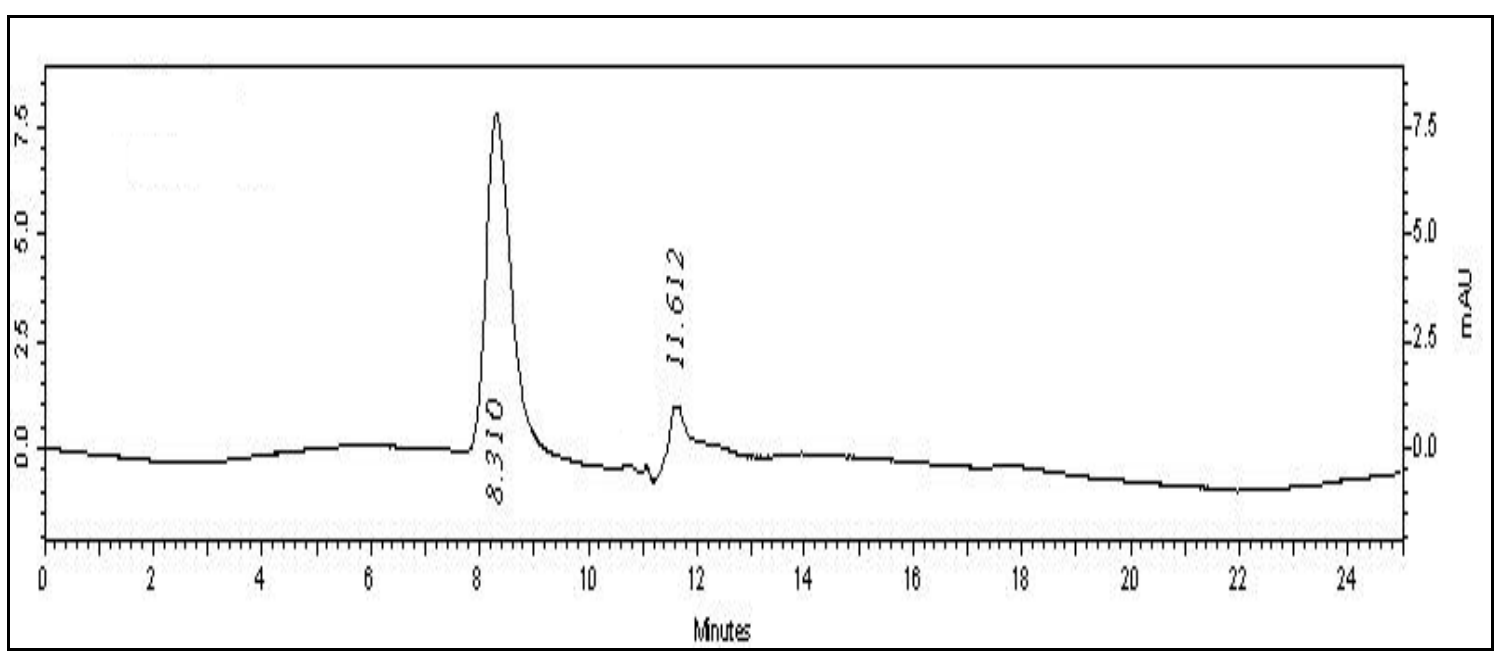

Figura 13. Perfil de CLAE (UV - $280 \mathrm{~nm}$ ) do anticorpo conjugado com DTPA na razão molar de 1:20 purificado na coluna PD 10 e concentrado com tubo Amicon Ultra-15 (30.000 MWCO), junção das frações 3-5 da purificação, contendo o anticorpo conjugado 
A figura 14 a seguir, mostra o perfil de CLAE do ultrafiltrado da primeira fração de ultrafiltração, no qual observa-se apenas o pico correspondente ao quelante.

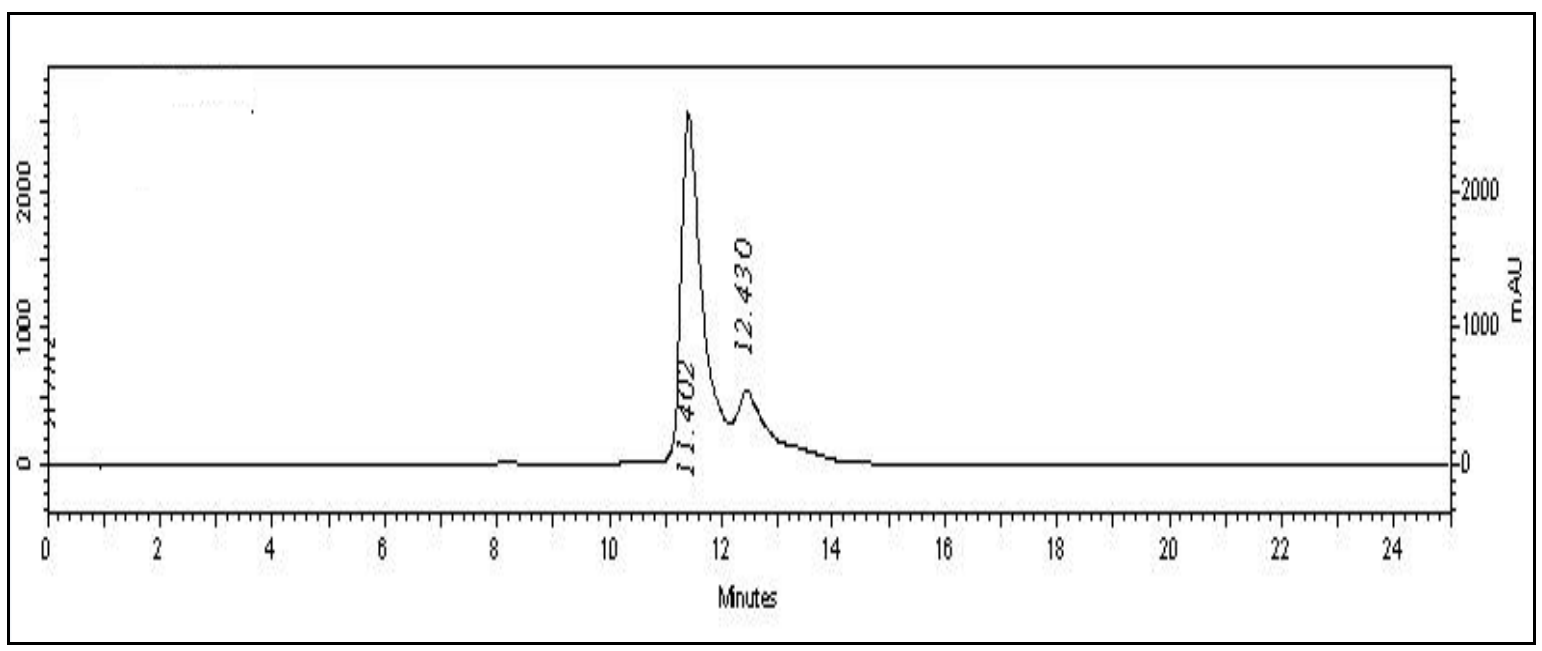

Figura 14. Perfil CLAE (UV $280 \mathrm{~nm}$ ) do ultrafiltrado do anticorpo conjugado com DTPA na razão molar de 1:20 purificado na coluna PD 10 e concentrado com tubo Amicon Ultra15 (30.000 MWCO $15 \mathrm{~mL}$ ), primeiro ultrafiltrado da concentração da junção das frações 3-5 do anticorpo conjugado

A figura 15 monstra o perfil de CLAE do ultrafiltrado das frações $3-5$, após 13 ciclos de ultracentrifugação. Pode-se observar além do pico do quelante um pico correspondente ao anticorpo conjugado, demonstrando que ao final do processo de purificação utilizado ocorreu perda de massa proteica. 


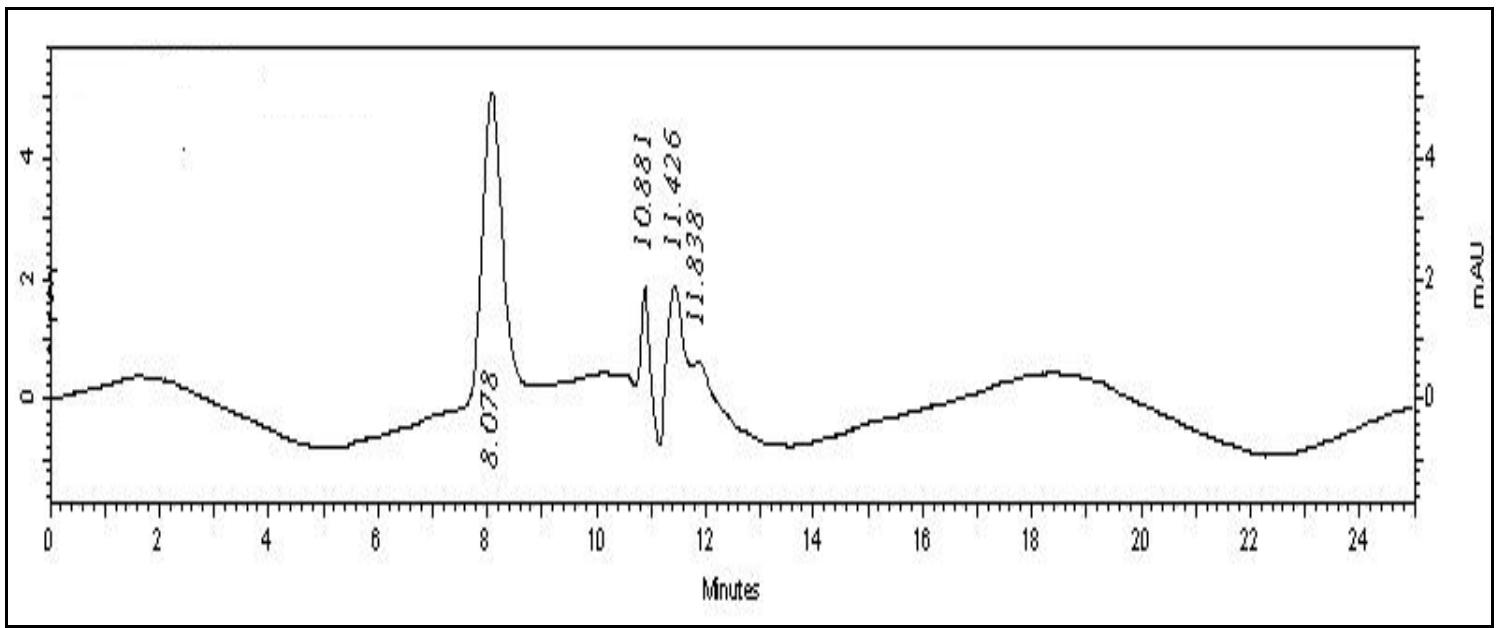

Figura 15. Perfil CLAE (UV - $280 \mathrm{~nm}$ ) do ultrafiltrado do anticorpo conjugado com DTPA na razão molar de 1:20 purificado na coluna PD 10 e concentrado com tubo Amicon Ultra-15 (30.000 MWCO $15 \mathrm{~mL}), 13^{\circ}$ ultrafiltrado da concentração da junção das frações 3-5 do anticorpo conjugado

A Figura 16 mostra o perfil de CLAE do quelante $p$-SCN-Bn-DTPA.

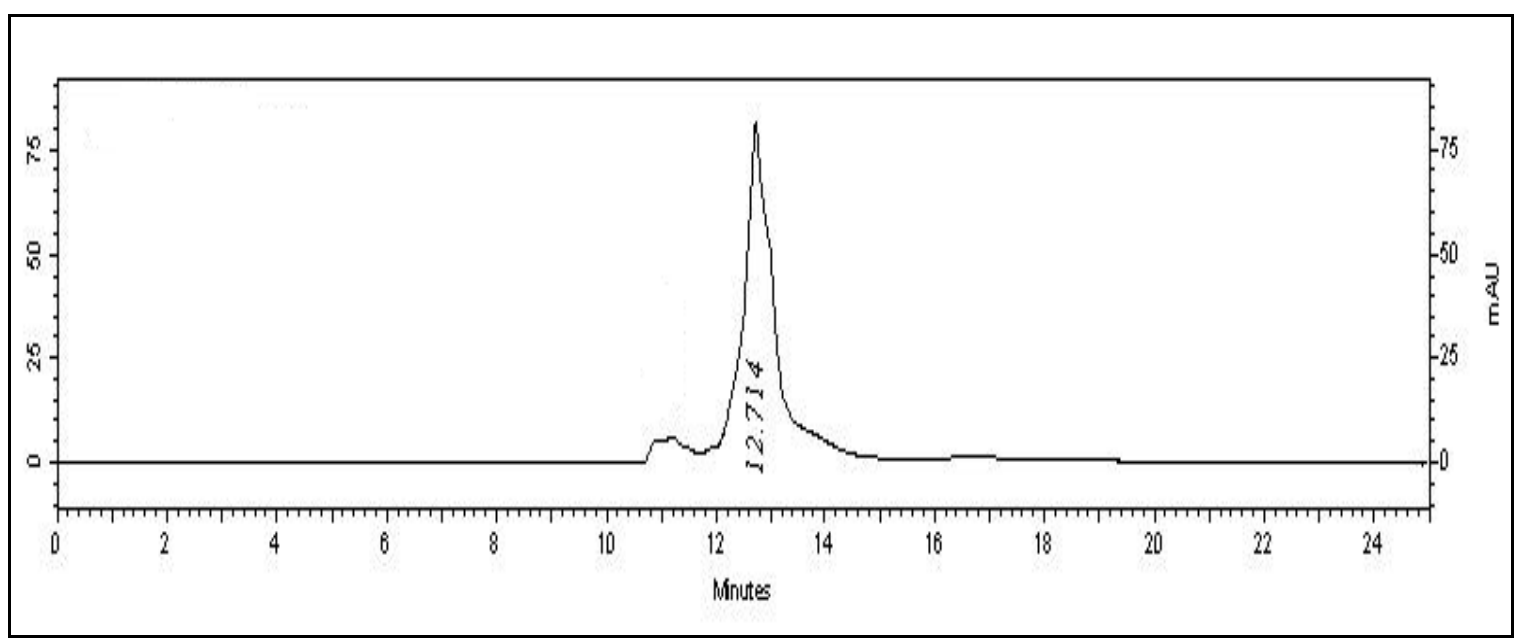

Figura 16. Perfil de CLAE (UV - $280 \mathrm{~nm}$ ) do quelante p-SCN-Bn-DTPA

Finalmente, considera-se que a metodologia onde a cromatografia de exclusão molecular (coluna PD 10) é combinada com ultrafiltração (tubo concentrador de proteína) seja a mais ideal para uso rotineiro em procedimentos de produção de 
radiofármacos anticorpo-conjugados, envolvendo o uso de purificação e concentração dos mesmos. O procedimento é simples, prático e rápido, ademais, evita a exposição do anticorpo a situação estressante de treze centrifugações sucessivas, com risco de perda proteica por ruptura da membrana do tubo.

\subsection{Estudo de método de marcação do anticorpo conjugado com lutécio-177}

Quando a massa de $1 \mathrm{mg}$ de amostra de anticorpo conjugado em razões molares de 1:20, 1:10, 1:5, purificado e concentrado, foi marcada com $37 \mathrm{MBq}$ (1 mCi) de cloreto de lutécio-177, obtivemos um produto com PR de cerca de $80 \%$ em todas as condições avaliadas (Tabela 14). Sendo que a pureza radioquímica destas marcações foram determinadas com o sistema utilizando papel Whatman 1 como suporte e o metanol:acetato de amônio 0,4 M (50:50 v/v) como fase móvel.

Tabela 14. Pureza radioquímica (\%) do composto conjugado $(1 \mathrm{mg})$ com DOTA (24 hs), razão molar: 1:5, 1:10, e 1:20 marcado com $37 \mathrm{MBq}(1 \mathrm{mCi}){ }^{177} \mathrm{Lu}(\mathrm{n}=5)$

\section{Pureza Radioquimica (\%)}

\section{Razão Molar}

$1: 5$

$1: 10$

$1: 20$
Imediato

$79,7 \pm 1,4$

$88,0 \pm 1,1$

$82,1 \pm 0,3$

Nas conjugações com quelante DOTA observou-se composto com pureza radioquímica inferior a $40 \%$ (1:50); enquanto que nas conjugações com DTPA observou-se composto com pureza radioquímica próximo a 95\% (1:20) Tabela 15. 
Tabela 15. Pureza radioquímica (\%) do anticorpo conjugado com DOTA e DTPA purificado e concentrado, marcado com $37 \mathrm{MBq}(1 \mathrm{mCi}){ }^{177} \mathrm{Lu}(\mathrm{n}=5)$

DOTA

\begin{tabular}{rlcc}
\multicolumn{4}{c}{ Razão Molar } \\
$1: 100$ & $1: 50$ & $1: 50$ & $1: 20$ \\
$4,9 \pm 1,7$ & $7,4 \pm 0,1$ & $50,0 \pm 0,1$ & $59,4 \pm 0,1$ \\
$6,7 \pm 0,1$ & $11,6 \pm 0,2$ & $53,4 \pm 0,9$ & $59,9 \pm 0,1$ \\
$19,4 \pm 3,5$ & $11,8 \pm 0,1$ & $55,9 \pm 0,1$ & $80,1 \pm 0,6$ \\
$22,2 \pm 0,2$ & $30,8 \pm 1,3$ & $62,3 \pm 1,2$ & $89,8 \pm 1,2$ \\
$27,2 \pm 0,3$ & $38,1 \pm 0,2$ & $75,8 \pm 0,6$ & $94,2 \pm 1,2$
\end{tabular}

$\mathrm{Na}$ tabela 15, optou-se por apresentar os resultados individuais dos cinco estudos de marcação realizados, ao invés de apresentar a média dos resultados, tendo em vista a variabilidade relativamente grande nos resultados.

Comparando-se os resultados obtidos nas Tabelas 14 (razões molares baixas) e 15 (razões molares altas), para o quelante DOTA, pode-se concluir, de forma geral, que o uso de razões molares mais elevadas, como 1:100 e 1:50, não melhorou a pureza radioquímica das marcações. Pelo contrário, razões molares muito elevadas devem contribuir para a introdução de um número excessivamente grande de quelantes na estrutura do anticorpo, aumentando a instabilidade do conjugado e favorecendo o desligamento do quelante durante o armazenamento do mesmo ou durante $\mathrm{o}$ procedimento de marcação.

Para investigar esta possibilidade, as marcações nas razões molares altas foram avaliadas pelos dois sistemas cromatográficos de camada delgada, previamente descrita, de modo a identificar se a impureza radioquímica presente na preparação corresponderia a lutécio-177 na forma livre ou quelada ao DOTA. Os resultados demonstraram que a impureza radioquímica das marcações encontrava-se na forma de lutécio-177 livre, nas marcações investigadas, descartando a possibilidade de 
desacoplamento do quelante incorporado ao anticorpo. Esta característica também foi observada para as conjugações do anticorpo com DOTA utilizando-se razões molares baixas.

Também foi determinado o número de quelantes incorporados ao anticorpo para a razão molar 1:50 do DOTA, em duas oportunidades, tendo sido obtidos os resultados de 6,4 e 47,2 quelantes por anticorpo para o composto conjugado em 1 e 24 horas respectivamente. Quando os anticorpos conjugados foram marcados com lutécio-177, os resultados de PR obtidos foram de 26,7\% e 7,2\%, respectivamente, indicando que o grande número de quelantes por anticorpo não contribuiu para a eficiência de marcação.

As Figuras 17 e 18 mostram o perfil cromatográfico da CLAE de amostras do anticorpo conjugado com DOTA nas razões molares de 1:100 e 1:50, respectivamente, radiomarcadas com ${ }^{177} \mathrm{Lu}$. Nos dois cromatogramas, observam-se dois picos, sendo 0 menor correspondente ao anticorpo ( $R T=8,1$ minutos), e maior ao quelante radiomarcado ( $R T=11,02$ minutos), indicando o desligamento do quelante do anticorpo ou a presença de quelante livre no meio de marcação, resultado de purificação ineficiente do imunoconjugado.

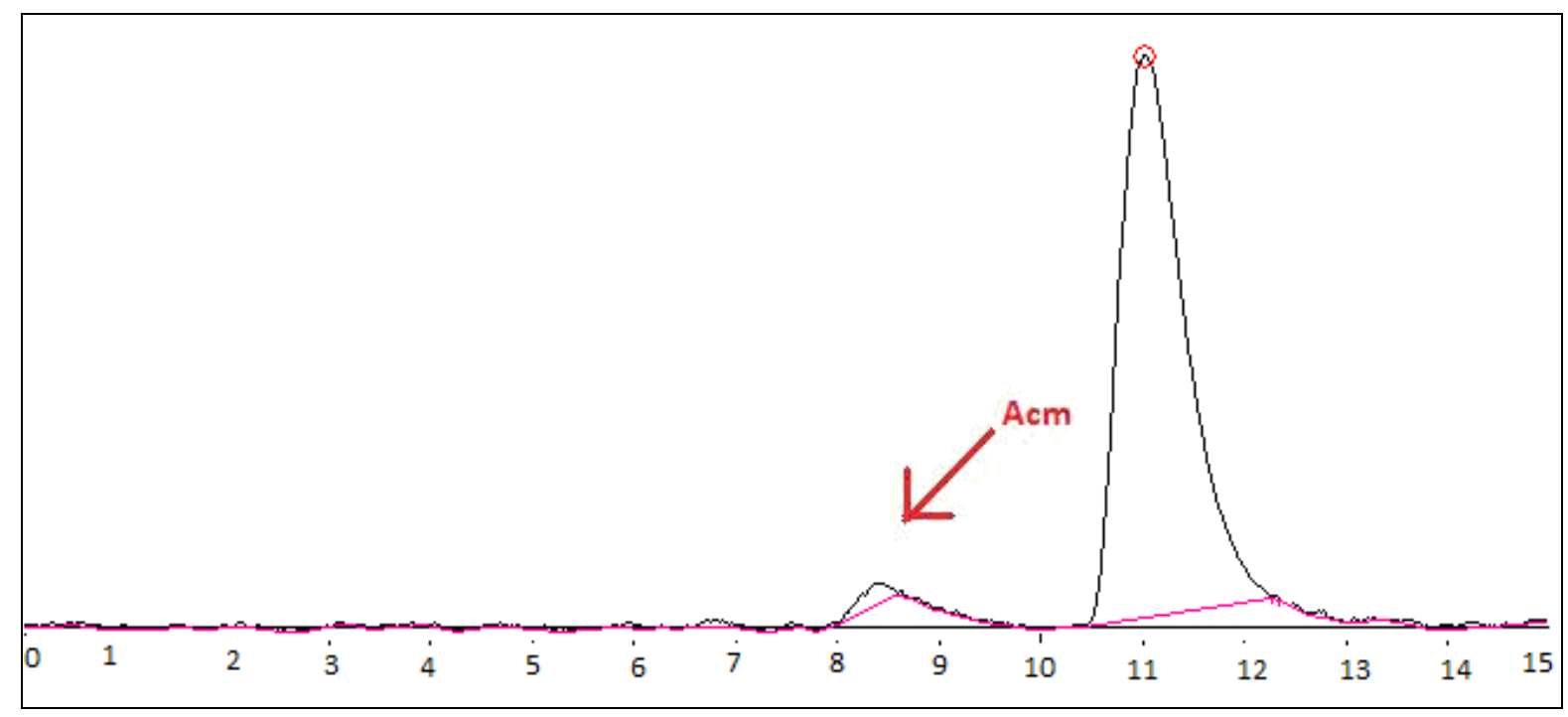

Figura 17. Perfil CLAE radioativo do anticorpo conjugado com DOTA 1:100 purificado e marcado com lutécio-177. 


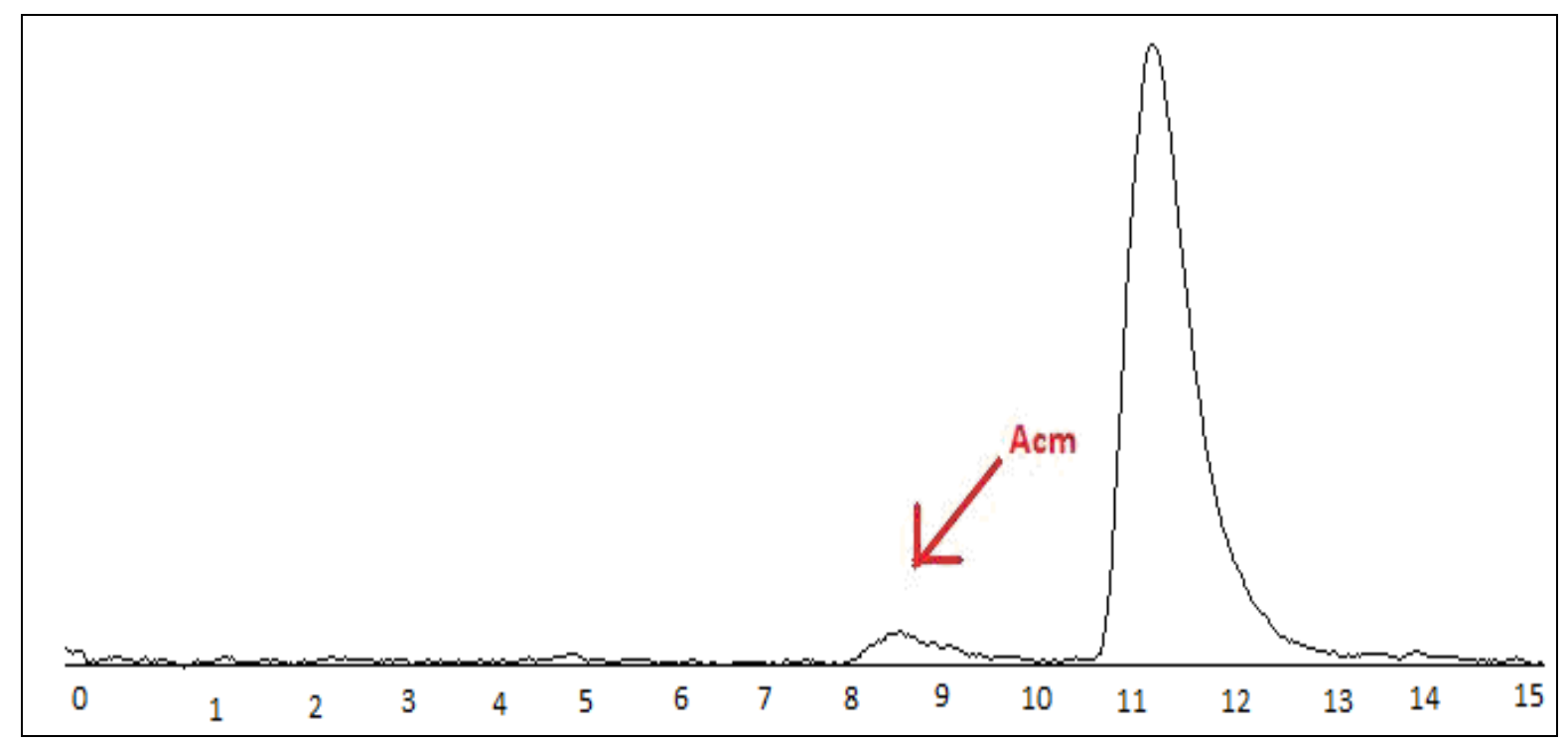

Figura 18. Perfil CLAE radioativo do anticorpo conjugado com DOTA 1:50 purificado e marcado com lutécio-177.

De fato, a maior dificuldade neste estudo foi a de reproduzir os resultados observados, quando os experimentos foram repetidos com lotes de lutécio diferentes e com anticorpos conjugados em procedimentos distintos.

Tentando investigar os motivos de tal variabilidade, vários fatores relacionados à conjugação e marcação foram investigados. Os sais de grau analítico foram substituídos por ultra puros; utilizou-se somente água tratada com resina chellex 100 , para preparo de reagentes e enxague final de vidrarias no intuito de prevenir contaminações por cátions que pudessem interferir no rendimento das marcações; as vidrarias foram lavadas e tratadas com ácido clorídrico para remoção de resíduos que pudessem interferir nos procedimentos de conjugação e radiomarcação entre outras providências. Desta forma, a qualidade dos insumos utilizados nas reações foi controlada, com exceção do lutécio-177, para o qual apenas verificou-se o certificado de qualidade fornecido pelo fornecedor (IDB), no qual constam os valores de atividade específica, bem como do conteúdo de alguns cátions trivalentes relacionados ao processo de produção do radioisótopo, tendo em vista a interferência dos mesmos nos procedimentos de marcação. Entretanto, não foram realizados ensaios de verificação. 
Desta forma, a hipótese de que as amostras de lutécio-177 poderiam representar a fonte da variação dos resultados obtidos não pode ser confirmada.

Um outro fator observado durante os estudos foi que os melhores resultados foram obtidos quando as amostras de lutécio-177 fornecidas para os procedimentos de pesquisa, apresentavam-se na forma original (em solução de ácido clorídrico). Em algumas vezes, a amostra de lutécio-177, advinda sempre do setor de produção de radiofármacos do IPEN, apresentava-se diluída em tampão acetato de sódio pH 5,5. Nestes casos, o rendimento das marcações foi sempre menor e por vezes, tão baixos que os resultados dos experimentos correspondentes foram desconsiderados deste estudo. Apesar do pH do tampão acetato ser ácido, estudos de cromatografia em camada delgada do lutécio livre, utilizando o mesmo sistema de solventes utilizados na determinação da pureza radioquímica das marcações, demonstraram haver diferença no perfil de distribuição do cloreto de lutécio, quando o mesmo apresenta-se diluído em ácido clorídrico ou no tampão acetato.

Neste último, ocorre a formação de espécie radioquímica possivelmente oxidada, que permanece na origem da fita de TLC-SG, quando se utiliza soluções alcalinas como solvente para a cromatografia. As formas oxidadas do lutécio-177 não são compatíveis com o procedimento de ligação aos quelantes bifuncionais, resultando em diminuição do rendimento radioquímico. Curiosamente, entretanto, a porcentagem de formas oxidadas de lutécio, observadas quando o mesmo foi diluído no tampão acetato de sódio pH 5,5, não foram constante, indicando haver outra causa atuando na oxidação do lutécio e não somente o solvente de diluição.

Segundo relatos na literatura, é consenso geral de que tampões de coordenação são necessários para uma quelação ou ligação eficientes de metais, ou melhor, tampões de coordenação fracos, como acetato e HEPES, facilitam ou proporcionam a formação de ligação estável de metais com grupamentos quelantes como DOTA e DTPA $[44,66]$. Deste modo, avaliamos a influência e a eficiência desses tampões e não observamos diferenças significantes no uso dos mesmos.

Segundo relatos na literatura, a eficiência de marcação de anticorpos conjugados com quelante bifuncional DOTA e seus derivados pode ser prejudicada 
pela cinética lenta de reação, levando a baixo rendimento nas marcações. Além disso, os quelantes bifuncionais, quando são conjugados com anticorpos, parecem diminuir a capacidade de ligação e a estabilidade termodinâmica de reação destes compostos. Além de fatores como contaminação de metais, a presença de quelantes não conjugados ou livres no meio de marcação, contribuem para a baixa pureza radioquímica e/ou rendimento de marcações observados nesses compostos $[44,70,75]$.

Além disto, as limitações do uso do quelante DOTA e seus derivados estão diretamente ligados ao problema de estabilidade; a taxa lenta de formação do complexo compromete o rendimento de marcação, a eficiência e atividade específica. Além disso mecanismo complexo em múltiplas etapas para a marcação do imunoconjugado com metais tem limitado severamente o uso do quelante DOTA e, de fato, pode ter contribuído para alguns resultados questionáveis utilizando este quelante. A cinética lenta de formação do complexo pode, em parte, ser resolvida se o imunoconjugado tolerar aquecimento por um determinado período de tempo. Ao contrário de quelantes DTPA e seus análogos que apresentam mecanismo simples de complexação e cinética de reação mais rápida, sendo as marcações realizadas à temperatura ambiente. Desta forma, a escolha do quelante depende também da aplicação específica [70].

Ademais, um trabalho comparativo realizado por Brom e colaboradores (2012), observou que os imunoconjugados de DOTA foram menos eficientes que os imunoconjugados de DTPA. Relataram que a marcação de imunoconjugados de DOTA resultou em atividade específica de 5 a 20 vezes inferior aos apresentados pelos imunoconjugados de DTPA. Provavelmente, a contaminação por metais pode ser a causa da disparidade observada com DOTA; e esse fato deve exercer menos influência nos compostos conjugados com DTPA [65].

De forma similar, neste trabalho, os compostos conjugados com DTPA apresentam sempre PR superior aos compostos conjugados com DOTA (TAB. 11,15 e 16). 
Os estudos de radiomarcação dos anticorpos conjugados demonstraram que os imunoconjugados utilizando-se quelante DTPA apresentaram maior eficiência de marcação, com resultados de pureza radioquímica maiores quando comparados com imunoconjugados que utilizaram DOTA como quelante bifuncional, considerando-se as diferentes razões molares utilizadas (Tabela 15 e 16).

A Tabela 16 demonstra os resultados obtidos quando amostras do anticorpo conjugado com DOTA e DTPA foram marcadas com cloreto de lutécio de dois fornecedores diferentes: IDB (Holanda) fornecedor habitual e Perkin Elmer (E.U.A), do qual foram recebidas amostras para teste. A diferença entre o lutécio dos dois fornecedores é, basicamente, a atividade específica, sendo maior para o lutécio da Perkin Elmer, uma vez que é produzido por reação indireta. As amostras de lutécio utilizadas nos experimentos da Tabela 16 apresentaram atividade específica de 860 $\mathrm{MBq} / \mathrm{mg}$ e $960 \mathrm{MBq} / \mathrm{mg}$ para IDB e Perkin Elmer, respectivamente.

Tabela 16. Pureza radioquímica do anticorpo conjugado com DOTA e DTPA marcado com $37 \mathrm{MBq}(1 \mathrm{mCi}){ }^{177}$ Lu da Perkin Elmer (E.U.A) e IDB (Holanda) ( $\left.\mathrm{n}=2\right)$

IDB (HOLANDA)

Razão molar DOTA

DTPA

Anticorpo

1:50

1:20

1:10

$$
62,3 \pm 0,9
$$

$34,3 \pm 1,4$

$90,1 \pm 0,3$

$38,9 \pm 0,8$

$89,9 \pm 0,1$
$64,0 \pm 1,2$

$24,4 \pm 4,0$

$94,3 \pm 0,9$
Perkin Elmer (E.U.A)

DOTA

DTPA

$91,3 \pm 0,2$

$93,8 \pm 0,1$

$93,8 \pm 0,4$

A utilização do lutécio de maior atividade específica (Perkin Elmer) mostrou-se útil, particularmente quando a conjugação do anticorpo foi realizada com a razão molar menor (1:10). Neste caso, o uso de lutécio com atividade específica mais alta foi 
decisivo para garantir alta pureza radioquímica nas marcações, especialmente quando o anticorpo foi conjugado com DOTA. Este é um resultado muito importante, uma vez que os estudos de ligação às células tumorais poderão identificar a influência da razão molar na capacidade do anticorpo em reconhecer e se ligar a receptores nas células tumorais e, normalmente, as utilizações de razões molares elevadas nos processos de conjugação promovem a perda da capacidade do anticorpo de se ligar aos receptores e até mesmo a perda de imunoreatividade do anticorpo, obrigando a utilização de razões molares menores nos procedimentos de conjugação.

Por fim, realizou-se estudo de variação da atividade de marcação do anticorpo conjugado com DOTA para as razões molares 1:50 e 1:20. Para atividades maiores, também foram realizadas marcações com massa maior do anticorpo (5 mg) (Tabela 17). No mesmo experimento, a estabilidade das marcações foi avaliada por até 48 horas. 
Tabela 17. Porcentagem de PR do imunoconjugado com DOTA nas razões molares 1:50 e 1:20: variação da atividade específica da marcação

\% Pureza Radioquímica das marcações

Razão molar Ac:DOTA 1:50

\begin{tabular}{ccccc}
\hline Massa Ac & $\begin{array}{c}\text { Atividade } \\
\text { (MBq) }\end{array}$ & Imediato & 24 horas & 48 horas \\
\hline $1 \mathrm{mg}$ & 185 & $59,6 \pm 8,5$ & $68,1 \pm 4,4$ & $58,4 \pm 8,6$ \\
$1 \mathrm{mg}$ & 370 & $68,5 \pm 2,6$ & - & - \\
$5 \mathrm{mg}$ & 370 & $88,1 \pm 8,5$ & $81,7 \pm 3,9$ & $87,5 \pm 6,4$ \\
\hline & & Razão molar Ac:DOTA 1:20 & \\
\hline $1 \mathrm{mg}$ & 185 & $24,5 \pm 0,3$ & $27,2 \pm 1,7$ & - \\
\hline $5 \mathrm{mg}$ & 370 & $32,4 \pm 15,7$ & $47,9 \pm 6,7$ & - \\
\hline
\end{tabular}

Os resultados da tabela 17 demonstram que o rendimento radioquímico da marcação não foi comprometido para atividades específicas mais altas, ao se comparar a PR da marcação de $1 \mathrm{mg}$ de anticorpo com diferentes atividades de lutécio. Por outro lado, o aumento da massa de anticorpo para $5 \mathrm{mg}$ (diminuindo a atividade específica) contribuiu para melhorar a PR da marcação. 


\subsubsection{Estudo de método de controle de pureza radioquímica do Anticorpo conjugado e marcado com lutécio-177.}

O sistema cromatográfico empregado utilizando-se cromatografia em papel Whatman No. 1 como fase estacionária e solução de metanol : acetato de amônio 0,4 M (50:50 v/v) como fase móvel mostrou-se ineficiente para resolver as três espécies radioquímicas presentes na preparação, pois neste sistema tanto o produto como lutécio livre ficam na origem da fita. O mesmo ocorre para o sistema utilizando cromatografia em camada delgada de TLC-SG e $\mathrm{NaOH} 0,1 \mathrm{M}$ em $\mathrm{NaCl} 0,9 \%$.

O outro sistema avaliado, utilizando-se cromatografia em camada delgada como fase estacionária e tampão citrato de sódio $0,1 \mathrm{M} \mathrm{pH} \mathrm{5,0} \mathrm{como} \mathrm{fase} \mathrm{móvel,}$ também não resolve as três espécies, pois, neste caso, o lutécio livre e o ${ }^{177}$ Lu-DOTA / DTPA migram para frente do solvente.

Os dois sistemas que empregam solventes alcalinos são eficientes em separar as impurezas radioquímicas do anticorpo marcado quando se adicionar DTPA em excesso no meio de reação no final de marcação, pois o lutécio livre quelado ao DTPA migra para frente do solvente. Neste caso, a desvantagem deste sistema é que ele não possibilitaria distinguir o DTPA $-{ }^{177}$ Lu assim formado de um eventual lutécio ligado ao quelante que porventura se desprendesse do anticorpo.

Desta forma optou-se por não inserir DTPA no final da marcação e utilizar os dois sistemas cromatográficos para discriminar as três possíveis espécies radioquímicas, possibilitando avaliar melhor a eficiência de marcação dos compostos conjugados com os dois quelantes bifuncionais em porcentagem (\%) do produto marcado com distinção da forma química da espécie não ligada ao anticorpo.

\subsubsection{Estudo de método de purificação do Anticorpo conjugado e marcado com lutécio-177}

O anticorpo conjugado com DOTA e DTPA e radiomarcados com pureza radioquímica inferior a 95\% foram purificados com coluna de Sephadex G25 PD10, eluida com tampão acetato de sódio $0,4 \mathrm{M} \mathrm{pH} \mathrm{5,5} \mathrm{ou} \mathrm{7,0.} \mathrm{Observou-se} \mathrm{que} \mathrm{os}$ conjugados radiomarcados com PR superior a $30 \%$, quando purificados, passaram a 
apresenta PR superior ou próxima a 95\%. Deste modo, o sistema empregado (cromatografia de exclusão molecular com PD 10) mostrou-se eficiente e prático, pois o produto foi eluido na terceira a quinta fração com pureza radioquímica superior a 95\% (TAB. 18).

As colunas cromatográficas do tipo PD10 (Pharmacia) são obtidas prontas, necessitando apenas da troca do tampão original pelo tampão de eluição do anticorpo, antes de seu uso. Além disto, podem ser descartadas ao final do processo representando mais uma facilidade relativa à produção rotineira de anticorpos marcados, evitando contaminações microbiológicas ou pirogênicas.

Na purificação com esta coluna de exclusão molecular, o lutécio livre fica retido na coluna, tendo em vista o baixo peso molecular do cátion, sendo eluído, somente, se um grande volume de tampão for utilizado na lavagem da coluna. No caso de ocorrer desligamento do quelante marcado da estrutura do anticorpo, a impureza radioquímica gerada (AQB- ${ }^{177} \mathrm{Lu}$ ) será eluída a partir de $12 \mathrm{~mL}$ do tampão.

Tabela 18. Pureza radioquímica (\%) do anticorpo conjugado com DOTA e DTPA marcado com $37 \mathrm{MBq}(1 \mathrm{mCi}){ }^{177} \mathrm{Lu}$, purificado em cromatografia de exclusão molecular (PD 10) $(n=2)$

\section{Pureza Radioquímica (\%)}

\section{Razão molar}

\section{Anticorpo}

$1: 50$

$1: 20$

$1: 10$
DOTA Imediato

$62,3 \pm 0,9$

$34,3 \pm 1,4$

$32,8 \pm 0,8$

\section{Purificado}

Imediato

$97,4 \pm 1,3$

$64,0 \pm 1,2$

$94,9 \pm 0,3$

$24,4 \pm 4,0$
$96,8 \pm 0,1$

DTPA

\section{Purificado}

$98,7 \pm 0,2$

$97,4 \pm 0,4$ 
5.4 Estudo de estabilidade in vitro do anticorpo conjugado e marcado com lutécio-177

Os resultados dos estudos de estabilidade realizados para o anticorpo conjugado ao quelante DOTA e radiomarcado foram apresentados na Tabela 17.

A estabilidade do anticorpo marcado, em to das as situações, foi comprovada, após armazenamento do mesmo sob refrigeração $\left(2\right.$ a $\left.8{ }^{\circ} \mathrm{C}\right)$, confirmando a estabilidade do composto marcado, própria do quelante DOTA [70].

\subsection{Ensaio de ligação Específica in vitro dos compostos conjugados e marcado com lutécio-177 às células Raji ("Binding")}

Devido a diversos problemas técnicos, particularmente a grande variação no rendimento de marcação do anticorpo conjugado ao quelante DOTA, foram realizados ensaios de ligação celular apenas com o anticorpo conjugado ao DTPA nas três razões molares estudadas $(1: 50 ; 1: 20$ e 1:10) , representadas nas figuras 19, 20 e 21, respectivamente.

Os composto conjugados nas razões molares de 1:50 e 1:20 apresentaram perfil semelhante de ligação. Observou-se o aumento da porcentagem de ligação específica com o aumento da concentração celular (FIG 19 e 20). 


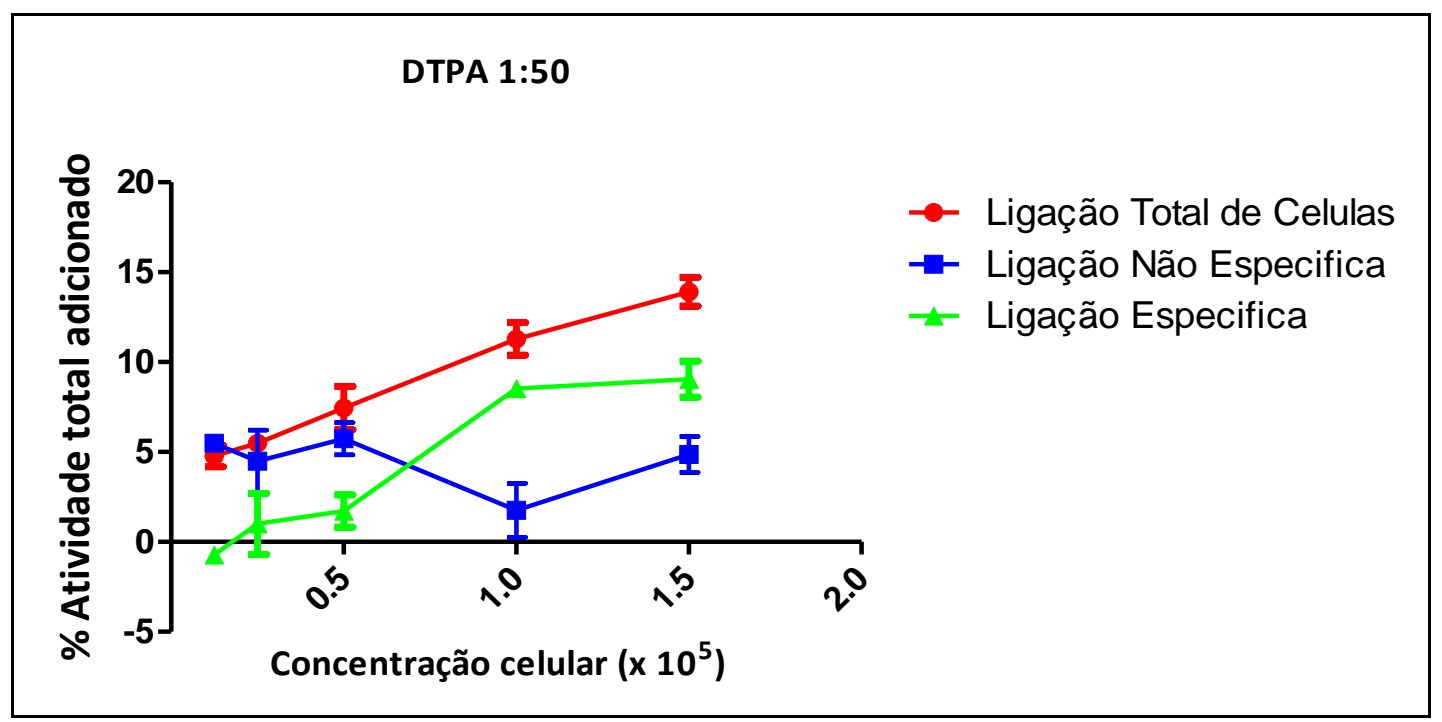

Figura 19. Ligação específica in vitro às células Raji (Binding) do anticorpo conjugado com DTPA na razão molar 1:50

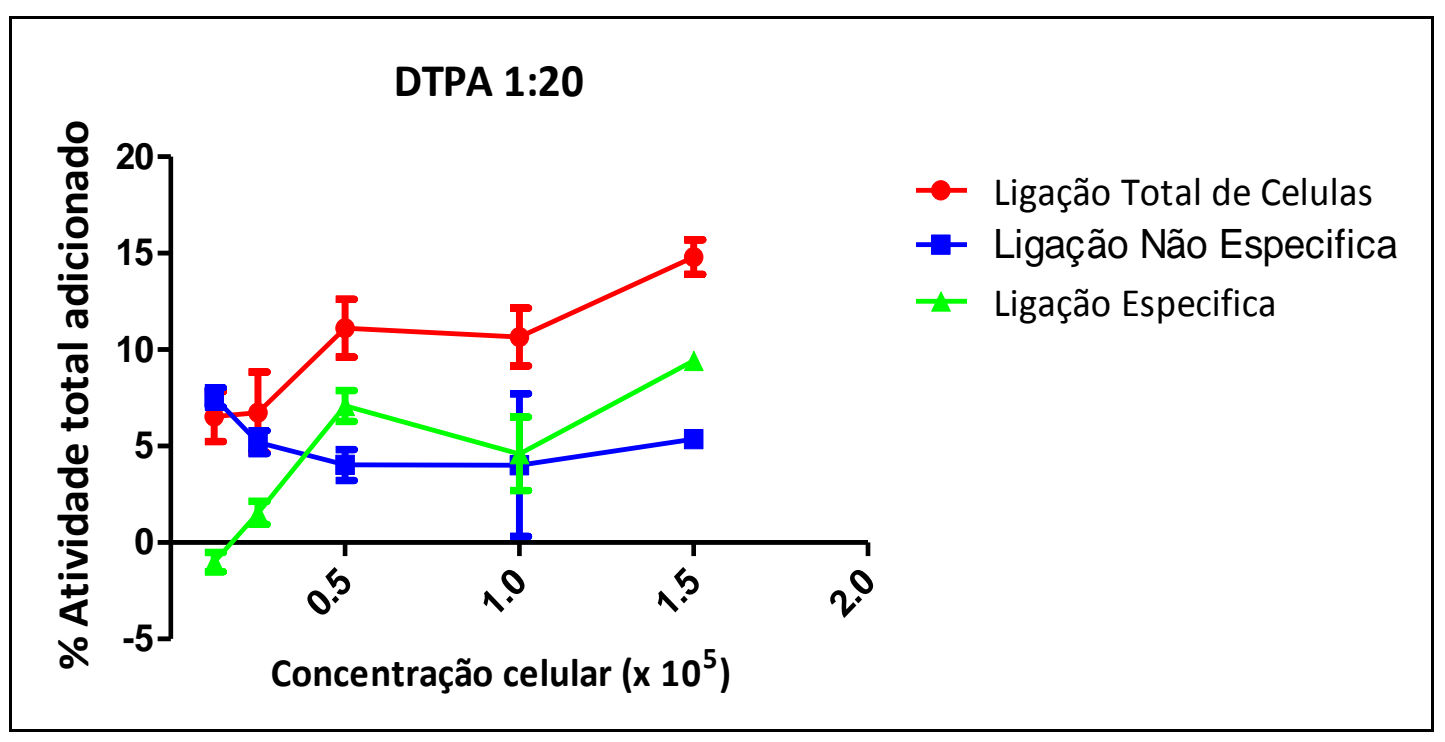

Figura 20. Ligação específica in vitro às células Raji (Binding) do anticorpo conjugado com DTPA na razão molar 1:20

Já para o anticorpo conjugado na razão molar 1:10, observou-se perfil de ligação às células diferente, apresentou alta porcentagem de ligação não específica (FIG. 21). 


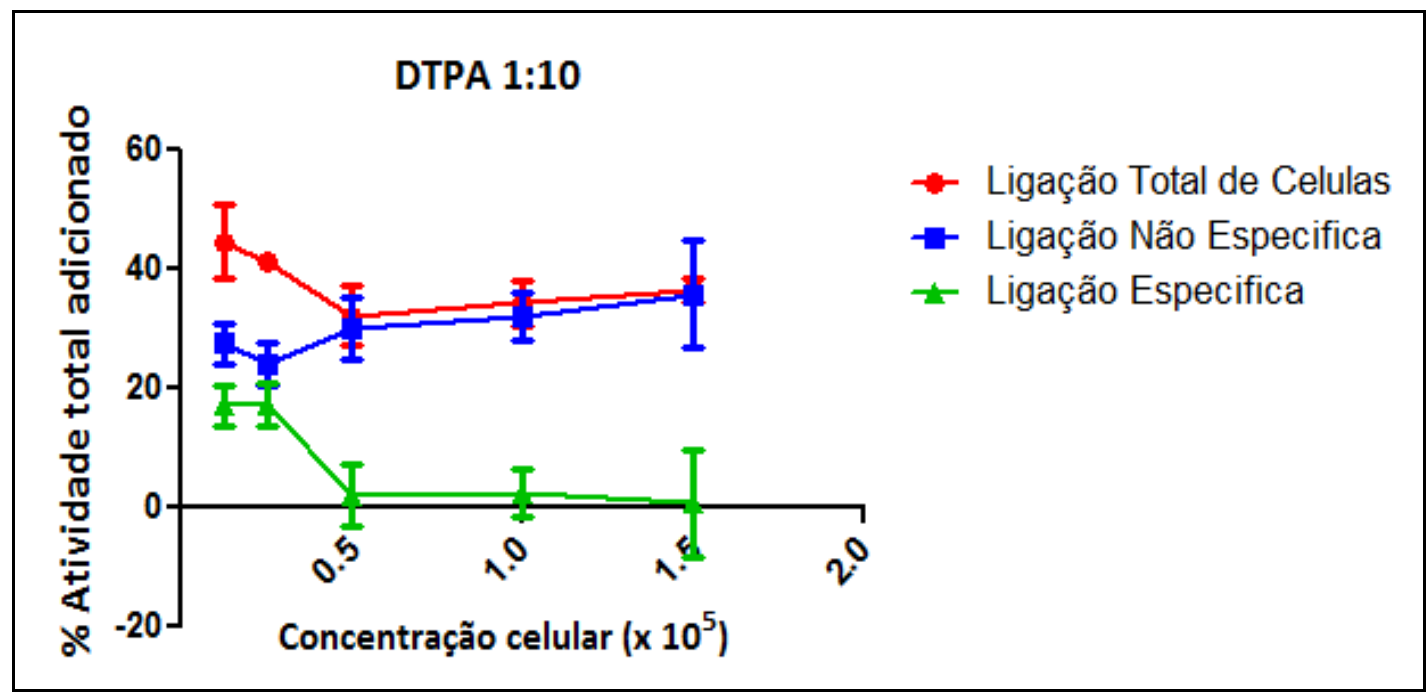

Figura 21. Ligação específica in vitro às células Raji (Binding) do anticorpo conjugado com DTPA na razão molar 1:10

A partir deste estudo preliminar, pode-se concluir que a razão molar 1:10 comprometeu a ligação específica do anticorpo conjugado radiomarcado, ao contrário das razões molares 1:50 e 1:20. Os resultados obtidos neste estudo podem estar relacionados à problemas de estabilidade do anticorpo marcado para razão molar 1:10, não avaliada neste trabalho.

Segundo estudos de ligação específica realizada por Forrer e colaboradores [37], e Audicio e colaboradores [58], com imunoconjugados de DOTA, os imunoconjugados demonstraram ligação específica às células estudadas que possuíam receptores específicos para o anticorpo anti-CD20.

O estudo de Audicio e col. utilizou o anticorpo rituximab conjugado ao DOTA, porém não informa a relação molar utilizada. O estudo de ligação às células utilizou extrato de membrana de células $B$ humanas e a capacidade máxima de ligação determinada foi de $35 \pm 5 \%$. O estudo mostrou inibição da ligação celular $(78,1 \pm 2,1 \%)$ quando 2,2 pM do anticorpo não marcado foi introduzido no meio de reação [59].

O estudo de Forrer e col. utilizou o anticorpo rituximab conjugado ao DOTA na razão molar de 1:5 e 1:20. Segundo os autores, o número médio de quelantes incorporados ao anticorpo foi de 4 e 8 quelantes, para as razões 1:5 e 1:20, 
respectivamente. A imunoreatividade foi avaliada por método citofluorimétrico, que indicou para a razão molar 1:5 uma moderada perda de imunoreatividade e para a razão 1:20, uma drástica redução da imunoreatividade [37].

Estes resultados de Forrer e col. contrastam com os resultados preliminares obtidos neste trabalho para o quelante DTPA, que indicaram ligação específica nas razões molares 1:20 e 1:50 e ligação não específica na razão 1:10. Estudos de ligação específica bem como de competição (utilizando-se o anticorpo não marcado) deverão ser realizados, também com o anticorpo quelado ao DOTA, de modo a confirmar a especificidade da ligação às células nas diferentes razões molares.

\subsection{Estudo de distribuição biológica em camundongos $B A L B / c$ sadios}

Os resultados obtidos no estudo de biodistribuição do anticorpo conjugado com DOTA na razão molar de 1:50 e 1:20 em camundongos Balb-c sadios são demonstrados nas Tabelas 19 e 20, respectivamente, e foram expressos em porcentagem de atividade captada pelo tecido em função da atividade administrada, e porcentagem de atividade por grama de tecido em função da atividade administrada.

$\mathrm{Na}$ Tabela 19, os resultados de biodistribuição do anticorpo radiomarcado, conjugado na razão molar 1:50, demonstram clareamento sanguíneo lento, compatível com a biodistribuição de um anticorpo radiomarcado. Entretanto, a captação observada no fígado é relativamente baixa para um anticorpo radiomarcado em todos os tempos observados (TAB. 19, FIG. 22 e 23). Da mesma forma, a captação renal bastante elevada, é mais compatível com a biodistribuição de compostos hidrofílicos, como o DOTA $-{ }^{177} \mathrm{Lu}$ ou a forma livre do lutécio-177. Neste caso, poderia estar ocorrendo, in vivo, o desligamento do quelante radiomarcado da estrutura do anticorpo. A captação óssea significativa relaciona-se, provavelmente, à forma livre de lutécio-177 e corresponde à metabolização in vivo do composto radiomarcado. Neste estudo, observou-se alta captação óssea principalmente nas primeiras horas, porém, essa captação decresce progressivamente nas horas finais do estudo. 
Tabela 19. Biodistribuição do rituximab-DOTA- ${ }^{177}$ Lu conjugado na razão molar 1:50, em diferentes tempos após a administração de 0,185 $\mathrm{MBq}$ do radioimunoconjugado em camundongos $B A L B / C$ sadios $(n=4)$

\% Atividade administrada (\%Al) e \% Atividade administrada/grama (\% Al/g)

$(\mathrm{N}=4)$

$1 \mathrm{~h} \quad 4 \mathrm{hs} \quad 24 \mathrm{hs}$

\begin{tabular}{cllllll}
\hline & $\%$ Al & $\%$ Al/g & $\%$ Al & $\%$ Al/g & $\%$ Al & $\%$ Al/g \\
\hline Coração & $2,6 \pm 0,1$ & $0,4 \pm 0,1$ & $1,9 \pm 0,5$ & $0,3 \pm 0,0$ & $1,0 \pm 0,2$ & $0,2 \pm 0,1$ \\
Pulmões & $3,2 \pm 0,4$ & $0,6 \pm 0,2$ & $2,8 \pm 0,4$ & $0,4 \pm 0,0$ & $1,1 \pm 0,2$ & $0,3 \pm 0,1$ \\
Baço & $3,2 \pm 1,0$ & $0,4 \pm 0,2$ & $2,5 \pm 0,5$ & $0,4 \pm 0,1$ & $1,1 \pm 0,3$ & $0,2 \pm 0,0$ \\
Estômago & $0,7 \pm 0,2$ & $0,5 \pm 0,1$ & $0,6 \pm 0,1$ & $0,4 \pm 0,1$ & $0,3 \pm 0,1$ & $0,3 \pm 0,1$ \\
Fígado & $4,6 \pm 1,0$ & $2,0 \pm 0,3$ & $3,8 \pm 0,3$ & $1,5 \pm 0,2$ & $1,3 \pm 0,1$ & $0,7 \pm 0,3$ \\
Rins & $23,9 \pm 2,8$ & $14,4 \pm 2,3$ & $18,0 \pm 0,8$ & $13,6 \pm 0,6$ & $10,1 \pm 1,4$ & $6,0 \pm 2,0$ \\
Intestinos & $3,4 \pm 0,4$ & $0,6 \pm 0,1$ & $2,3 \pm 0,4$ & $0,4 \pm 0,1$ & $0,9 \pm 0,1$ & $0,2 \pm 0,0$ \\
Músculo & $8,6 \pm 0,7$ & $0,4 \pm 0,3$ & $6,7 \pm 0,3$ & $0,3 \pm 0,0$ & $5,4 \pm 1,1$ & $0,3 \pm 0,1$ \\
Osso & $12,2 \pm 2,3$ & $1,7 \pm 0,6$ & $10,0 \pm 1,7$ & $1,5 \pm 0,2$ & $7,6 \pm 1,3$ & $1,2 \pm 0,1$ \\
\hline Sangue Total & $19,5 \pm 0,9$ & $6,6 \pm 2,0$ & $11,6 \pm 1,6$ & $3,5 \pm 0,7$ & $8,1 \pm 0,4$ & $2,6 \pm 0,2$ \\
\hline
\end{tabular}




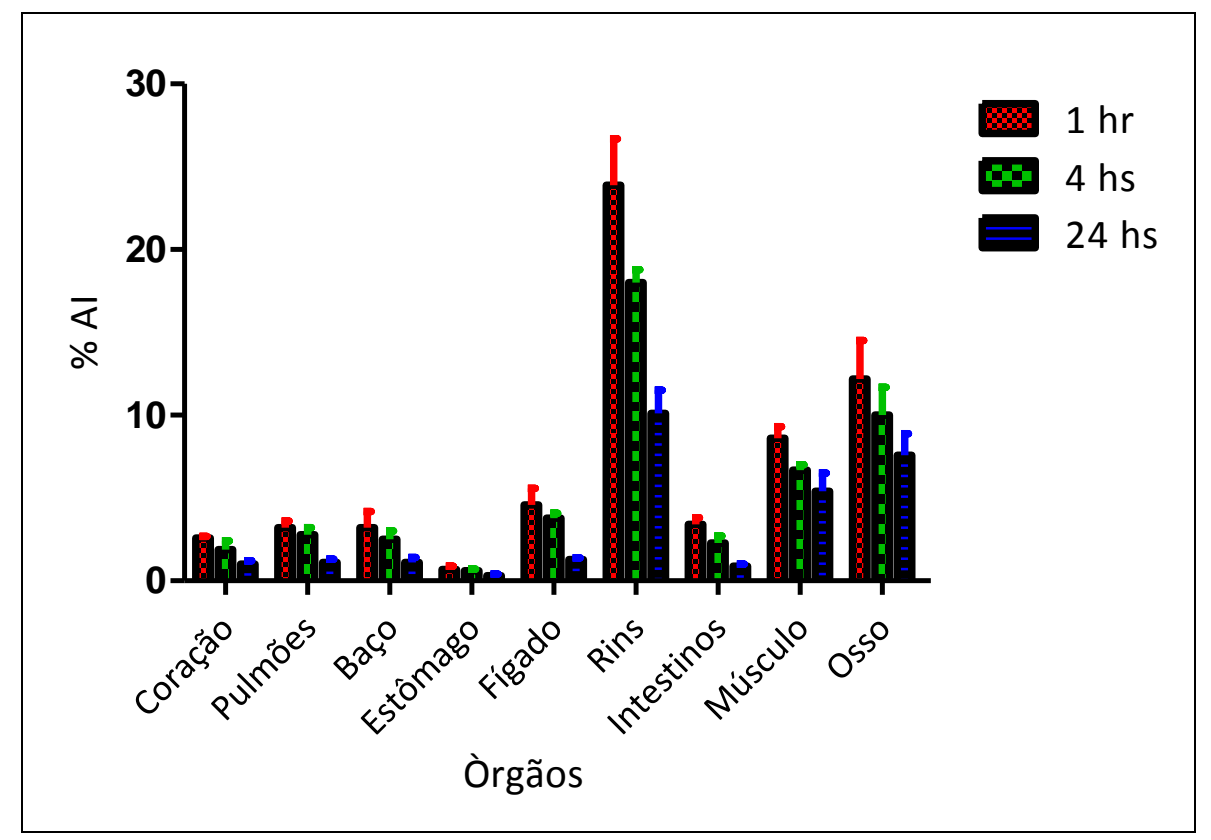

Figura 22. Biodistribuição (em \% de atividade captada pelo tecido ou órgão) do rituximab-DOTA- ${ }^{177} \mathrm{Lu}(1: 50)$ em camundongos $B A L B / C$ sadios

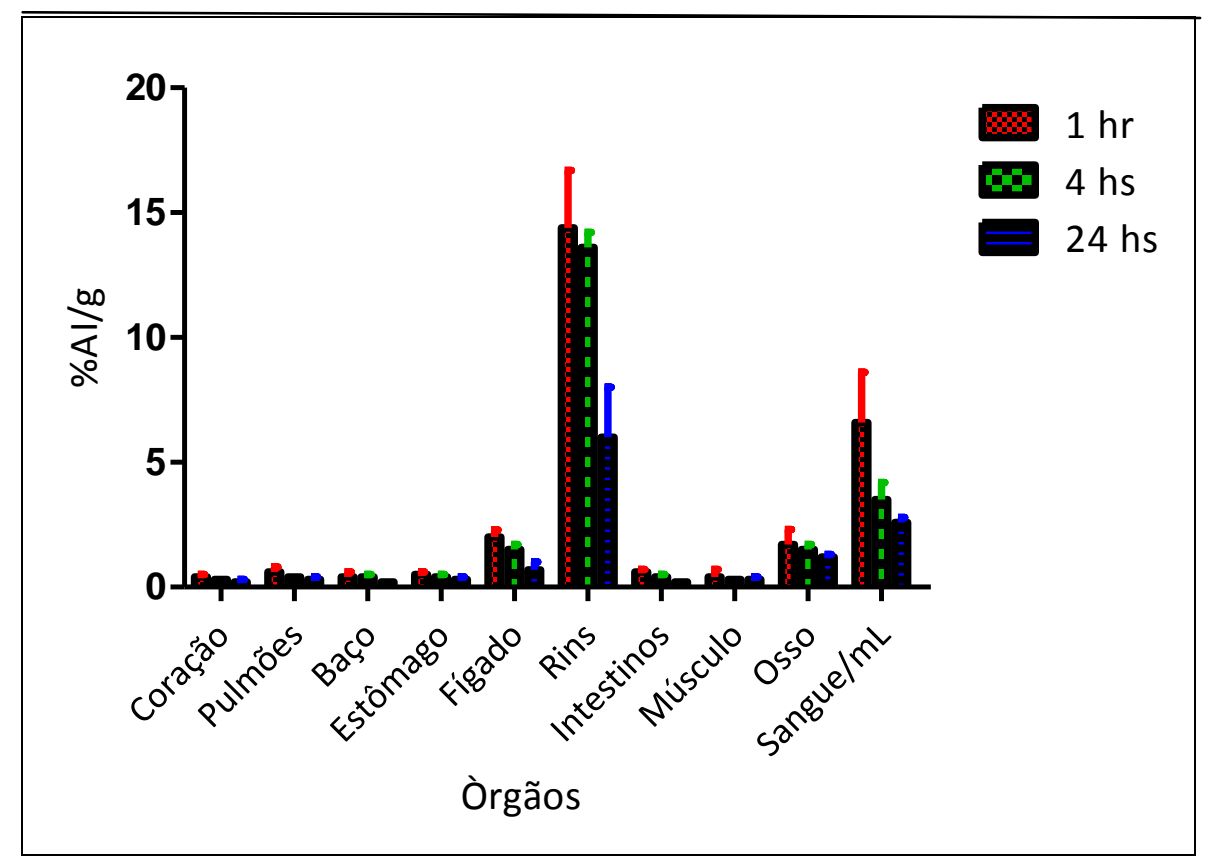

Figura 23. Biodistribuição (em \% de atividade captada por grama de tecido ou órgão) do rituximab-DOTA- ${ }^{177} \mathrm{Lu}(1: 50)$ em camundongos $B A L B / C$ sadios 
Na Tabela 20 e FIG 24 e 25, estão representados os resultados do estudo de biodistribuição em camundongos Balb-c, do rituximab-DOTA- ${ }^{177}$ Lu, conjugado na razão molar de 1:20, após administração de 0,185 MBq do radioimunoconjugado por via venosa.

Tabela 20. Biodistribuição do rituximab-DOTA- ${ }^{177}$ Lu conjugado na razão molar 1:20, em diferentes tempos após a administração de $0,185 \mathrm{MBq}$ do radioimunoconjugado em camundongos $B A L B / C$ sadios $(n=4)$

\% Atividade administrada (\%Al) e \% Atividade administrada/grama (\% Al/g)

$(\mathrm{N}=4)$

$1 \mathrm{~h}$

4 hs

24 hs

\begin{tabular}{ccccccc}
\hline & $\% \mathbf{A l}$ & $\% \mathbf{A l} / \mathbf{g}$ & $\% \mathbf{A l}$ & $\% \mathrm{Al} / \mathbf{g}$ & $\% \mathbf{A l}$ & $\% \mathbf{A l} / \mathbf{g}$ \\
\hline Coração & $9,1 \pm 1,0$ & $0,9 \pm 0,1$ & $3,4 \pm 0,6$ & $0,7 \pm 0,1$ & $2,1 \pm 0,2$ & $0,5 \pm 0,1$ \\
Pulmões & $9,1 \pm 1,0$ & $1,6 \pm 0,5$ & $4,0 \pm 1,0$ & $1,2 \pm 0,1$ & $1,9 \pm 0,2$ & $0,7 \pm 0,1$ \\
Baço & $7,6 \pm 0,6$ & $0,9 \pm 0,2$ & $4,6 \pm 1,4$ & $0,8 \pm 0,1$ & $2,9 \pm 0,2$ & $0,6 \pm 0,1$ \\
Estômago & $1,9 \pm 0,2$ & $0,9 \pm 0,3$ & $1,3 \pm 0,7$ & $0,7 \pm 0,1$ & $0,7 \pm 0,1$ & $0,6 \pm 0,1$ \\
Fígado & $16,8 \pm 1,3$ & $13,2 \pm 1,2$ & $15,6 \pm 0,7$ & $12,5 \pm 1,8$ & $12,2 \pm 1,3$ & $7,4 \pm 1,2$ \\
Rins & $9,7 \pm 1,3$ & $3,2 \pm 0,4$ & $7,8 \pm 0,8$ & $3,0 \pm 0,4$ & $5,1 \pm 0,9$ & $2,1 \pm 0,3$ \\
Intestinos & $4,3 \pm 1,0$ & $1,4 \pm 0,4$ & $4,2 \pm 1,2$ & $1,1 \pm 0,2$ & $3,6 \pm 0,6$ & $0,8 \pm 0,2$ \\
Músculo & $5,7 \pm 0,5$ & $1,0 \pm 0,2$ & $4,0 \pm 0,4$ & $0,9 \pm 0,2$ & $1,7 \pm 0,2$ & $0,8 \pm 0,1$ \\
Osso & $9,3 \pm 0,9$ & $3,4 \pm 0,5$ & $14,0 \pm 1,1$ & $4,8 \pm 0,8$ & $16,6 \pm 2,3$ & $4,9 \pm 0,7$ \\
\hline Sangue Total & $27,4 \pm 1,7$ & $8,6 \pm 0,8$ & $15,5 \pm 1,0$ & $5,4 \pm 0,6$ & $8,5 \pm 0,6$ & $4,8 \pm 0,8$ \\
\hline
\end{tabular}

Comparativamente, a captação hepática para o anticorpo marcado, conjugado na razão molar 1:20, foi superior à observada para o anticorpo marcado conjugado na razão molar 1:50. Ainda de forma comparativa, a captação renal, ao contrário, foi menor para o composto conjugado na razão 1:20. Tais características, em 
conjunto, combinadas com o clareamento sanguíneo relativamente lento, são compatíveis com a biodistribuição de um anticorpo radiomarcado. A captação óssea foi significativa e o aumento da mesma em função do tempo, sugere desligamento in vivo do lutécio da estrutura do anticorpo radiomarcado (FIG. 24 e 25).

Contudo, os dados observados neste estudo confirmam o perfil biológico in vivo do anticorpo rituximab, suas características e afinidades conhecidas e relatadas em outros estudos, como o de Audicio col. (2011). A biodistribuição realizada por Audicio e col. em camundongos normais também mostra captação hepática significativa do rituximab conjugado ao DOTA radiomarcado com lutécio-177, que neste estudo variou de cerca de 20 a 40 \% Al de 4 a 24 horas e a captação renal ficou em torno de $5 \%$ nos mesmos tempos estudados [58].

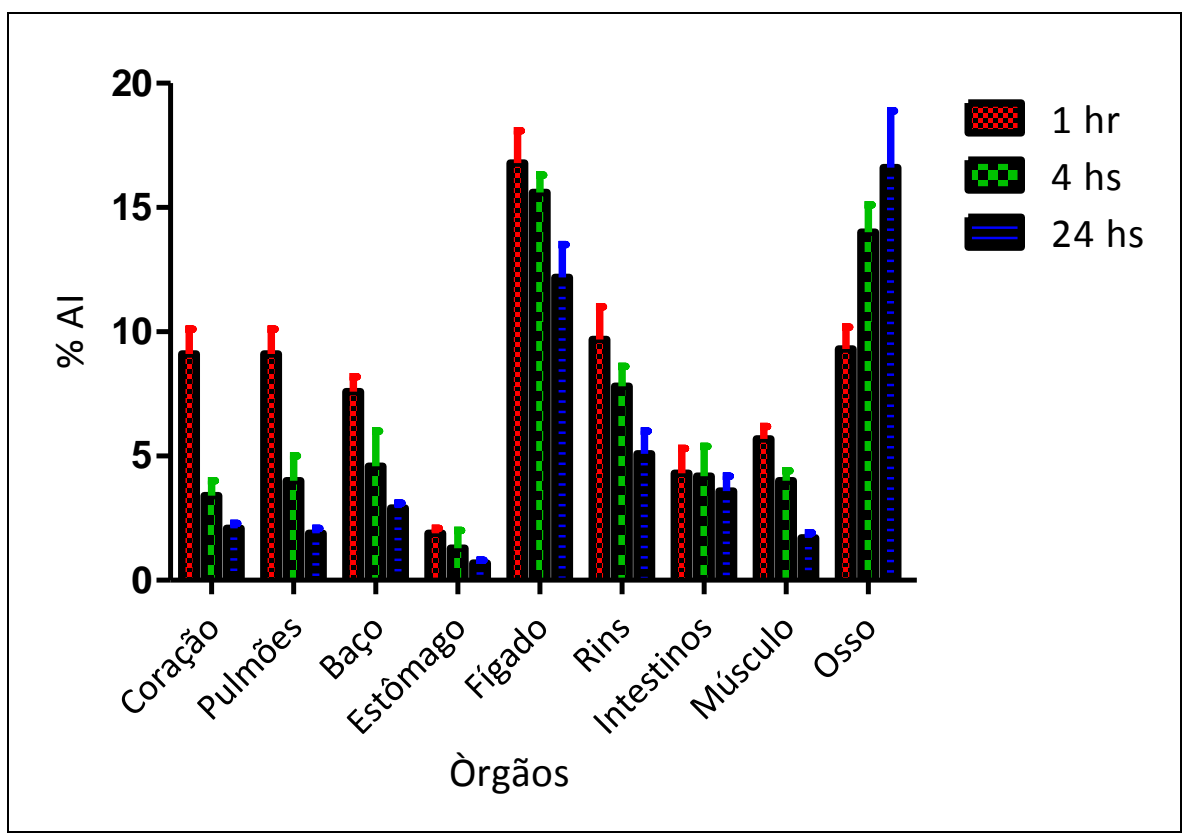

Figura 24. Biodistribuição (em \% de atividade captada pelo tecido ou órgão) do rituximab-DOTA- ${ }^{177}$ Lu (1:20) em camundongos $B A L B / c$ sadios 


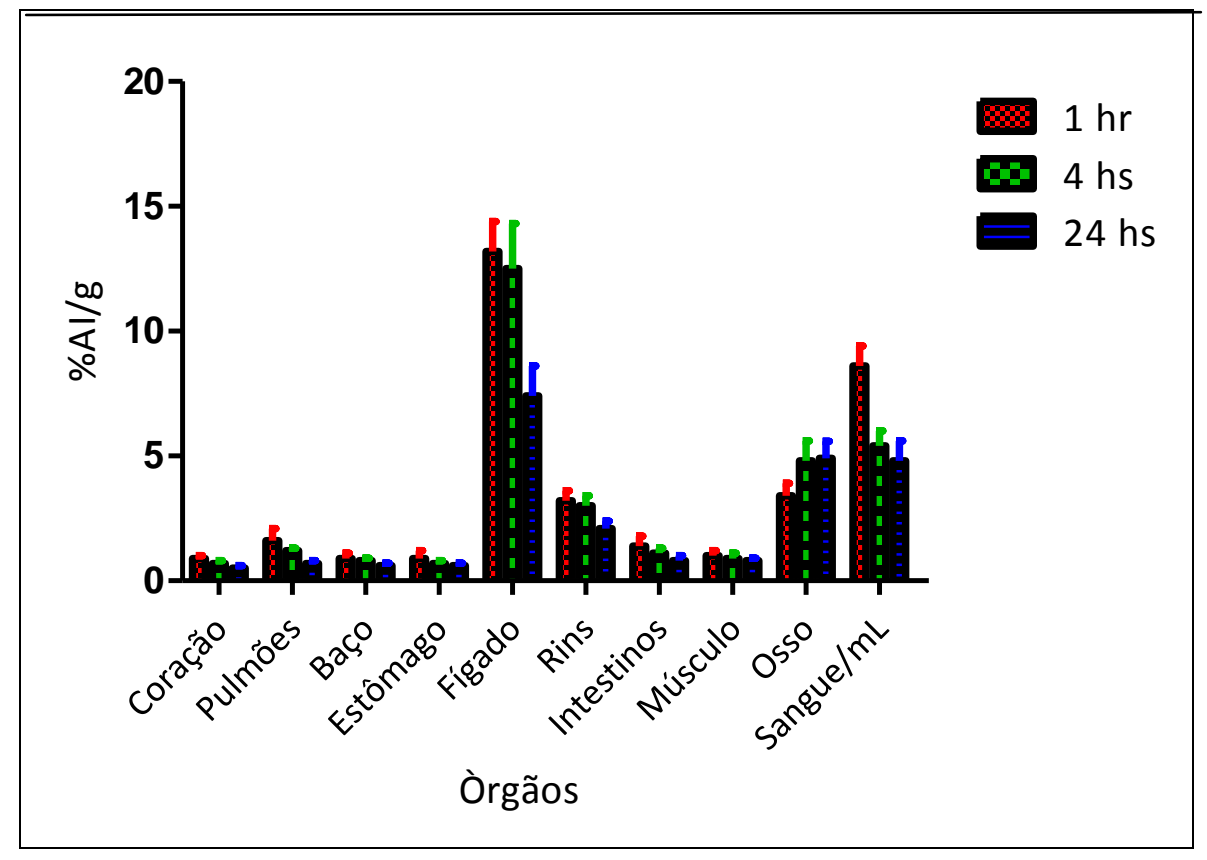

Figura 25. Biodistribuição (em \% de atividade captada por grama do tecido ou órgão) do rituximab-DOTA $-{ }^{177} \mathrm{Lu}(1: 20)$ em camundongos $B A L B / C$ sadios

Os resultados obtidos no estudo de biodistribuição do anticorpo conjugado com DTPA na razão molar de 1:50; 1:20 e 1:10 em camundongos Balb-c sadios são demonstrados nas Tabelas 21, 22 e 23 respectivamente, expressos em porcentagem de atividade administrada em função de atividade captada pelo tecido, e por grama de tecido. Os mesmos resultados podem ser observados nas figuras 26 a 31 .

O anticorpo conjugado ao DTPA na razão molar 1:50 apresentou clareamento sanguíneo mais lento, quando comparado com o anticorpo quelado ao DTPA nas razões molares 1:20 e 1:10, sendo que esta última razão molar apresentou o clareamento sanguíneo mais rápido. Em contrapartida, a razão molar 1:10 apresentou maior captação hepática dos três conjugados compatível com a biodistribuição do Acm radiomarcado. Também no caso da razão molar 1:10, a captação no osso foi maior, aumentando com o tempo, indicando a provável liberação de lutécio-177 do complexo de DTPA.

A biodistribuição observada para o Acm quelado ao DTPA nas razões molares de 1:50 e 1:20, analisando-se principalmente o rápido clareamento sanguíneo (1:20), a baixa captação hepática e a persistente captação renal, são mais compatíveis com a 
biodistribuição do próprio DTPA- ${ }^{177} \mathrm{Lu}$, indicando provável instabilidade in vivo da conjugação do quelante ao Acm. Neste caso, entretanto, não se observou captação ósseo significante o que sugere que o ${ }^{177}$ Lu permaneceu ligado à estrutura do quelante DTPA e assim foi eliminado. Neste sentido, os estudos futuros deverão ser concentrados no DOTA-imunoconjugado particularmente o preparado no razão molar 1:20, que apresentou melhores resultados de estabilidade in vivo. Apesar dos estudos de ligação às células Raji indicaram a ligação específica dos derivados de DTPA obtidos com razões molares de 1:50 e 1:20, os estudos de biodistribuição constataram a instabilidade in vivo destas preparações radiomarcadas.

Os estudos futuros relacionados a ensaios de ligação às células Raji serão conduzidos para o derivado DOTA conjugado na razão molar 1:20. 
Tabela 21. Biodistribuição do rituximab-DTPA- ${ }^{177}$ Lu conjugado na razão molar 1:50, em diferentes tempos após a administração de 0,185 $\mathrm{MBq}$ do radioimunoconjugado em camundongos $B A L B / C$ sadios $(n=4)$

\% Atividade administrada (\%Al) e \% Atividade administrada/grama (\% Al/g)

$(\mathrm{N}=4)$

$1 \mathrm{~h}$

4 hs

24 hs

\begin{tabular}{cllllll}
\hline & $\%$ Al & $\%$ Al/g & $\%$ Al & $\%$ Al/g & $\%$ Al & $\%$ Al/g \\
\hline Coração & $4,1 \pm 0,5$ & $0,5 \pm 0,2$ & $3,6 \pm 0,1$ & $0,7 \pm 0,1$ & $2,7 \pm 0,4$ & $0,4 \pm 0,1$ \\
Pulmões & $3,2 \pm 0,5$ & $1,0 \pm 0,4$ & $3,0 \pm 0,3$ & $1,3 \pm 0,3$ & $2,2 \pm 0,6$ & $0,6 \pm 0,1$ \\
Baço & $4,0 \pm 1,2$ & $0,6 \pm 0,2$ & $3,9 \pm 1,2$ & $0,6 \pm 0,1$ & $3,3 \pm 0,7$ & $0,4 \pm 0,1$ \\
Estômago & $1,3 \pm 0,1$ & $0,5 \pm 0,1$ & $1,2 \pm 0,3$ & $0,5 \pm 0,1$ & $0,5 \pm 0,1$ & $0,3 \pm 0,0$ \\
Fígado & $7,6 \pm 0,7$ & $6,4 \pm 0,9$ & $5,9 \pm 1,2$ & $5,5 \pm 1,0$ & $4,5 \pm 0,5$ & $4,2 \pm 0,3$ \\
Rins & $5,5 \pm 0,4$ & $2,1 \pm 0,2$ & $5,7 \pm 1,4$ & $1,8 \pm 0,3$ & $4,1 \pm 0,2$ & $1,2 \pm 0,1$ \\
Intestinos & $2,8 \pm 0,7$ & $0,6 \pm 0,1$ & $2,5 \pm 0,8$ & $1,0 \pm 0,2$ & $1,6 \pm 0,4$ & $0,6 \pm 0,1$ \\
Músculo & $3,3 \pm 0,3$ & $0,5 \pm 0,1$ & $2,4 \pm 0,3$ & $1,0 \pm 0,2$ & $1,6 \pm 0,1$ & $0,6 \pm 0,2$ \\
Osso & $4,0 \pm 0,7$ & $2,7 \pm 0,5$ & $4,3 \pm 0,4$ & $1,7 \pm 0,3$ & $2,6 \pm 0,2$ & $1,0 \pm 0,1$ \\
\hline Sangue Total & $45,4 \pm 2,8$ & $16,9 \pm 2,4$ & $36,7 \pm 0,9$ & $15,8 \pm 1,4$ & $23,8 \pm 2,2$ & $14,5 \pm 1,9$ \\
\hline
\end{tabular}




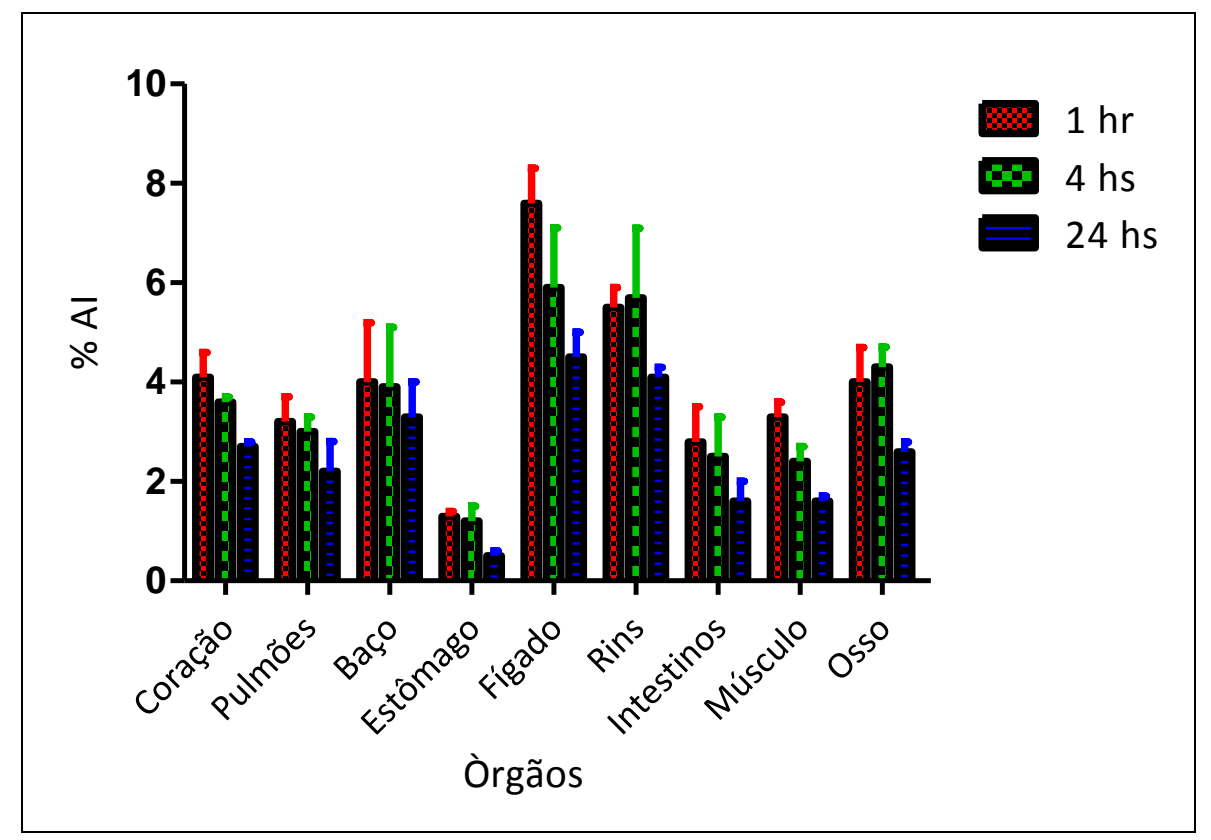

Figura 26. Biodistribuição (em \% de atividade captada pelo tecido ou órgão) do rituximab-DTPA- ${ }^{177}$ Lu (1:50) em camundongos $B A L B / C$ sadios

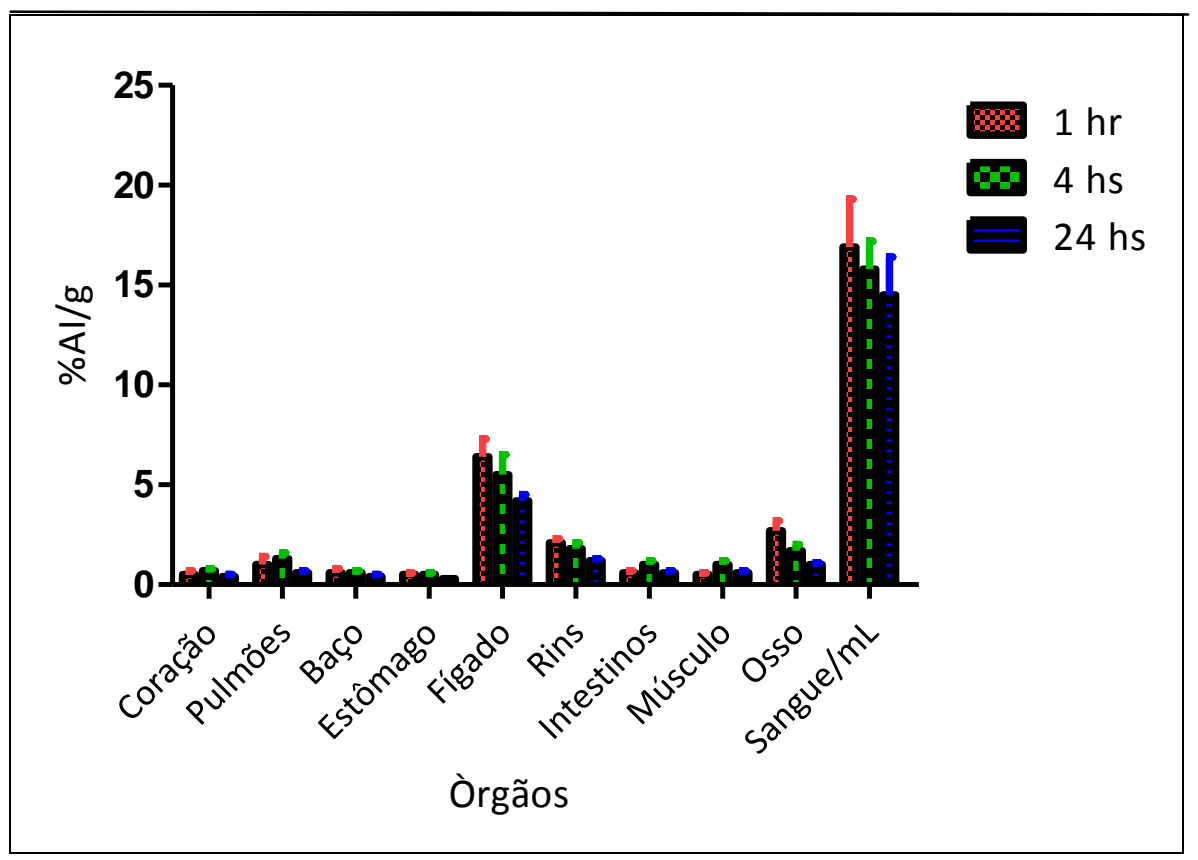

Figura 27. Biodistribuição (em \% de atividade captada por grama do tecido ou órgão) do rituximab-DTPA- ${ }^{177} \mathrm{Lu}(1: 50)$ em camundongos $B A L B / C$ sadios 
Tabela 22. Biodistribuição do rituximab-DTPA- ${ }^{177}$ Lu conjugado na razão molar 1:20, em diferentes tempos após a administração de 0,185 $\mathrm{MBq}$ do radioimunoconjugado em camundongos $B A L B / C$ sadios $(n=4)$

\% Atividade administrada (\%Al) e \% Atividade administrada/grama (\% Al/g)

$(\mathrm{N}=4)$

$1 \mathrm{~h}$

4 hs

24 hs

\begin{tabular}{cllllll}
\hline & $\%$ Al & $\%$ Al/g & $\%$ Al & $\%$ Al/g & $\%$ Al & $\%$ Al/g \\
\hline Coração & $2,2 \pm 0,5$ & $0,3 \pm 0,1$ & $1,3 \pm 0,3$ & $0,2 \pm 1,2$ & $1,0 \pm 0,2$ & $0,2 \pm 0,0$ \\
Pulmões & $2,9 \pm 0,8$ & $1,3 \pm 0,5$ & $2,1 \pm 0,2$ & $0,5 \pm 0,1$ & $1,1 \pm 0,6$ & $0,3 \pm 0,1$ \\
Baço & $2,0 \pm 0,6$ & $0,3 \pm 0,1$ & $0,9 \pm 0,3$ & $0,2 \pm 0,0$ & $0,6 \pm 0,1$ & $0,2 \pm 0,1$ \\
Estômago & $0,7 \pm 0,2$ & $0,3 \pm 0,1$ & $0,5 \pm 0,2$ & $0,2 \pm 0,1$ & $0,4 \pm 0,1$ & $0,2 \pm 0,1$ \\
Fígado & $4,4 \pm 0,5$ & $3,8 \pm 0,6$ & $3,8 \pm 0,3$ & $2,6 \pm 0,4$ & $3,0 \pm 0,1$ & $2,0 \pm 0,3$ \\
Rins & $5,4 \pm 0,4$ & $1,5 \pm 0,4$ & $2,5 \pm 1,4$ & $1,4 \pm 0,2$ & $1,8 \pm 0,2$ & $1,1 \pm 0,2$ \\
Intestinos & $1,4 \pm 0,5$ & $0,8 \pm 0,3$ & $1,2 \pm 0,2$ & $0,6 \pm 0,1$ & $1,1 \pm 0,5$ & $0,4 \pm 0,1$ \\
Músculo & $1,8 \pm 0,2$ & $0,4 \pm 0,1$ & $1,3 \pm 0,3$ & $0,3 \pm 0,1$ & $0,9 \pm 0,2$ & $0,2 \pm 0,1$ \\
Osso & $3,2 \pm 1,0$ & $1,5 \pm 0,2$ & $1,6 \pm 0,5$ & $0,5 \pm 0,1$ & $1,4 \pm 0,4$ & $0,4 \pm 0,2$ \\
\hline Sangue Total & $14,4 \pm 1,1$ & $1,5 \pm 0,2$ & $8,9 \pm 2,6$ & $1,1 \pm 0,3$ & $5,0 \pm 0,5$ & $0,8 \pm 0,1$ \\
\hline
\end{tabular}




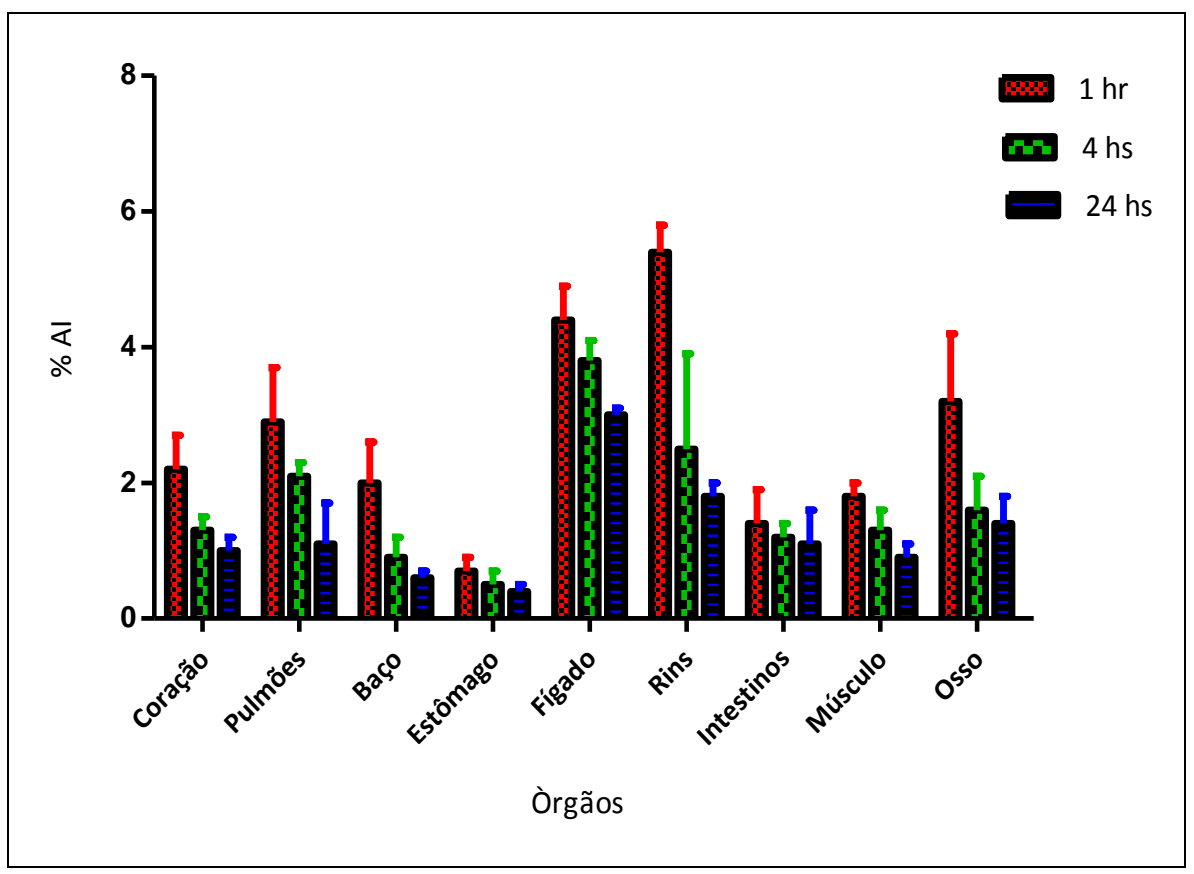

Figura 28. Biodistribuição (em \% de atividade captada pelo tecido ou órgão) do rituximab-DTPA- ${ }^{177}$ Lu (1:20) em camundongos $B A L B / C$ sadios

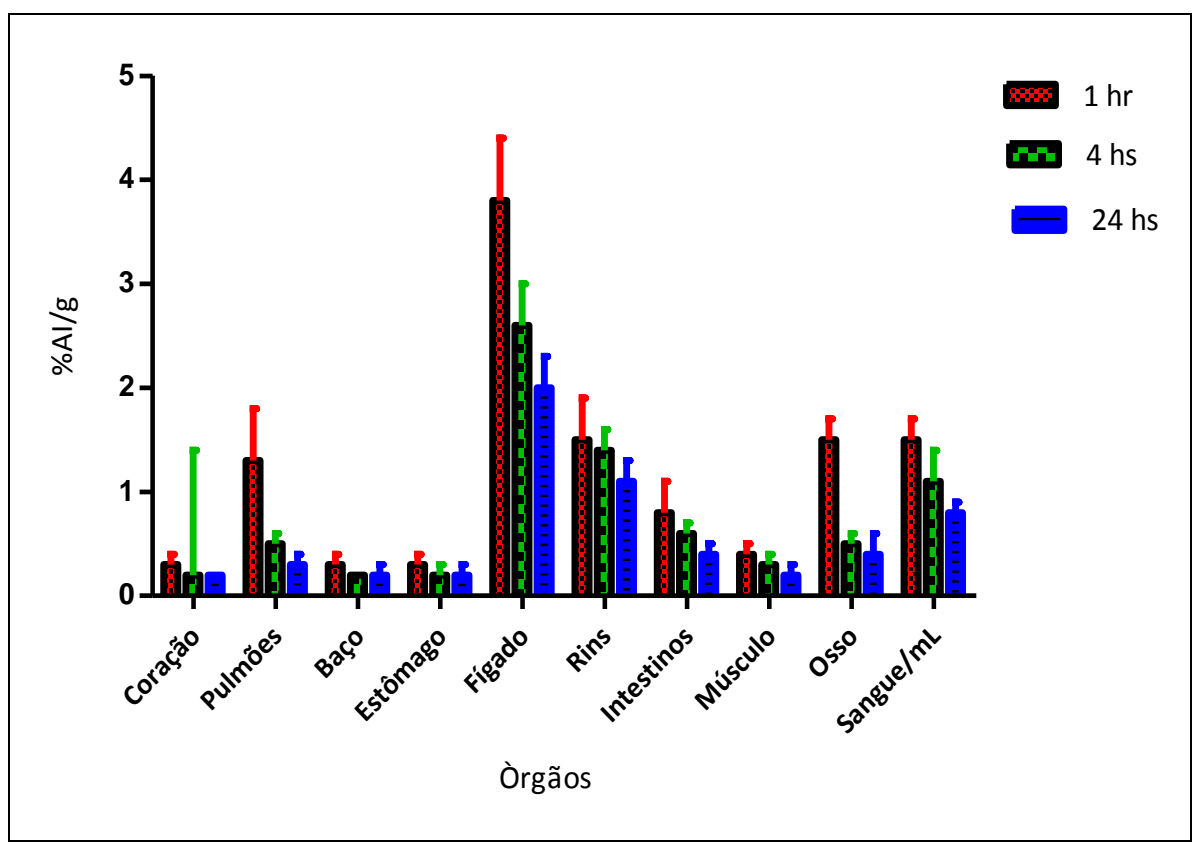

Figura 29. Biodistribuição (em \% de atividade captada por grama do tecido ou órgão) do rituximab-DTPA- ${ }^{177}$ Lu $(1: 20)$ em camundongos $B A L B / C$ sadios 
Tabela 23. Biodistribuição do rituximab-DTPA- ${ }^{177}$ Lu conjugado na razão molar 1:10, em diferentes tempos após a administração de 0,185 $\mathrm{MBq}$ do radioimunoconjugado em camundongos $B A L B / C$ sadios $(n=4)$

$\%$ Atividade administrada (\%Al) e \% Atividade administrada/grama (\% Al/g)

$(\mathrm{N}=4)$

$1 \mathrm{~h}$

4 hs

24 hs

\begin{tabular}{ccccccc}
\hline & $\% \mathbf{A l}$ & $\% \mathbf{A l} / \mathbf{g}$ & $\% \mathbf{A l}$ & $\% \mathbf{A l} / \mathbf{g}$ & $\% \mathbf{A l}$ & $\% \mathbf{A l} / \mathbf{g}$ \\
\hline Coração & $1,9 \pm 0,6$ & $0,2 \pm 0,1$ & $1,5 \pm 0,6$ & $0,3 \pm 0,1$ & $1,1 \pm 0,2$ & $0,1 \pm 0,0$ \\
Pulmões & $2,4 \pm 0,2$ & $0,5 \pm 0,1$ & $1,7 \pm 0,4$ & $0,4 \pm 0,1$ & $1,4 \pm 0,1$ & $0,1 \pm 0,0$ \\
Baço & $33,1 \pm 1,5$ & $2,1 \pm 0,4$ & $23,7 \pm 1,4$ & $2,2 \pm 0,4$ & $23,2 \pm 1,4$ & $1,5 \pm 0,5$ \\
Estômago & $0,9 \pm 0,2$ & $0,3 \pm 0,0$ & $0,9 \pm 0,1$ & $0,3 \pm 0,1$ & $0,8 \pm 0,3$ & $0,1 \pm 0,0$ \\
Fígado & $27,6 \pm 2,9$ & $15,8 \pm 3,1$ & $23,1 \pm 1,6$ & $13,7 \pm 0,5$ & $14,6 \pm 1,6$ & $12,5 \pm 1,9$ \\
Rins & $8,5 \pm 2,1$ & $2,5 \pm 0,3$ & $7,6 \pm 0,7$ & $2,2 \pm 0,4$ & $6,3 \pm 0,4$ & $0,8 \pm 0,1$ \\
Intestinos & $1,7 \pm 0,2$ & $0,5 \pm 0,1$ & $1,1 \pm 0,1$ & $0,5 \pm 0,1$ & $0,5 \pm 0,1$ & $0,3 \pm 0,1$ \\
Músculo & $2,7 \pm 0,7$ & $0,5 \pm 0,2$ & $2,3 \pm 0,3$ & $0,5 \pm 0,1$ & $1,4 \pm 0,5$ & $0,3 \pm 0,1$ \\
Osso & $9,0 \pm 0,2$ & $3,4 \pm 0,5$ & $9,0 \pm 0,2$ & $3,5 \pm 0,5$ & $22,2 \pm 2,6$ & $9,3 \pm 2,3$ \\
\hline Sangue Total & $6,9 \pm 1,0$ & $6,8 \pm 1,1$ & $5,6 \pm 0,4$ & $4,2 \pm 0,7$ & $2,6 \pm 0,6$ & $1,9 \pm 0,4$ \\
\hline
\end{tabular}




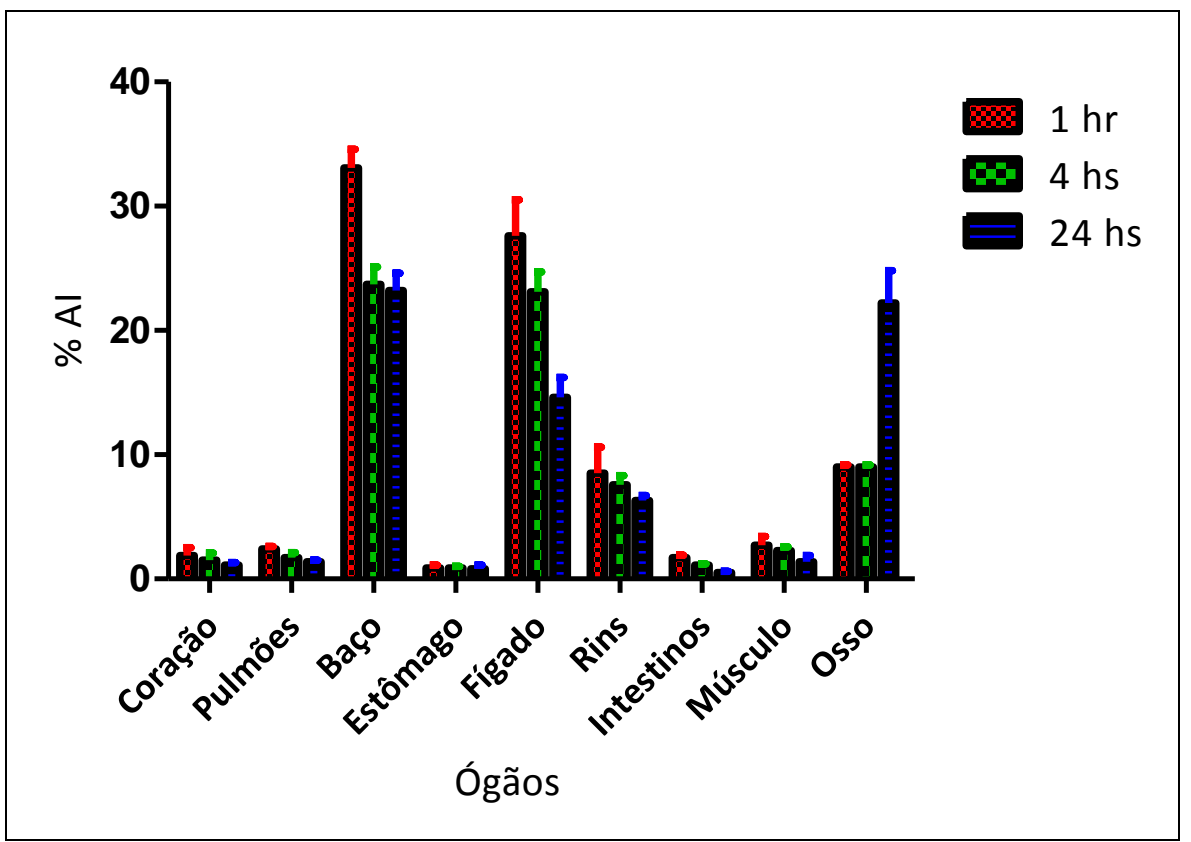

Figura 30. Biodistribuição (em \% de atividade captada pelo tecido ou órgão) do rituximab-DTPA ${ }^{177}$ Lu $(1: 10)$ em camundongos $B A L B / C$ sadios

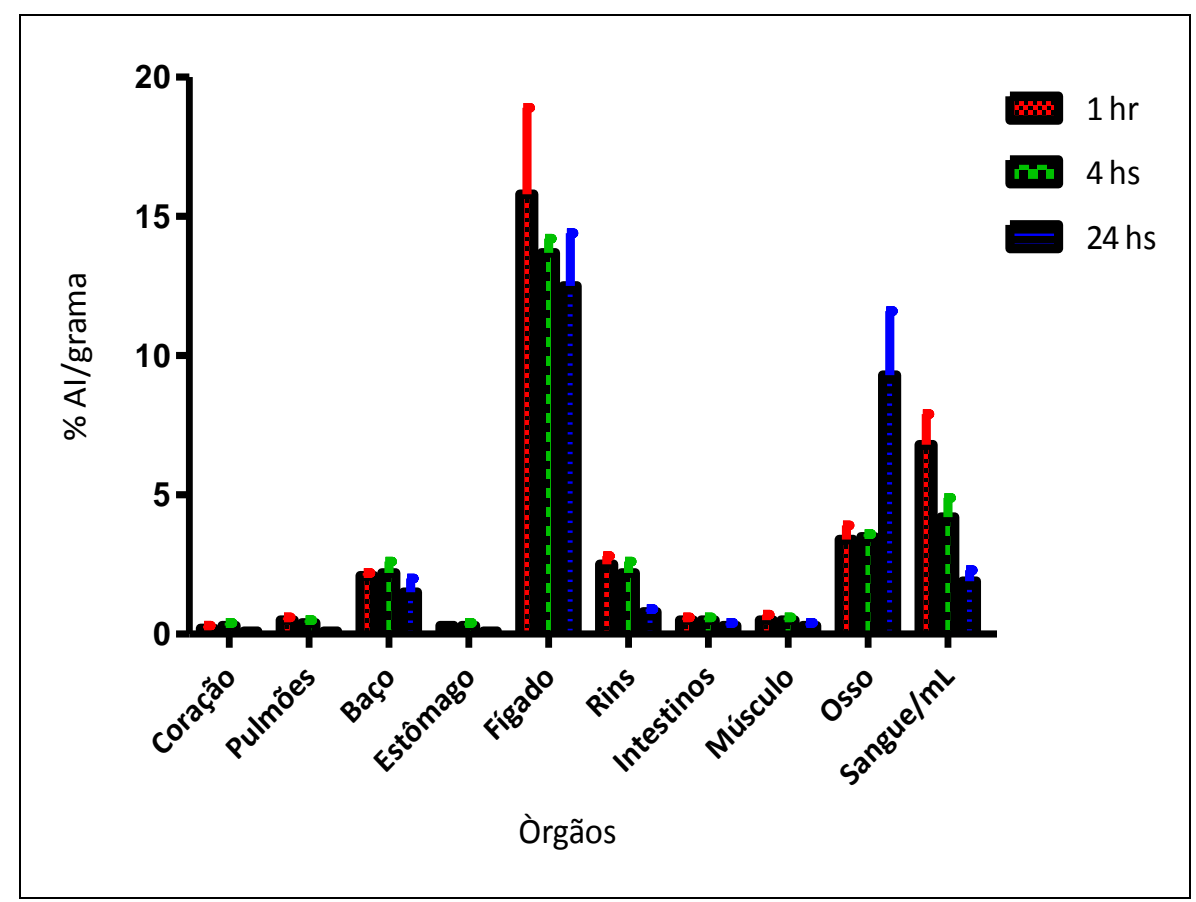

Figura 31. Biodistribuição (em \% de atividade captada por grama do tecido ou órgão) do rituximab-DTPA- ${ }^{177}$ Lu $(1: 10)$ em camundongos $B A L B / C$ sadios 


\section{CONCLUSÕES}

a) A purificação prévia do anticorpo monoclonal anti-CD20 rituximab (MabThera ${ }^{\circledR}$ ) é necessária e importante para remoção de possíveis impurezas presentes na solução original que interferem no procedimento de conjugação, possibilitando ainda a troca da solução original pelo tampão de conjugação.

b) A metodologia de ultrafiltração foi considerada a mais eficiente na prépurificação do anticorpo monoclonal sendo simples prática e podendo ser aplicada a procedimentos rotineiros de produção de radiofármacos.

c) A metodologia empregada na determinação do número de grupamentos quelantes acoplados à molécula do anticorpo foi útil para monitorar as condições de conjugação. Entretanto poderá ser modificada, caso haja disponibilidade de equipamentos específicos como espectrômetro de massa, com ganho na determinação mais precisa da quantidade de grupamentos quelantes incorporados à molécula, possibilitando o estudo de estabilidade do anticorpo conjugado.

d) Foi apresentada, no estudo de método de purificação do anticorpo conjugado, uma abordagem inédita, na qual a cromatografia de exclusão molecular foi combinada com a ultrafiltração resultando em eficiência na purificação e preservação da estrutura do anticorpo.

e) Os estudos de radiomarcação demonstraram que os imunoconjugados utilizando quelante DTPA apresentaram, de forma geral, maior eficiência de marcação, com resultados mais reprodutíveis quando comparados com imunoconjugados que utilizaram DOTA como quelante bifuncional, considerando-se as diferentes razões molares utilizadas.

f) As metodologias cromatográficas (papel e camada delgada), empregadas no controle de pureza radioquímica do composto conjugado e radiomarcado demonstraram-se adequadas e eficientes, de forma combinada, pois 
proporcionaram a discriminação das três possíveis espécies radioquímicas no meio de marcação.

g) A metodologia de purificação do composto conjugado e radiomarcado utilizando coluna de exclusão molecular Sephadex G-25 (PD-10), demonstrou-se apropriada e eficiente na separação do produto marcado do lutécio livre ou outras prováveis espécies presentes no meio de marcação.

h) O ensaio de ligação específica dos compostos conjugados e radiomarcados às células tumorais deverão ser aprofundados, considerando-se concentrações celulares mais adequadas. Recomenda-se ainda a realização de ensaios de competição in vitro.

i) Os resultados obtidos nos estudos de biodistribuição in vivo do anticorpo conjugado e radiomarcado nem sempre se mostraram compatíveis com a biodistribuição de anticorpos radiomarcados íntegros. No caso do quelante DOTA, o imunoconjugado obtido a partir da razão molar 1:20, apresentou melhores características de biodistribuição. No caso do quelante DTPA, a razão molar utilizada pareceu refletir diretamente no clareamento sanguíneo do anticorpo e todos os razões molares utilizadas apresentaram instabilidade in vivo.

j) Os resultados apresentados neste estudo demonstraram a viabilidade de formulação de um radiofármaco com potencialidade para aplicação na terapia do linfoma não-Hodgkin pelo princípio de radioimunoterapia, baseado na conjugação de rituximab ao quelante DOTA, que possibilitará a continuidade dos estudos para disponibilizar um radiofármaco para tratamento de neoplasias de células-B de LNH. 


\section{REFERÊNCIAS BIBLIOGRÁFICAS}

1. Associação Brasileira de Linfoma e Leucemia (ABRALE). Os linfomas: Linfoma de Hodgkin, e Linfoma Não-Hodgkin. Disponível em: <http://www. abrale.org. br /conteudo_view.asp?>. Acesso em: 18 out. 2012.

2. Instituto Nacional do Câncer (INCA). Estimativa /2012 - Incidência de câncer no Brasil. Disponível em: <http://www.inca.gov.br/conteudo_view.asp?id=457>. Acesso em: 18 out. 2012.

3. Jemal, A.DVM, PhD; Bray, F,PhD; Center, M.M, MPH; Ferlay, J, ME; Ward, E,PhD; Forman, D, PhD. Global Cancer Statistics. CA Cancer J Clin., v.61, p.69-90, 2011.

4. Akanji, A.G. Estudo de marcação com iodo-131 de anticorpo monoclonal antiCD20 usado na terapia de linfoma não-Hodgkin. Dissertação (Mestrado) Instituto de Pesquisas Energéticas e Nucleares, São Paulo, 2007.

5. Massicano, A.V.F. Estudo da conjugação e radiomarcação do anticorpo monoclonal rituximab para aplicação em terapia radionuclídica. Dissertação (Mestrado) - Instituto de Pesquisas Energéticas e Nucleares, São Paulo, 2011.

6. Araújo, L.H.L.; Victorino, A.P.O.S.; Melo, A.C.; Assad, D.X.; Lima, D.S.; Alencar, D.R.; Moreira, M.M.L.; Filho, O.M.; Coelho, R.F.S.; Asmar, S.B.; Pereira, B.S.V.; Scheliga, A. Linfoma Não-Hodgkin de alto grau - Revisão da literatura. Revista Brasileira de Cancerologia, v. 54 p. 175-183, 2008.

7. McLaughlin, P. Monoclonal Antibodies. Crit Rev in Oncol/Hematol., v. 40, p. 316, 2001.

8. Cersosimo, R.J. Monoclonal antibodies in the treatment of cancer, part 1. Am J Health-Syst Pharm., v. 60, p. 1631-1548, 2003.

9. Rose, A.L.; Smith, B.E.; Maloney, D.G. Glucocorticoids and rituximab in vitro: synergistic direct antiproliferative and apoptotic effects. Blood., v. 100, p. 1765-1773, 2002. 
10. Kaminski, M.S.; Ester, J.; Zasadry, K.R.; Francis, I.R.; Ross, C.W.; Tuck, M.; Regan, D.; Fisher, S.; Gutierrez, J.; Kroll.S.; Stagg, R.; Tidmarsh, G.; Wahl, R.L. Radioimmunotherapy with iodine ${ }^{131}$ I tositumomab for relapsed or refractory B-cell non-Hodgkin lymphoma: updated results and long-term follow-up of the University of Michigan experience. Blood., v. 96, p. 1259-1266, 2000.

11. Chinn, P.; Braslawsky, G.; White, C. Antibody therapy of non-Hodgkin's B-cell Iymphoma. Cancer Immunol Immunother., v. 52, p. 257-280, 2003.

12. DeNardo, G.L. MD; Sysko, V.V.; DeNardo, S.J. M.D. Cure of incurable Lymphoma. Int. J. Radiat Oncol Biol. Phys., v.66, n. 2, p. 546-556, 2006.

13. Skvortsova, I.; Popper, B.A.; Skvortsov, S.; Saurer, M.; Auer, T.; Moser, R.; Kamleitner, M.; Zwierzina, H.; Lukas, P. Pretreatment with Rituximab Enhances Radiosensitivity of NonHodgkin's Lymphoma Cells. J. Radiat. Res., v. 46, p. 241248, 2005.

14. Press, O.W.; Leonard, J.P.; Coiffier, B.; Levy, R.; Timmerman, J. Immunotherapy of Non-Hodgkin's Lymphomas. American Society of Hematology., v. , p. 221240, 2001.

15. Rajendran, J.G. Radioimmunotherapy for the $21^{\text {st }}$ century: An Old Approach with a New Paradigm. Int J Nucl Med., v. 3, p. 81-88, 2004.

16. Juweid, M.E. MD. Radioimmunotherapy of B-Cell Non-Hodgkin's Lymphoma: From Clinical Trials to Clinical Practice. J Nucl Med., v. 43, p. 1507-1529, 2002.

17. Pagel, J.M.; Pantelias, A.; Hedin, N.; Wilbur, S.; Saganic, L.; Lin, Y.; Axworthy, D.; Hamlin, D.K.; Wilbur, D.S.; Gopal, A.K.; Press, O.W. Evaluation of CD20, and CD22, and HLA-DR Targeting for Radioimmunotherapy of B-Cell Lymphomas. Cancer Res., v., 12, p. 5921-5928, 2007.

18. Goldenberg, D.M. ScD., MD. Targeted Therapy of Cancer with Radiolabeled Antibodies. J Nucl Med., v. 43, p. 693-713, 2002. 
19. Hernandez, M.C. MD.; Knox, S.J. PhD., MD. Radiobiology of Radioimmunotherapy: Targeting CD20 B-Cell Antigen in Non-Hodgkin's Lymphoma. Int J. Radiation Oncology Biol. Phys., v. 59, n. 5, p. 1274-1287, 2004.

20. Behr, Th.M.; Gotthard, M.; Becker, W.; Béhé, M. Radioiodination of monoclonal antibodies, proteins and peptides for diagnosis and therapy. Nuclearmedizin., v. 41, p. 71-9, 2002.

21. Dixon, K.L. The radiation biology of radioimmunotherapy. Nuclear Medicine Communications., v. 24, p. 951-957, 2003.

22. Verel, I.M.S; Visser, G.W.M. PhD.; Boellaard, R. PhD.; Walsum, M.S. BSc.; Snow, G.B. MD., PhD.; Dongen, G.A.M.S. PhD. ${ }^{89} \mathrm{Zr}$ Immuno-PET: Comprehensive Procedures for Production of ${ }^{89} \mathrm{Zr}$-Labeled Monoclonal Antibodies. J Nucl Med., v. 44, p. 1271-1281, 2003.

23. Perk, L.R, MSc.; Visser, G.W.M, PhD.; Vosjan, M.J.W.D, BSc.; Walsum, M.S. BSc.; Tijink, B.M, MD.; Leemans, C.R, MD, PhD.; Dongen, A.M.S, PhD. ${ }^{89} \mathrm{Zr}$ as a PET Surrogate Radioisotope for Scouting Biodistribution of the Therapeutic Radiometals ${ }^{90} \mathrm{Y}$ and ${ }^{177} \mathrm{Lu}$ in Tumor-Bearing Nude Mice After Coupling to the Internalizing Antibody Cetuximab. J Nucl Med., v. 46, p. 1896-1906, 2005.

24. Zhu, H.; Baxter, L.T.; Jain, R.K. Potential and Limitations of Radioimmunodetection and Radioimmunotherapy with Monoclonal Antibodies. J Nucl Med., v. 38, p. 731-741, 1997.

25. Vallabhajosula, S. PhD.; Goldsmith, S.J. MD.; Hamacher, K.A. PhD.; Kostakoglu, L. MD.; Konishi, S. MD.; Milowski, M.I. MD.; Nanus, D.M. MD.; Bander, N.H. MD. Prediction of Myelotoxicity Based on Bone Marrow Radiation-Absorbed Dose: Radioimmunotherapy Studies Usaing ${ }^{90} \mathrm{Y}$ - and ${ }^{177} \mathrm{Lu}$ - Lbeled J591 Antibodies Specific for Prostate-Specific Membrane Antigen. J Nucl Med., v. 46, p. 850858, 2005. 
26. Mulligan, T.; Carrasquillo, J.A.; Chung, Y.; Milenic, D.I.; Schlom, J.; Feuerstein, I.; Paik, C.; Perentesis, P.; Reynolds, J.; Curt, G.; Goeckeler, W.; Fordyce, W.; Cheng, R.; Riseberg.; D.; Cowan, K.; O'Shaughnessy, J. Phase I Study of Intravenous ${ }^{177}$ Lu-labeled CC49 Murine Monoclonal Antibody in Patients with Advanced Adenocarcinoma. Clinical Cancer Research., v.1, p. 1447-1454, 1995.

27. Tempero, M.; Leichner, P.; Kortylewicz, J.B.; Harrison, K.; Augustine, S.; Schlom, J.; Anderson, J.; Wisecarver, J.; Colcher, D. High-Dose Therapy with ${ }^{90}$ Yttriumlabeled Monoclonal Antibody CC49: A Phase I Trial. Clinical Cancer Research., v.6, p. 3095-3102, 2000.

28. DeNardo, G.L. et al. Radiation dosimetry. Cancer Biother Radiophar., v. 17, p.107-118, 2002.

29. Witzig, Th.E.; Gordon, L.I.; Cabanillas, F.; Czuczman, M.S.; Emmanouilides, C.; Joyce, R.; Pohlman, B.L.; Bartlet, N.L.; Wiseman, G.A.; Padre, N.; Grillo-Lopez, A.J.; Multani, P.; White, C.A. Randomized Controlled Trial of Yttrium-90-Labeled Ibritumomab Tiuxetan Radioimmunotherapy Versus Rituximab Immunotherapy for Patients With Relapsed or Refractory Low-Grade, Follicular, or Transformed B-cell Non-Hodgkin's Lymphoma. J Clin Oncol., v. 20, p. 2453-2463, 2002.

30. Davies, A.J.; Rohatiner, A.Z.S.; Howel, S.; Britton, K.E.; Owens, S.E.; Micallef, I.N.; Deakin, D.P.; Carrington, B.M.; Lawrence, J.A.; Vinnicombe, S.; Mather, S.J.; Clayton, J.; Foley, R.; Jan, H.; Kroll, S.; Harris, M.; Amess, J.; Norton, A.J.; Lister, T.A.; Radford, J.A. Tositumomab and lodine ${ }^{131}$ I Tositumomab for Recurente Indolente and Transformed B-Cell Non-Hodgkin's Lymphoma. J Clin Oncol., v. 22, n. 8, p. $1469-1479,2004$.

31. Goldsmith, S.J. MD. Radioimmunotherapy of Lymphoma: Bexxar and Zevalin. Semin Nucl Med., v. 40, p. 122-135, 2010.

32. DeNardo, G.; DeNardo, S. MD. Dose Intensified Molecular Targeted Radiotherapy for Cancer-Lymphoma as a Paradigm. Semin Nucl Med., v. 40, p. 136-144, 2010. 
33. Fink-Bennett, D.M.MD.; Thomas, K. MHA, CNMT. ${ }^{90}$ Y-Ibritumomab Tiuxetan in the Treatment of Relapsed or Refractory B-Cell Non-Hodgkin's Lymphoma. J Nucl Med Technol., v. 31, p. 61-68, 2003.

34. Wahl, R.L. MD. Tositumomab and ${ }^{131}$ I Therapy in Non-Hodgkin's Lymphoma. J Nucl Med., v. 46, p. 128S-140S, 2005.

35. Hens, M.; Vaidyanathan, G.; Welsh, P.; Zalutsky, M. Labeling internalizing antiepidermal growth factor receptor variant III monoclonal antibody with ${ }^{177} \mathrm{Lu}$ : in vitro comparison of acyclic and macrocyclic ligands. Nucl Med and Biol., v. 36, p. 117-128, 2009.

36. Lewis, M.R.; Kao, J.Y.; Anderson, A.J.; Shively.; Raubitschek. A. An improved Method for Conjugating Monoclonal Antibodies with NHydroxysulfosuccinimidyl DOTA. Bioconjugate Chem., v. 12, p. 320-324, 2001.

37. Forrer, F.; Chen, j.; Fani, M.; Powell, P.; Lohri, A.; Muller-Brand, J.; Moldenhauer, G.; Maecke, H.R. In vitro characterization of ${ }^{177}$ Lu-radiolabeled chimeric anti-CD20 monoclonal antibody and a preliminary dosimetry study. Eur J Nucl Med Mol. Imaging., v. 36, n. 9, p. 1443-1452, 2009.

38. Stein, R.; Govindan, S.V.; Chen, S.; Reed, L.; Richel, H.; Griffiths, G.L.; Hansen, H.J.; Goldenberg, D.M. Radioimmunotherapy of a Human Lung Cancer Xenograft with Monoclonal Antibody RS7: Evaluation of ${ }^{177} \mathrm{Lu}$ and Comparison of Its Efficacy with That of ${ }^{90} \mathrm{Y}$ and Residualizing ${ }^{131}$ I. J. Nucl Med., v. 42, p. 967974, 2001.

39. Mohsin, H.; Jia, F.; Sivaguru, G.; Hudson, M.J.; Shelton, T.D.; Hoffman, T.J.; Cutler, C.S.; Ketring, A.R.; Athey, P.S.; Simon, J.; Frank, R.K.; Jurisson, S.S.; Lewis, M.R. Radiolanthanide-Labeled Monoclonal Antibody CC49 for Radioimmunotherapy of Cancer: Bilogical Comparison of DOTA Conjugates and ${ }^{149} \mathrm{Pm},{ }^{166} \mathrm{Ho}$, and ${ }^{177} \mathrm{Lu}$. Bioconjugate Chem., v. 17, p. 485-492, 2006.

40. Mohsin, H.; Fitzsimmons, J.; Shelton, T.; Hoffman, T.J.; Cutler, C.S.; Lewis, M.R.; Athey, P.S.; Gulyas, G.; Kiefer, G.E.; Frank, K.R.; Simon, J.; Lever, S.Z.; Jurisson, 
S.S. Preparation and biological evaluation of ${ }^{111} \mathrm{In}-,{ }^{177} \mathrm{Lu}$ - and ${ }^{90} \mathrm{Y}$-labeled DOTA analogues conjugated to B72.3. Nucl Med and Biol., v. 34, p. 493-502, 2007.

41. Jalilian, A.R.; Mirsadeghi, L.; Kamali-dehghan, L.; Moradhhani, S.; Saddahi, F. Preparation and Quality Control of Radiometal-DOTA-Rituximab. World J. Nucl Med., v. 7, p.135-141, 2008.

42. Milenic, D.E.; Garmestanik, Chappell, L.L. et al. In Vivo Comparison of macrocyclic and acyclic ligands for radioimmunotherapy of Mabs with ${ }^{177} \mathrm{Lu}$ for RIT therapeutic applications. Nucl Med Biol., v. 29, p.431-442, 2002.

43. Cooper, M.S.; Sabbah, E.; Mather, S.J. Conjugation of chelating agents to proteins and radiolabeling with trivalent metallic isotopes. Nature Protocols., v. 1, n. 1, p. 314-317, 2006.

44. Nikula, T.K.; Curcio, M.J.; Brechbiel, M.W.; Gansow, O.A.; Finn, R.D.; Sheinberg, Rajendran, J.G. Radioimmunotherapy for the $2^{1 \text { st }}$ century: An Old Approach with a New Paradigm. Int J Nucl Med., v. 3, p. 81-88, 2004.

45. Smith-Jones, P.M.; Vallabhajosula, S.; Goldsmith, S.J.; Navarro, V.; Hunter, C.J.; Bastidas, D.; Bader, N.H. In vitro Characterization of Radiolabeld Monoclonal Antibodies Specific for the Extracellular Domain of Prostrate-specific Membrane Antigen. Cancer Research., v. 60, p, 5237-5243, 2000.

46. Schlom, J.S.K.; Milenic, D.E.; Eggersperger, D.; Colcher, D.; Miller, L.S.; Houchens, D.; Cheng, R.; Kaplan, D.; Goeckeler, W. Monoclonal antibody-based therapy of a human tumor xenogaft with a ${ }^{177}$ Lutetium-labeled immunoconjugate. Cancer Res., v. 51, p.2889-2896, 1991.

47. Meredith, R.F.; Partridge, E.E.; Alvarez, R.D.; Khazacli, M.B.; Plott, G.; Russell, C.D.; Wheeler, R.H.; Liu, T.; Grizzle, W.E.; Schlom, J.; LoBuglio, A.F. Intraperitonial radioimmunotherapy of ovarian câncer with lutetium-177-CC49. J. Nucl. Med., v. 37, p. 1491-1496, 1996. 
48. Tran, T.H. Pharmaceutical development and clinical application of radiolabeled rituximab. Gildeprint Drukkerijen, Enschede, The Netherlands. ISBN/EAN 97890122881, 2009. Cap. 1, p. 13-35.

49. Grillo-Lopez. Biotech 21 - Into the next decade. In: Pharmaceutical Biotechnology, Drug Discovery and Clinical Applications. Wiley-VCH verlag GmbH \& co. 2004. Cap IV, p. 213-229.

50. Jalilian, A. R.; Radfar, R.; Yousefnia, H.; Samani, A. B.; Maragheh, A. D. A comparative study of preliminary dosimetry for human based on distribution data in rats with ${ }^{111} \mathrm{I},{ }^{90} \mathrm{Y},{ }^{153} \mathrm{Sm}$, and ${ }^{177}$ Lu labeled rituximab. Nucl Tech \& Radiation Protection. v. 27, n. 2, p. 144-151, 2012.

51. Reff, M. E.; Carner, K.; Chambers, K. S. et al. Review of the preclinical data on rituximab. Blood., v. 83, n. 2, p. 435-445, 1994.

52. Coiffier, B.; Lepage, E.; Briére, J. et al. Key article on the new "gold standard" in the therapy of aggressive NHL. N. Engl. J. Med., v. 346, n. 4, p. 235-242, 2002.

53. Davis, T. A., Maloney, D. G.; Grillo- López, A. J. et al. Clin. Cancer Res., v. 6, p. 2644-2652, 2000.

54. Sacchi, S.; Frederico, M.; Vitolo, U. et al., Haematologica., v.86, p. 951-958, 2001.

55. Demidem, A.; Lam, T.; Alas, S. et al. Cancer Biother. Radiopharm., v. 12, n. 3, p. 177-185, 1997.

56. A. J. Grillo-L'opez. Expert Rev. Anticancer Ther., v. 2, n. 5, p. 485-493, 2002.

57. Jalilian, A. R.; Radfar, R.; Yousefnia, H.; Samani, A. B.; Maragheh, A. D. A comparative study of preliminary dosimetry for human based on distribution data in rats with ${ }^{111} \mathrm{I},{ }^{90} \mathrm{Y},{ }^{153} \mathrm{Sm}$, and ${ }^{177} \mathrm{Lu}$ labeled rituximab. Nucl Tech \& Radiation Protection., v. 27, n. 2, p. 144-151, 2012. 
58. Audicio, P. F.; Castellano, G.; Tassano, M. R.; Rezzano, M. E.; Fernandez, M.; Riva, E.; Robles, A.; Cabral, P.; Balter, H.; Oliver, P. ${ }^{177}$ Lu-DOTA-anti-CD20: Labeling and pré-clinical studies. Applied Radiation and Isotopes., v. 69, p. 924928, 2011.

59. Shuang Liu. Bifunctional coupling agents for radiolabeling of biomolecules and target-specific delivery of metallic radionuclides. Advanced Drug Delivery Reviews., v. 60, p. 1347-1370, 2008.

60. Volkert, W.A.; Hoffman, T.J. Therapeutic radiopharmaceuticals. Chem. Rev., v. 99, p. 2269-2292, 1999.

61. Carroll, V.; Demoin, D.W.; Hoffman, T.J.; Jurisson, S.S. Inorganic chemistry in nuclear imaging and radiotherapy: current and future directions. Radiochim. Acta., v. 100, p. 653-667, 2012.

62. Hens, M.; Vaidyanathan, G.; Zhao, Z-G.; Binger, D. D.; Zalutsky, M. Anti-EGFRvIII monoclonal antibody armed with ${ }^{177} \mathrm{Lu}$ : in vivo comparison of macrocyclic and acyclic ligands. Nucl Med and Biology., v. 37, p. 741-750, 2010.

63. Knogler, K.; Grünberg, J.; Novak-Hofer, I.; Zimmermann, K.; Schubiger, P.A. Evaluation of ${ }^{177}$-Lu-DOTA-labeled aglycosilated monoclonal anti-L1-CAM antibody chCE7: influence of the number of chelators on the in vitro and in vivo properties. Nucl Med and Biology., v. 33, p. 883-889, 2006.

64. Waentig, L.; Jakubowski, N.; Hardt, S.; Scheler, C.; Roos, P.H.; Linscheid, M.W. Comparison of different chelates for lanthanide labeling of antibodies and application in a Western blot immunoassay combined with detection by laser ablation (LA-) ICP-MS. J. Anal. At Spectrom., v. 27, p. 1311-1320, 2012.

65. Brom, M.; Joostern, L.; Oyen, W. JG.; Gotthardt, M.; Boerman, O. Improved labeling of DTPA- and DOTA- conjugated peptides and antibodies with ${ }^{111}$ In in HEPES and MES buffer. Eur Jorn Nucl Med \& Mol Imag., v. 2, n. 4, p. 2-11, 2012. 
66. Liu, S.; Edward, E.S. Fundamentals of receptor-based diagnostic metalloradiophamaceuticals. Top curr chem., v.222, p. 259-278, 2002.

67. Liu, S.; Edward, E.S. Bifunctional chelators for target-specific therapeutic lanthanide radiopharmaceuticals. Bioconjug chem., v. 12, p. 7-34, 2001.

68. Durbin, P.W. Metabolic characteristics within a chemical family. Health Phys., v.2, p. 225-238, 1960.

69. Brechbiel, M.W. Bifunctional chelates for metal nuclides. Q. J. Nucl Med. Imaging., v. 52, p. 166-173, 2008.

70. Liu, S.; Pietryka, J.; Ellas, C.E.; Edwards, D.S. Comparison of yttrium and indium complexes of DOTA-BA and DOTA-MBA: models for ${ }^{90} \mathrm{Y}$ and ${ }^{111} \mathrm{In}$-labeled DOTAbiomolecule conjugates. Bioconjug. Chem., v. 13, p. 902-913, 2002.

71. Kukis, D.L.; DeNardo, S.J.; DeNardo, G.L.; Donnell, R.T.O.; Meares, L.F. Optimized conditions for chelation of yittrium-90-DOTA immunoconjugates. J. Nucl Med., v. 39, p. 2105-2110, 1998.

72. Cooper, M.S.; Ma, M.T.; Sunassee, K.; Shaw, P.K.; Williams, J.D.; Paul, L.R.; Donnelly, S.P.; Blower, P.J. Comparison of ${ }^{64} \mathrm{Cu}$-Complexing Bifunctional Chelators for Radioimmunoconjugation: Labeling Efficiency, Specific Activity, and in Vitro/in Vivo Stability. Bioconjug Chem., v. 23, p. 1029-1039, 2012.

73. PUJATTI, P.B. Desenvolvimento de derivados da bombesina radiomarcados com lutécio-177: relação estrutural e potencial diagnóstico-terapêutico para tumor de próstata. Dissertação (Mestrado) - Instituto de Pesquisas Energéticas e Nucleares, São Paulo, 2009.

74. Bartlett, D.W.; Colcher, D.; Raubitschek, A. A. Rapid and Efficiente Production of Radiolabeled Antibody Conjugates Using Vacuum Dialfiltration Guided by Mathematical Modeling. Bioconjug Chem., v. 19, n. 9, p. 1927-1937, 2008. 
75. Wu, C.; Gansow, O.A.; Brechbiel, M.W. Evaluation of methods for large scale preparation of antibody ligand conjugates. Nucl Med Biol., v. 26, n. 3, p. 339342, 1999.

76. Nikula, T.K.; Curcio, M.J.; Brechbiel, M.W.; Gansow, O.A.; Finn, R.D.; Scheinberg, D.A. A Rapid, Single Vessel Method for Preparation of Clinical Grade Ligand Conjugated Monoclonal Antibodies. Nucl Med. Biol., v. 22, n. 3, p. 387-390, 1995.

77. Pippin, C.G.; Parker, T.A.; McMurry, T.J.; Brechbiel, M.W. Spectrophotometric Method for the Determination of a Bifunctional DTPA Ligand in DTPSMonoclonal Antibody Conjugates. Bioconjugate Chem., v. 3, p. 342-345, 1992.

78. Al-Ejeh, F.; Darby, J.M.; Thierry, B.; Brown, M.P. A simple suite methods to evaluate chelator conjugation of antibodies: effects on hydrodynamic radius and biodistribution. Nucl Med \& Biol., v. 36, p. 395-402, 2009. 